ROBERTO SARTI CÔRTES

\title{
OTIMIZAÇÃO ROBUSTA APLICADA À OPERAÇÃO DE RESERVATÓRIOS PARA A GERAÇÃO DE ENERGIA
}

\author{
Dissertação apresentada à Escola \\ Politécnica da Universidade de São \\ Paulo para obtenção do título de \\ Mestre em Ciências.
}

São Paulo

2013 
ROBERTO SARTI CÔRTES

\section{OTIMIZAÇÃO ROBUSTA APLICADA À OPERAÇÃO DE RESERVATÓRIOS PARA A GERAÇÃO DE ENERGIA}

Dissertação apresentada à Escola Politécnica da Universidade de São Paulo para obtenção do título de Mestre em Ciências.

Área de Concentração:

Engenharia Hidráulica

Orientador:

Prof. Dr. Renato Carlos Zambon

São Paulo

2013 
Este exemplar foi revisado e corrigido em relação à versão original, sob responsabilidade única do autor e com a anuência de seu orientador.

São Paulo, de agosto de 2013.

Assinatura do autor

Assinatura do orientador

FICHA CATALOGRÁFICA

Côrtes, Roberto Sarti

Otimização robusta aplicada à operação de reservatórios para geração de energia / R.S. Côrtes. - versão corr. -- São Paulo, 2013.

102 p.

Dissertação (Mestrado) - Escola Politécnica da Universidade de São Paulo. Departamento de Engenharia Hidráulica e Ambiental.

1.Geração de energia 2.Reservatórios 3.Otimização robusta I.Universidade de São Paulo. Escola Politécnica. Departamento de Engenharia Hidráulica e Ambiental II.t. 


\section{DEDICATÓRIA}

À minha esposa Daniela, meus pais e minha irmã. Ao meu avô Fioravante Sarti, in memoriam 


\section{AGRADECIMENTOS}

Ao Prof. Dr. Renato Carlos Zambon, pela amizade, incentivo e orientação durante todo o projeto de pesquisa.

A todos os ex-colegas de trabalho da Themag Engenharia e, em especial, aos engenheiros Paulo Celso G. Serra, Sydnei Lázaro Martins, David Michael Delgado e Patrícia Veiga pela amizade e pelo incentivo no início do programa de mestrado.

Aos professores Paulo Barbosa e Alberto Francato da UNICAMP pela participação na banca de Qualificação e pelos elogios e críticas realizados.

Ao meu primo, amigo e eterno orientador Dr. Arnaldo Sarti, pela minha iniciação na pesquisa e pelo exemplo de pessoa e profissional.

Aos meus amigos, os engenheiros Pedro Bergamasco e Thales Braguim, que não me deixaram desistir desta empreitada nos momentos de dificuldade e que foram exemplos de força de vontade e superação em suas próprias pesquisas.

Aos meus pais Antônio Carlos e Maria Rita, minha irmã Laura e demais membros da família. Sem o amor, a educação recebida, o carinho e o ombro nos momentos difíceis eu não estaria aonde estou hoje.

À minha esposa Daniela, pelo amor, carinho, compreensão e por estar ao meu lado em todos os momentos, inclusive me ajudando no árduo trabalho de organização das inúmeras tabelas de resultados. Sem ela este trabalho não seria possível.

À todos os colegas e ex-colegas de trabalho da empresas KTY Engenharia, Canhedo Beppu Engenheiros Associados e CCB-P Engenharia e Projetos pelo apoio e compreensão.

Aos meus irmãos de ofício, por toda convivência, amizade e conhecimentos que me foram concedidos.

E, finalmente, à todos aqueles que direta ou indiretamente contribuíram para a realização deste trabalho. 
"Without deviation from the norm, progress is not possible." Frank Zappa 


\section{RESUMO}

Este trabalho tem como objetivo avaliar a viabilidade da aplicação de técnicas de otimização robusta $(\mathrm{OR})$ no planejamento da operação de reservatórios para geração de energia hidrelétrica. A OR é uma técnica de otimização que visa encontrar resultados que sejam menos sensíveis às incertezas nas variáveis do modelo através da minimização da variância da função objetivo para diferentes cenários. Desta forma foi desenvolvido um modelo de otimização robusta aplicado à operação de reservatórios para a geração de energia hidrelétrica, chamado HIDROOR, utilizando o software General Algebraic Modeling System (GAMS). Para estudo de caso foram utilizados os dados da UHE Sinop, a ser instalada no rio Teles Pires MT. Inicialmente foi realizada uma análise de sensibilidade utilizando diferentes combinações dos coeficientes de ponderação da função objetivo e três conjuntos de cenários. Nesta abordagem, o modelo resultou em vertimentos indesejados para realizar a diminuição do desvio padrão dos resultados entre os diferentes cenários. Uma solução encontrada para o problema foi realizar a otimização em duas etapas. $\mathrm{Na}$ primeira etapa ocorre a otimização robusta propriamente dita e são fixados os resultados para o primeiro mês de operação. Na segunda etapa, apenas a função objetivo principal é otimizada e, assim, são corrigidos os vertimentos indesejados. No entanto, com a otimização em duas etapas, não ocorreram mudanças na operação do reservatório para os diferentes coeficientes de ponderação. Ao final do trabalho conclui-se que, apesar dos resultados da análise de sensibilidade terem sido praticamente iguais com a otimização em duas etapas, estes podem ser considerados robustos pois são factíveis para todos os cenários. Por fim, são realizadas sugestões para a continuidade das pesquisas utilizando as técnicas de OR para a operação de usinas hidrelétricas. 


\begin{abstract}
This work aims to evaluate the feasibility of robust optimization techniques (OR) for reservoir management for hydropower production. The OR is an optimization technique which aims to find results that are less sensitive to the randomness of variables in the model by minimizing the variance of the objective function for different scenarios. One OR model was developed to the operation of reservoirs for hydropower production, called HYDRO-OR, using the software General Algebraic Modeling System (GAMS). As study case, data from the Sinop hydropower plant were used, which will be constructed in the Teles Pires river - MT. First, a sensitivity analysis was performed using different combinations of weigh coefficients of the objective function with three sets of scenarios. Preliminary results in this approach showed that the model resulted in unwanted spills to force the reduction of the standard deviation of the results from different scenarios. To correct this, the model was reconfigured to perform the optimization in two stages, the first one being the OR itself in which the results were obtained for the first month of planning. In the second step, the model was optimized again for subsequent months. In this case the model corrected the unnecessary spills but the results were quite similar for the three combinations of the weight coefficients. However the results can be considered robust because it is feasible for all scenarios. Finally, suggestions are made for further studies using the techniques of OR for the operation of hydropower plants.
\end{abstract}




\section{LISTA DE FIGURAS}

Figura 1: Casa de força da UHE Sinop (EPE, 2010a) ................................... 28

Figura 2: Exemplo da formação de cenários .

Figura 3: Esquema de funcionamento do modelo HIDRO-OR com a otimização em duas etapas. .34

Figura 4: Série histórica de vazões afluentes da UHE Sinop no período de Janeiro/1931 até Dezembro/2006 (EPE, 2010b). 39

Figura 5: Distribuição de frequência da série de vazões naturais da UHE Sinop......40

Figura 6: Curvas de permanência mensais para a UHE Sinop. .40

Figura 7: Cenários de Vazões Afluentes - Estudo 1 .43

Figura 8: Valores das funções F1 e F2 para o Estudo 1. 45

Figura 9: Média de energia produzida e seu desvio padrão no Estudo 1 para diferentes coeficientes de ponderação. 45

Figura 10: Média da potência por cenário no Estudo 1 para diferentes combinações coeficientes de ponderação

Figura 11: Média mensal de produção do modelo no Estudo 1 para diferentes combinações de coeficientes de ponderação.

Figura 12: Média do volume armazenado mensalmente no Estudo 1 para diferentes coeficientes de ponderação

Figura 13: Média da vazão turbinada mensalmente no Estudo 1 para diferentes combinações dos coeficientes de ponderação.

Figura 14: Cenários de Vazões Afluentes - Estudo 4. .50

Figura 15: Valores das funções F1 e F2 para o Estudo 2. .52

Figura 16: Média de energia produzida e seu desvio padrão no Estudo 2 para diferentes coeficientes de ponderação. .52

Figura 17: Média da potência por cenário no Estudo 2 para diferentes combinações coeficientes de ponderação

Figura 18: Média mensal de produção de energia do modelo no Estudo 2 para diferentes combinações de coeficientes de ponderação.

Figura 19: Média mensal do volume armazenado no Estudo 2 para diferentes combinações dos coeficientes de ponderação. 
Figura 20: Média mensal da vazão turbinada no Estudo 2 para diferentes combinações dos coeficientes de ponderação.......................................................54

Figura 21: Cenários de vazões afluentes - Estudo 3..............................................59

Figura 22: Média de energia produzida e seu desvio padrão no Estudo 3 para diferentes coeficientes de ponderação.

Figura 23: Média de energia produzida e seu desvio padrão no Estudo 2 para diferentes coeficientes de ponderação.

Figura 24: Média da potência por cenário no Estudo 3 para diferentes combinações coeficientes de ponderação

Figura 25: Média mensal de produção de energia do modelo no Estudo 3 para diferentes combinações dos coeficientes de ponderação.

Figura 26: Média mensal do volume armazenado do modelo no Estudo 3 para diferentes combinações dos coeficientes de ponderação.

Figura 27: Média mensal da vazão turbinada do modelo no Estudo 3 para diferentes combinações dos coeficientes de ponderação. 62

Figura 28: Valores das funções F1 e F2 para o Estudo 4. 63

Figura 29: Média de energia produzida e seu desvio padrão no Estudo 4 para diferentes coeficientes de ponderação.

Figura 30: Média da potência por cenário no Estudo 4 para diferentes combinações coeficientes de ponderação

Figura 31: Média mensal de produção de energia do modelo no Estudo 4 para diferentes combinações dos coeficientes de ponderação.

Figura 32: Média mensal do volume armazenado do modelo no Estudo 4 para diferentes combinações dos coeficientes de ponderação.

Figura 33: Média mensal do volume armazenado do modelo no Estudo 4 para diferentes combinações dos coeficientes de ponderação. 66

Figura 34: Valores das funções F1 e F2 para o Estudo 5.

Figura 35: Média de energia produzida e seu desvio padrão no Estudo 4 para diferentes coeficientes de ponderação.

Figura 36: Média da potência por cenário no Estudo 5 para diferentes combinações coeficientes de ponderação

Figura 37: Média mensal de produção de energia do modelo no Estudo 5 para diferentes combinações dos coeficientes de ponderação. 
Figura 38: Média mensal do volume armazenado do modelo no Estudo 5 para diferentes combinações dos coeficientes de ponderação. .......................................69 Figura 39: Média mensal da vazão turbinada do modelo no Estudo 5 para diferentes combinações dos coeficientes de ponderação.....................................................70 


\section{LISTA DE TABELAS}

Tabela 1: Série História de Vazões Afluentes da UHE Sinop (EPE, 2010) ................37

Tabela 2: Valores representativos da série histórica de vazões da UHE Sinop .........39

Tabela 3: Coeficientes das curvas Cota x Volume, Cota x Área e Curva do Canal de

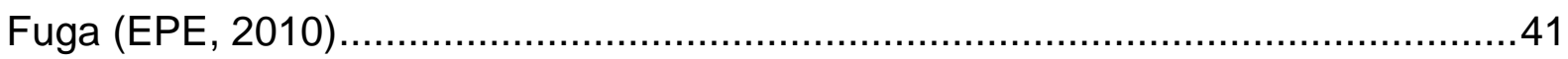

Tabela 4: Usos consultivos da água na UHE Sinop (EPE, 2010)..........................41

Tabela 5: Combinações dos coeficientes de ponderação utilizados nos estudos. ....42

Tabela 6: Composição dos Cenários de Vazões (m³/s) - Estudo 1 ..........................44

Tabela 7: Vazões vertidas $\left(\mathrm{m}^{3} / \mathrm{s}\right)$ na Combinação 1 - Estudo 1 . ..............................48

Tabela 8: Vazões vertidas $\left(\mathrm{m}^{3} / \mathrm{s}\right)$ na Combinação 2 - Estudo 1 . .............................48

Tabela 9: Vazões vertidas $\left(\mathrm{m}^{3} / \mathrm{s}\right)$ na Combinação 3 - Estudo 1 . .............................48

Tabela 10: Composição dos Cenários de Vazões $\left(\mathrm{m}^{3} / \mathrm{s}\right)$ - Estudo 2 .......................51

Tabela 11: Vazões vertidas $\left(\mathrm{m}^{3} / \mathrm{s}\right)$ na Combinação 1 - Estudo 2.............................55

Tabela 12: Vazões vertidas $\left(\mathrm{m}^{3} / \mathrm{s}\right)$ na Combinação 2 - Estudo 2............................55

Tabela 13: Vazões vertidas $\left(\mathrm{m}^{3} / \mathrm{s}\right)$ na Combinação 3 - Estudo 2 ............................56

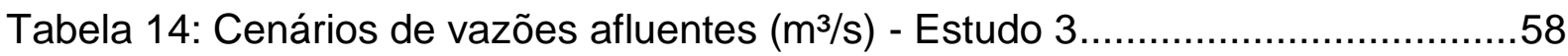

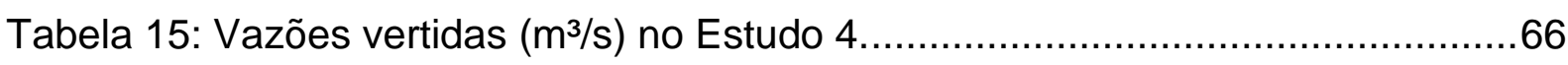

Tabela 16: Vazões vertidas no Estudo 5, para as Combinações 1 e 2. ....................70

Tabela 17: Vazões turbinadas $\left(\mathrm{m}^{3} / \mathrm{s}\right)$ no Estudo 5 para a Combinação 3.................71 


\section{SUMÁRIO}

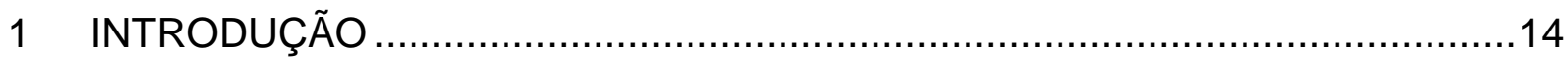

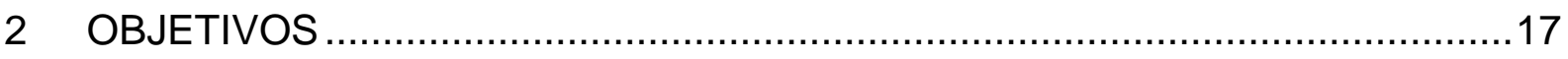

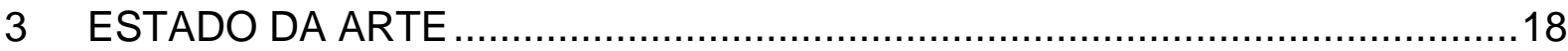

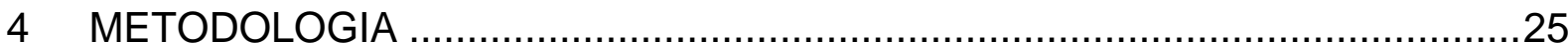

4.1 Formulação Geral de um Problema de Otimização Robusta .......................25

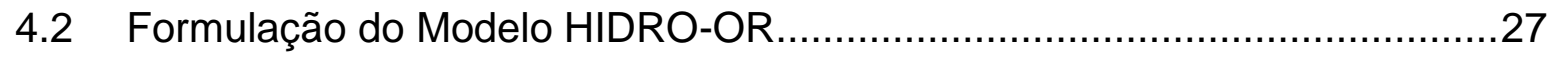

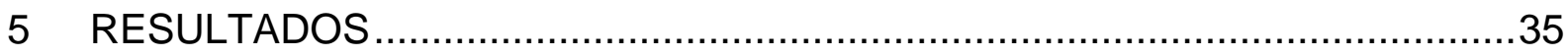

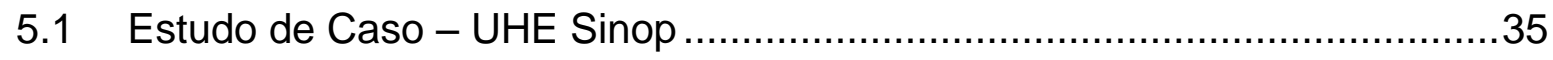

5.2 Análise dos Resultados Numéricos.........................................................

5.2.1 Estudo 1-20 Cenários com horizonte de 24 meses com otimização em

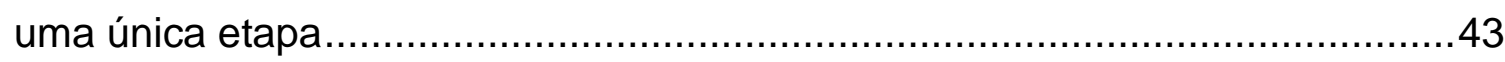

5.2.2 Estudo 2 - 35 Cenários com horizonte de planejamento de 24 meses com otimização em uma única etapa. .50

5.2.3 Estudo 3 - 10 cenários abaixo de $50 \%$ de permanência, com horizonte de 24 meses e volume inicial de $2480 \mathrm{hm}^{3}$ com otimização em uma única etapa 57

5.2.4 Estudo 4-20 Cenários com horizonte de 24 meses com otimização em duas etapas. 63

5.2.5 Estudo 5 - 35 Cenários com horizonte de 24 meses com otimização em duas etapas. 67

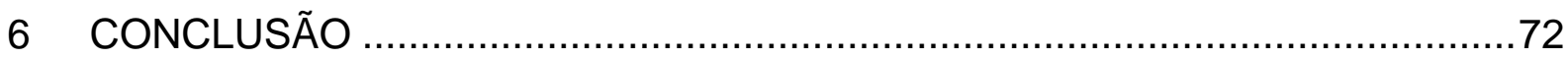

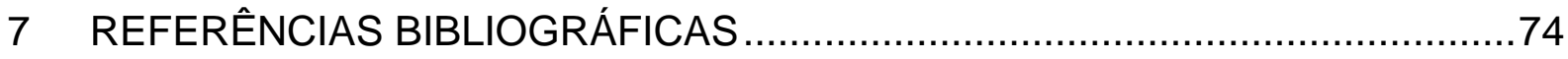




\section{INTRODUÇÃO}

A crescente demanda por energia se apresenta como um dos grandes desafios da humanidade tanto do ponto de vista econômico e tecnológico como ambiental. A queima de combustíveis, principalmente os de origem fóssil, foi a principal forma de produção de energia durante a Revolução Industrial e boa parte do século XX. Entretanto sabemos que a utilização de tais combustíveis se trata de uma fonte de energia não renovável e responsável por grandes impactos ambientais, tanto de ordem local quanto global. Portanto, o desenvolvimento e aprimoramento de novos meios de produção de energia com maior eficiência e com menores impactos no ambiente é uma das grandes prioridades da ciência.

A utilização da água como força motriz é uma técnica antiga. Em meados de 1770, o engenheiro francês Bernard Fórest de Bélidor desenvolveu em seu trabalho Architecture Hydraulique as primeiras máquinas hidráulicas de com eixos verticais e horizontais. No final do século 19 surgiram os primeiros geradores elétricos e estes puderam ser acoplados à sistemas hidráulicos, sendo que em 1878 foi desenvolvido o primeiro projeto de usina hidrelétrica na Inglaterra pelo engenheiro William George Armstrong. (U.S. DEPARTMENT OF ENERGY, 2011).

A energia hidrelétrica apresenta duas principais vantagens em relação aos sistemas térmicos de geração. A primeira delas é ser de operação mais barata, pois não necessita da queima de combustíveis para a geração da energia, sendo necessária apenas a força motriz hidráulica, e, portanto, se trata de uma fonte renovável de energia. Em segundo lugar, ela apresenta vantagens ambientais, já que os maiores impactos gerados por estas se concentram principalmente na bacia hidrográfica onde a usina foi inserida e, por não utilizar a queima de nenhum combustível, a quantidade de resíduos gerados pela operação da usina é bem menor se comparada com sistemas térmicos de mesmo porte.

Entretanto, a água é considerada um bem econômico de extrema importância e seu uso deve ser racional, levando-se em conta seus diversos usos: abastecimento, produção de alimentos, conservação e manutenção dos ecossistemas, produção de energia, navegação, recreação, etc. Dessa forma a 
utilização da água como fonte de energia também deve levar em conta o custo econômico, social e ambiental da mesma.

Além disso, a disponibilidade da água envolve uma imensa quantidade de fatores cuja previsão exata é impossível para a ciência hoje. Componentes de aleatoriedade, sazonalidade e tendência estão diretamente ligados a variáveis como as precipitações e as vazões afluentes em um sistema de recursos hídricos. Portanto os fenômenos hidrológicos devem ser tratados levando em conta as incertezas e a estocasticidade das variáveis envolvidas, com previsibilidade limitada.

Nesse contexto a utilização de técnicas computacionais para auxiliar as tarefas no gerenciamento dos recursos hídricos tem cada vez mais se demonstrado necessárias. A busca por modelos de simulação e de otimização que possam lidar adequadamente com a aleatoriedade das variáveis envolvidas e realizar uma distribuição justa e racional deste precioso bem tem sido um dos principais temas dentro da área de recursos hídricos.

Entre as técnicas de otimização na análise de sistemas de recursos hídricos destacam-se aplicações da programação linear (PL), programação não linear (PNL) e programação dinâmica estocástica (PDE). Quanto a aleatoriedade das variáveis envolvidas, encontram-se abordagens determinísticas com a utilização de um cenário de referência de planejamento e revisão periódica de seus dados e resultados, ou estocásticas com a consideração simultânea de múltiplos cenários. Os cenários são obtidos diretamente ou com a geração de séries sintéticas a partir de dados conhecidos do histórico do sistema.

Contudo, os modelos estocásticos convencionais não estão totalmente imunes a erros em seu planejamento, especialmente quando o comportamento das variáveis aleatórias do modelo se desviam de maneira mais significativa dos valores médios ou mais frequentes estudados, quando podem ocorrer infactibilidades das soluções previstas, déficits ou piora considerável dos objetivos pretendidos.

Uma abordagem alternativa é a aplicação da otimização robusta (OR), buscando não apenas o melhor resultado possível para um determinado cenário ou para a média dos cenários apresentados, mas também uma solução que atenda com menor risco uma faixa mais ampla de realizações possíveis das variáveis sujeitas a incertezas e a estocasticidade. 
De uma maneira geral, o emprego da OR se trata de um modelo estocástico que visa encontrar soluções que sejam factíveis ou próximas da factível nos diferentes cenários, através da minimização da variância da função objetivo entre os diferentes cenários. A OR não tem como objetivo encontrar apenas valores ótimos para os valores médios ou cenários apresentados das variáveis envolvidas, mas sim resultados mais consistentes que possam lidar com as incertezas presentes nos dados, de forma que erros de planejamento da operação ocorram com menor frequência ou que os mesmos possam ser contornados de maneira mais fácil.

A OR é uma ferramenta relativamente nova dentro da área de recursos hídricos, com poucos trabalhos publicados a respeito. Neste contexto esta pesquisa tem como finalidade fornecer um subsídio inicial para a aplicação de técnicas de OR dentro da área, em especial, a operação de reservatórios para a geração de energia. 


\section{OBJETIVOS}

Este trabalho tem como objetivo desenvolver e analisar um modelo de otimização robusta para a operação de reservatórios visando a produção de energia.

O trabalho se divide nas seguintes etapas:

- Pesquisa sobre o estado da arte referente a modelos de otimização aplicados à operação de reservatórios para a produção de energia elétrica e a otimização robusta aplicada em diferentes áreas.

- Formulação matemática do modelo de programação não linear (PNL), estocástico e de otimização robusta (OR), chamado HIDRO-OR.

- Implementação do modelo HIDRO-OR para a produção de energia elétrica utilizando o software General Algebraic Modeling System (GAMS, 2012).

- Aplicação para uma usina hidrelétrica com reservatório, para estudo de caso foi escolhida a UHE Sinop - MT, prevista na expansão do Sistema Interligado Nacional.

- Análise de sensibilidade dos resultados, verificando o comportamento do modelo proposto para diferentes combinações de coeficientes de ponderação das funções objetivo e cenários.

- Conclusão e propostas para trabalhos futuros. 


\section{ESTADO DA ARTE}

A pesquisa operacional na área de Recursos Hídricos começou a ser utilizada ao término da Segunda Guerra mundial em 1945. Um dos principais fatores que o pós-guerra trouxe ao mundo foi o desenvolvimento da tecnologia computacional, com destaques aos computadores digitais e as técnicas de pesquisa operacional como a programação matemática que foi desenvolvida para auxiliar os processos de logística militar. A iniciativa de utilizar tais técnicas de análise de sistemas ao planejamento na área de Recursos Hídricos partiu de pesquisadores da Universidade de Harvard, no início da década de 1960 e, desde então, aliados ao enorme desenvolvimento tecnológico na computação e métodos numéricos, tais técnicas se popularizaram, podendo ser encontradas no gerenciamento dos mais diferentes usos da água como a geração de energia elétrica, abastecimento, agricultura, lazer, etc. (BRANDÃO, 2004).

Mais especificamente na geração de energia elétrica, o uso destas técnicas permite uma melhor utilização da água armazenada nos reservatórios levando assim uma redução dos custos da produção de energia. Tal redução de custos se dá através de um melhor manejo dos recursos hídricos existentes, minimizando a utilização das usinas do sistema termelétrico e também através de estudos de motorização mais econômicos e eficientes para novas usinas e/ou usinas já existentes.

Os avanços tecnológicos na área computacional proporcionaram o surgimento de diferentes técnicas para o gerenciamento de recursos hídricos e a operação de reservatórios. Yeh (1985), Simonovic (1992), Wurbs (1993), Momoh et al. (1999a,b) e Labadie (2004) revisaram e comentaram vários métodos de otimização e seus respectivos modelos.

Yeh (1985) realizou um estudo relativo ao estado da arte da utilização de técnicas de otimização para a operação de reservatórios. Em seus estudos, ele destacou que, apesar dos grandes avanços realizados no campo teórico, a aplicação de tais modelos na prática ocorre ainda de maneira lenta. Wurbs (1993) também realizou um estudo semelhante em seu trabalho mencionando outros métodos também importantes. 
Simonovic (1992) discutiu as limitações presentes nos modelos de otimização aplicados à operação de reservatórios e medidas que poderiam ser tornadas para fazer com que estes se tornassem mais atrativos para os operadores.

Labadie (2004) em seu trabalho discutiu a utilização de diversas técnicas e modelos de programação para o manejo de recursos hídricos, destacando que muitos problemas relativos à operação de reservatórios - e em particular a geração de energia - devem ser lidados como PNL.

Yeh et al. (1992) desenvolveu um modelo para a operação em tempo real de sistemas hidrotérmicos, utilizando como estudo de caso um sistema hidrotérmico de médio porte da China.

O Brasil, devido ao tamanho e complexidade de seu sistema hidrotérmico, se tornou um pioneiro no desenvolvimento de técnicas de simulação e otimização de sistemas hidrotérmicos.

Atualmente o Operador Nacional do Sistema Elétrico (ONS) utiliza o modelo NEWAVE para o planejamento da operação do sistema hidrelétrico brasileiro. $O$ NEWAVE foi desenvolvido pelo Centro de Pesquisas de Energia Elétrica (CEPEL), pertencente ao sistema Eletrobrás, e do Instituto de Pós-Graduação e Pesquisa em Engenharia (COPPE) da Universidade Federal do Rio de Janeiro (UFRJ), de acordo com a metodologia proposta nos trabalhos de Pereira $(1985,1989)$ e Pereira e Pinto (1985). O modelo NEWAVE representa o parque hidrelétrico de forma agregada e o cálculo de operação baseia-se em Programação Dinâmica Dual Estocástica (PDDE), sendo composto por quatro módulos computacionais: (1) Módulo de cálculo do sistema equivalente, (2) Módulo de energias afluentes, (3) Módulo de cálculo da política de operação hidrotérmica e (4) Módulo de simulação da operação. A função objetivo do modelo NEWAVE busca minimizar o custo operacional do sistema, considerando o custo presente do combustível e o chamado custo futuro da água, e considera a estocasticidade de modo implícito. O processo de decisão é realizado para um horizonte de cinco anos, o quanto de energia deve ser produzido pelo sistema hidrotérmico para atender a demanda. Para viabilizar o emprego da técnica de PDDE, evitando problemas ocasionados pelo "mal da dimensionalidade" inerente na programação dinâmica (PD), o NEWAVE realiza uma simplificação do sistema hidrotérmico brasileiro, considerando que este é composto por quatro grandes 
subsistemas: Norte, Nordeste, Sudeste/Centro-Oeste e Sul; sendo cada subsistema formado por um grande reservatório de energia, com volume equivalente à somatória da "energia armazenada" em cada região. Os resultados do modelo NEWAVE servem como dados de entrada para o modelo DECOMP, que utiliza PL e é processado para um horizonte de curto prazo (cinco semanas). O modelo DECOMP define as parcelas de geração hidráulica e térmica para as usinas do sistema de modo individualizado.

Lopes (2001) analisou o desempenho de diferentes funções objetivo para a otimização de sistemas hidroenergéticos com técnicas de PNL. Como caso de estudo Lopes escolheu as usinas hidrelétricas do sistema Paranapanema, utilizando períodos de otimização de até 20 anos. Entre as funções objetivo estudadas estão a maximização da produção de energia, a minimização da complementação de energia e a maximização dos lucros sobre a energia secundária.

Leite (2003) em seu trabalho utilizou técnicas de inteligência artificial com algoritmos genéticos para a operação de sistemas hidrotérmicos. Neste trabalho foram realizados diversos testes, com sistemas complexos compostos por até 35 usinas do sistema hidrelétrico brasileiro, obtendo resultados bastante satisfatórios em termos de demanda, custos e confiabilidade geral do sistema.

Cicogna (2003) desenvolveu o Sistema de Suporte à Decisão (SSD) Hydrolab para o planejamento da operação de sistemas hidrotérmicos de grande porte a médio e longo prazo e a programação em curto prazo respeitando as metas estabelecidas no planejamento da operação. A cadeia de planejamento implementada pelo SSD Hydrolab baseia-se na utilização de um modelo de otimização determinística com usinas individualizados, sendo este modelo alimentado por um outro modelo de previsão de vazões. Posteriormente Toscano (2009) realizou uma comparação entre o modelo Otimização do Despacho Interligado Nacional (ODIN), baseado no modelo Hydrolab, com o modelo NEWAVE. Toscano concluiu que o modelo ODIN se mostrou mais eficiente e seguro, já que ele mantém os reservatórios mais cheios em todas as situações hidrológicas além de proporcionar menores custos de operação e maior geração de energia.

Barros et al. $(2003,2005)$ desenvolveu o sistema SISOPT, utilizado para a operação de sistemas de usinas hidrelétricas, utilizando técnicas de programação 
linear (PL), programação linear sucessiva (PLS) e PNL, sendo esta última baseada no solver MINOS (MURTAGH E SAUNDERS, 1987).

Marques (2006) apresentou uma metodologia de otimização, através da implementação de um algoritmo de PNL para o planejamento e operação de sistemas hidrelétricos, identificando períodos ótimos para a parada de máquinas para procedimentos de manutenção e minimizando efeitos de redução na potência média gerada pelos sistemas hidrelétricos.

Lopes (2007) desenvolveu o modelo SolverSIN para a operação de sistemas hidrotérmicos de grande porte. A otimização neste modelo é feita através de PNL utilizando as rotinas SNOPT, CONOPT e MINOS. Para a validação do modelo, foram utilizados os dados do Sistema Interligado Nacional (SIN). Lopes ainda afirma que a consideração das usinas hidrelétricas de forma individualizada pode acarretar em uma grande melhoria na solução do problema em substituição ao reservatório equivalente. Neste trabalho também foi realizada uma análise crítica de problemas com o detalhamento e a qualidade dos dados físicos disponíveis no SIN, já que vários deles são antigos e muitos estimados durante o desenvolvimento dos projetos das usinas. Entre os principais dados discutidos que interferem nos resultados do modelo temos o rendimento dos conjuntos de geração, a curva-chave de vazões à jusante do reservatório, a cota de montante em usinas com operação a fio d'água, a série histórica de vazões afluentes e o ajuste de valores médios dos dados físicos para longo período.

Barros et al. (2008a, 2009), Zambon (2008) e Zambon et al. (2010, 2011 e 2012) realizaram um aprimoramento do modelo SISOPT e desenvolveram o SSD HIDROTERM para o planejamento de sistemas hidrotérmicos de grande porte formados por um conjunto de usinas hidrelétricas e reservatórios interligados mais usinas termelétricas e intercâmbios operados para a geração e atendimento a demandas de energia elétrica. Tal SSD é composto de dois modelos distintos: o modelo HIDRO que realiza a otimização do sistema considerando as usinas individualizadas e aproveitando ao máximo a capacidade hidrelétrica instalada utilizando-se de PNL de modo determinístico, e o segundo modelo, TERM, otimiza o despacho térmico e intercâmbios entre os diversos subsistemas. Os dois modelos podem ser utilizados separadamente ou integrados no modelo HIDROTERM 
Zambon et al. (2013) desenvolveu uma nova versão do modelo HIDROTERM que incorpora a estocasticidade das vazões afluentes, através de cenários de vazões, deixando de ser um modelo determinístico para um modelo estocástico com recurso a dois estágios.

Aplicações de técnicas de otimização robusta (OR) foram encontradas em diversas áreas do conhecimento, mas seu uso na análise de sistemas de recursos hídricos ainda é incipiente.

De acordo com Paiva (2009) programação estocástica robusta é uma abordagem de modelagem que integra conceitos de programação de metas e de programação estocástica em dois estágios com recurso, de forma que se consiga garantir uma "solução robusta" e uma "modelagem robusta" para um dado conjunto de cenários que são considerados na análise. Mulvey et al. (1995) descreve como "solução robusta" toda solução que permanece próxima à solução ótima em todos os cenários considerados e "modelagem robusta" como toda modelagem que gera soluções factíveis ou quase factíveis em todos os cenários.

Beyer e Sendhoff (2007) descrevem duas principais correntes de pesquisa dentro da OR. A diferença entre as duas está relacionada à natureza das restrições presentes nos modelos. Enquanto a engenharia em geral, principalmente a mecânica e estrutural, lidam com restrições mais rígidas ("hard constraints") os problemas no campo da pesquisa contêm restrições flexíveis ("soft constraints"), além das restrições rígidas. Na área de pesquisa operacional o termo OR é atribuído a Mulvey et al. (1995), que utiliza variáveis de folga, funções adicionadas à função objetivo, para penalizar violações das restrições flexíveis. $\mathrm{Na}$ operação de reservatórios, um exemplo de variável flexível poderia ser a demanda de água para usos consuntivos: se uma comunidade necessita de uma vazão mínima de 200 litros per capita por dia, porém apenas 170 litros por dia estão disponíveis, eles terão que ser suficientes. Já um exemplo de variável rígida seria a capacidade máxima do reservatório que, por condições físicas (no caso a área e volume), não pode ser extrapolada.

Na área da engenharia, uma contribuição importante é o "Método Taguchi" de 1989 apud RAY et al. (2010) de projeto robusto, que tem como meta reduzir o desvio médio quadrático da relação sinal-ruído ("signal-to-noise ratio") (fatores de ruído são 
condições ambientais como temperatura e pressão ou tolerâncias quanto a imprecisões de produção, como peso e comprimento) na manufatura. Boa parte do trabalho recente na programação matemática robusta pode ser atribuído a Ben-Tal et al. (2009) cujo interesse principal é o efeito da incerteza presente em modelos com restrições rígidas, que são condições que precisam ser satisfeitas independentemente da incerteza dos dados. Outros trabalhos relevantes relativos à OR, aplicadas em diferentes áreas da engenharia e pesquisa operacional, podem ser encontrados em Bertsimas e Sim (2003, 2004), Bertsimas et al. (2004), Bertsimas e Thiele (2006), El-Ghaoui e Lebret (1997), El-ghaoui et al. (1998), Erdogan e lyengar (2006) e Yamashita et al. (2007).

Como o planejamento e operação de sistemas hídricos é uma das inúmeras aplicações da pesquisa operacional, deve ser enfatizado as técnicas de OR na pesquisa operacional como creditado por Mulvey et al. (1995).

Watkins e McKinney $(1995,1997)$ desenvolveu um modelo multiobjetivo, não linear, estocástico de 2 estágios com OR (MO-OR) para determinar a capacidade de expansão de abastecimento de um município, sendo que as decisões de investimento são tomadas em uma primeira etapa e as decisões operacionais são tomadas na segunda etapa. Neste modelo, além da função objetivo de minimizar os custos, também ocorre a minimização do desvio padrão das decisões de segundo estágio mais uma função penalidade para a escassez de água.

Um estudo muito esclarecedor do uso de OR no manejo de recursos hídricos foi realizado por Ray et al. (2010) que abrange uma revisão sobre as aplicações de técnicas de OR desenvolvidas nos últimos 15 anos e discute o emprego dos termos "otimização robusta" e "robustez" que são comumente empregados na literatura de modo que, seu significado específico e implicações, se tornaram vagos. Neste trabalho, Ray et al. utilizou como exemplo um problema clássico de abastecimento urbano, desenvolvido por Lund e Israel (1995) e adaptado por Watkins e McKinney (1997) para a aplicação de três diferentes técnicas de otimização, sendo elas: (1) Modelo de minimização dos custos, não linear, estocástico de 2 estágios; (2) Modelo MO-RO, igual ao desenvolvido por Watkins e McKinney (1995); (3) Um modelo de análise de performance, que utiliza da formulação matemática do segundo modelo e ainda acrescenta medidas de performance em relação a confiança do modelo, 
vulnerabilidade relativa e sustentabilidade. Cabe notar que o modelo (3) não se trata de um segundo método de OR por si, mas uma ferramenta que habilita a exploração de complicações de múltiplos objetivos nas recomendações do modelo. Tal ferramenta foi nomeada "the single-objective (check on) robust optimization (SORO)" pelos autores.

Em relação ao uso de técnicas de OR aplicadas à operação de reservatórios para a produção de energia não foram encontradas referências, o que demonstra que a aplicação de modelos de OR é ainda um campo novo, que precisa ser melhor estudado. No Brasil, atualmente, existe um projeto de pesquisa chamado Otimização Robusta - Metodologia de Apoio à Tomada de Decisão na Comercialização de Energia, desenvolvido pela Universidade Estadual de Campinas (UNICAMP) em parceria com a Universidade de São Paulo (USP) onde foi desenvolvido o emprego da OR para a comercialização de energia. 


\section{METODOLOGIA}

\subsection{Formulação Geral de um Problema de Otimização Robusta}

De acordo com Mulvey et al. (1995) modelos de otimização robusta (OR) tem dois componentes distintos: um componente estrutural que é fixado e livre de qualquer "ruído" nos seus dados de entrada, e um componente de controle que está sujeito aos "ruídos" nos dados. Para definir um modelo apropriado, é importante definir dois conjuntos de variáveis:

$x \in R^{n_{1}}$, corresponde ao vetor de variáveis de decisão cujos valores ótimos não estão condicionados a realização de certos parâmetros. Estas são chamadas variáveis de projeto.

$y \in R^{n_{2}}$, denota o vetor de controle de decisão, são variáveis que estão sujeitas a ajustes uma vez que parâmetros incertos são observados. Seu valor depende tanto de parâmetros aleatórios como do valor ótimo das variáveis de projeto.

De maneira geral, um modelo de otimização tem a seguinte estrutura:

$$
\text { Minimizar: } c^{T} x+d^{T} y
$$

$$
x \in R^{n_{1}}, y \in R^{n_{2}}
$$

Sujeito a:

$$
\begin{gathered}
A x=b \\
B x+C y=e \\
x, y \geq 0
\end{gathered}
$$

A Equação 2 representa as restrições estruturais cujos coeficientes são fixos e livres de perturbações. A Equação 3 representa as restrições de controle, cujos coeficientes estão sujeitos à perturbações devido à incerteza dos dados.

Para definir o problema de OR, é necessário introduzir um conjunto de cenários $\Omega=\{1,2,3, \ldots, S\}$. Com cada cenário $s \in \Omega$ é associado um conjunto $\left\{d_{s}, B_{s}, C_{s}, e_{s}\right\}$ de realização para as restrições de controle e a probabilidade de cada 
cenário $p_{s},\left(\sum_{s=1}^{s} p_{s}=1\right)$. A solução ótima do problema matemático (1)-(4) será robusta em se permanecer próxima a ideal para qualquer realização do cenário $s \in$ $\Omega$, ou seja, será considerada uma solução robusta. A solução também é robusta em relação à viabilidade se ela se for "quase" viável para qualquer realização de s, sendo assim o modelo considerado um modelo robusto.

Dificilmente qualquer solução para o problema (1)-(4) será viável e ótima para todos os índices de cenários $s \in \Omega$. Se o sistema que está sendo modelado tem redundâncias substanciais, então pode ser possível achar soluções que permaneçam viáveis e ótimas. De outra forma, é necessário um modelo que permita mensurar a "compensação" entre a solução ótima e a robusteza do modelo.

Isso pode ser atingido introduzindo um conjunto $\left\{\mathrm{y}_{1}, \mathrm{y}_{2}, \mathrm{y}_{3}, \ldots, \mathrm{y}_{\mathrm{z}}\right\}$ de variáveis de controle para cada cenário $s \in \Omega$ e outro conjunto $\left\{\mathrm{z}_{1}, \mathrm{z}_{2}, \mathrm{z}_{3}, \ldots, \mathrm{z}_{\mathrm{z}}\right\}$ de vetores de erro que irão medir a não viabilidade permitida nas restrições de controle para cada cenário s. Dessa forma, pode-se considerar a seguinte formulação do modelo de otimização robusta:

$$
\text { Minimizar: } \sigma\left(x, y_{1}, \ldots, y_{s}\right)+\omega \rho\left(z_{1}, \ldots, z_{s}\right)
$$

Sujeito a:

$$
\begin{gathered}
A x=b \\
B_{s} x+C_{s} y_{s}+z_{s}=e_{s}, \quad s \in \Omega \\
x \geq 0, y_{s} \geq 0, \quad s \in \Omega
\end{gathered}
$$

Com múltiplos cenários a solução objetivo $\xi=c^{T} x+d^{T} y$ se torna uma variável aleatória tendo o valor $\xi_{s}=c^{T} x+d_{s}^{T} y_{s}$ com probabilidade $p_{s}$. Desta forma não há apenas uma única escolha para um objetivo global. Algumas formas que poderiam ser usadas são o valor médio, que é a função utilizada na programação linear estocástica, representada na equação 9:

$$
\sigma(\cdot)=\sum_{s \in \Omega} p_{s} \xi_{s}
$$

Nas análises de pior caso o modelo minimiza o valor máximo, e a função objetivo pode ser definida por:

$$
\sigma(\cdot)=\max _{s \in \Omega} \xi_{s}
$$


Tanto a equação 9 quanto a equação 10 são casos especiais de $O R$, mas ambos são, no entanto, padrões na literatura.

Em situações de baixo risco, o valor fornecido na equação 9 pode ser usado. Entretanto, esta escolha se torna inapropriada em situações de risco moderado a alto devido à incerteza dos dados. Utilizar o valor objetivo esperado ignora tanto o risco atribuído ao tomador de decisões quanto a distribuição do valor objetivo $\xi_{s}$.

Uma forma popular de lidar com o risco são modelos média/variância (MARKOWITZ apud MULVEY et al., 1995). Neste modelo o risco é equacionado com a variância dos resultados. Uma variância alta para $\xi_{s}=c^{T} x+d_{s}^{T} y_{s}$ significa que os resultados são duvidosos. Utilizando a variância como um substituto para risco, os resultados tendem a ser minimizados para um determinado nível de risco. Uma escolha apropriada para $\sigma(\cdot)$ seria a média mais uma constante $(\lambda)$ multiplicando a variância, conforme apresentada na Equação 11 a seguir:

$$
\sigma\left(x, y_{1}, \ldots, y_{s}\right)=\sum_{s \in S} p_{s} \xi_{s}+\lambda \sum_{s \in S} p_{s}\left(\xi_{s}-\sum_{s^{\prime} \in S} p^{\prime}{ }_{s} \xi_{s^{\prime}}\right)^{2}
$$

Neste trabalho, para a confecção do modelo OR para a operação de reservatórios para a produção de energia será considerada a formulação proposta combinando as Equações 5-8 e 11, como pode ser visto na seção seguinte.

\subsection{Formulação do Modelo HIDRO-OR}

De uma maneira geral, um aproveitamento hidrelétrico consiste na formação de uma barragem em um curso d'água para a criação de um reservatório, de volume $S$, que irá represar a água. A diferença de cotas entre nível d'água a montante do barramento $(\mathrm{H})$ e a cota do nível de jusante $(\mathrm{HT})$ representa a queda bruta $(\mathrm{Hb})$ da usina. A água represada é captada ( $\left.R^{\prime}\right)$ através de um conjunto de estruturas hidráulicas (canal de adução, tomada d'água, conduto forçado, etc.) e levada até a casa de força, onde se encontra o conjunto turbina-gerador. Caso ocorra extravaso do reservatório, o excesso de água é vertido (R") para jusante do barramento. $O$ nível d'água de jusante é função da vazão presente no local ( $R$ '+R") e a potência 
gerada $(P)$ é função da vazão turbinada e da queda líquida, sendo que esta corresponde a queda bruta menos as perdas de carga provenientes do sistema de adução e circuito de geração.

A produção de energia elétrica ocorre basicamente através da transformação da energia potencial ocasionada pela diferença de cotas em energia cinética e energia de pressão dinâmica pela passagem da água pelos condutos forçados. Ao acionar a turbina, essa energia é convertida em energia mecânica que, por sua vez é transmitida ao gerador que a transforma em energia elétrica. Um esquema geral de funcionamento de uma usina hidrelétrica é apresentado na Figura 1.

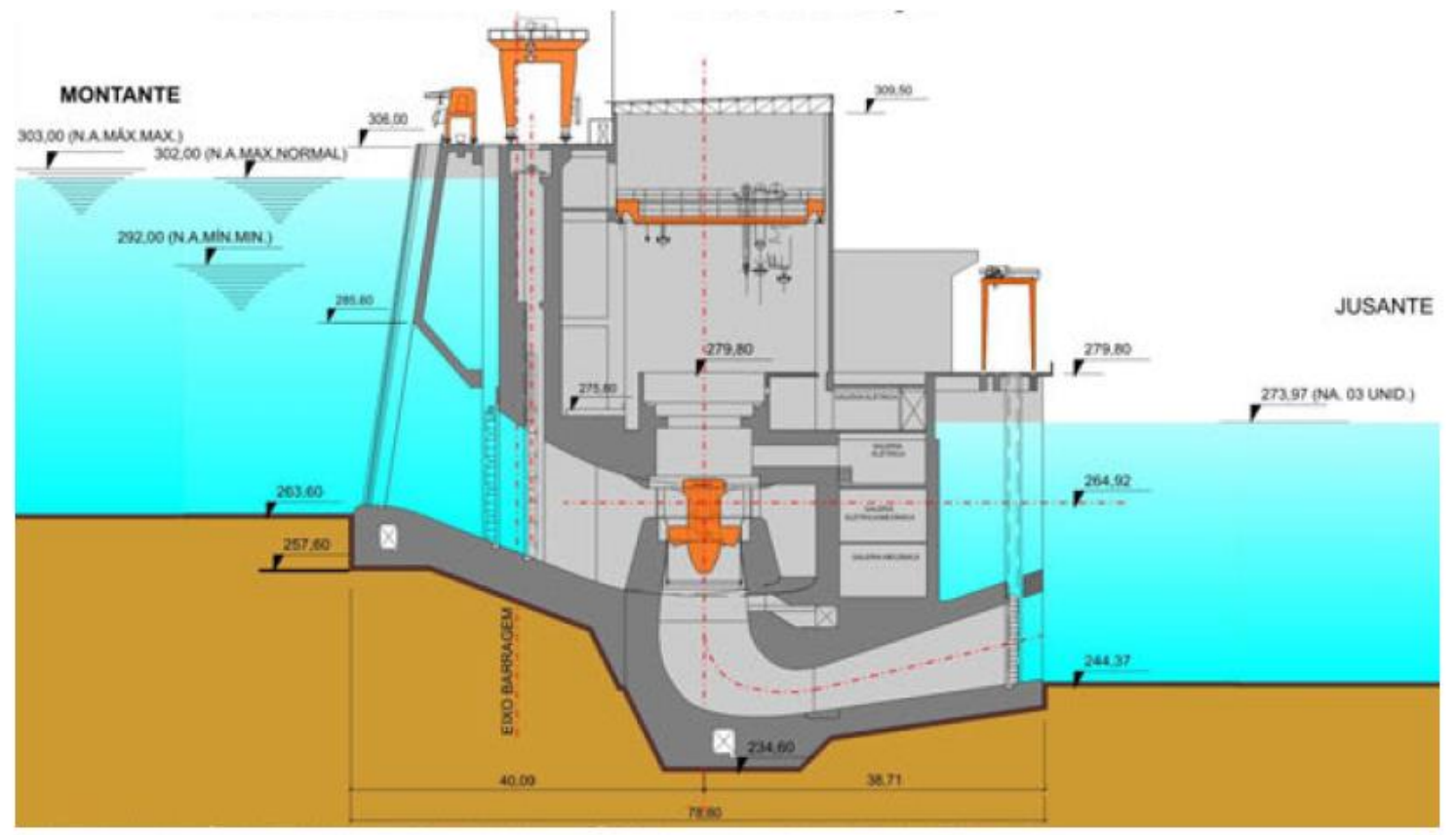

Figura 1: Casa de força da UHE Sinop (EPE, 2010a)

Conforme demonstrado na seção anterior, uma possível formulação matemática para o problema de OR consiste em um problema estocástico, onde são considerados múltiplos cenários de vazões afluentes. Segundo Fragnière e Gondzio (2002), o processo estocástico pode ser representado de uma maneira figurativa, como uma árvore de eventos que descreve o desdobramento das incertezas em um horizonte de planejamentos (Figura 2).

No caso do modelo HIDRO-OR as vazões do primeiro mês são consideradas iguais para todos os cenários. A vazão afluente corresponde a uma previsão única e as vazões turbinada e vertida correspondem a decisão cenário-independente de 
primeiro estágio, implementável no primeiro intervalo de tempo. A partir disso, cada cenário compõe um conjunto de vazões afluentes diferentes, podendo estas serem baseadas na própria série histórica de vazões ou a partir da criação de séries sintéticas. Tal composição de cenários pode ser retratada de maneira simples conforme mostrado na Figura 2:

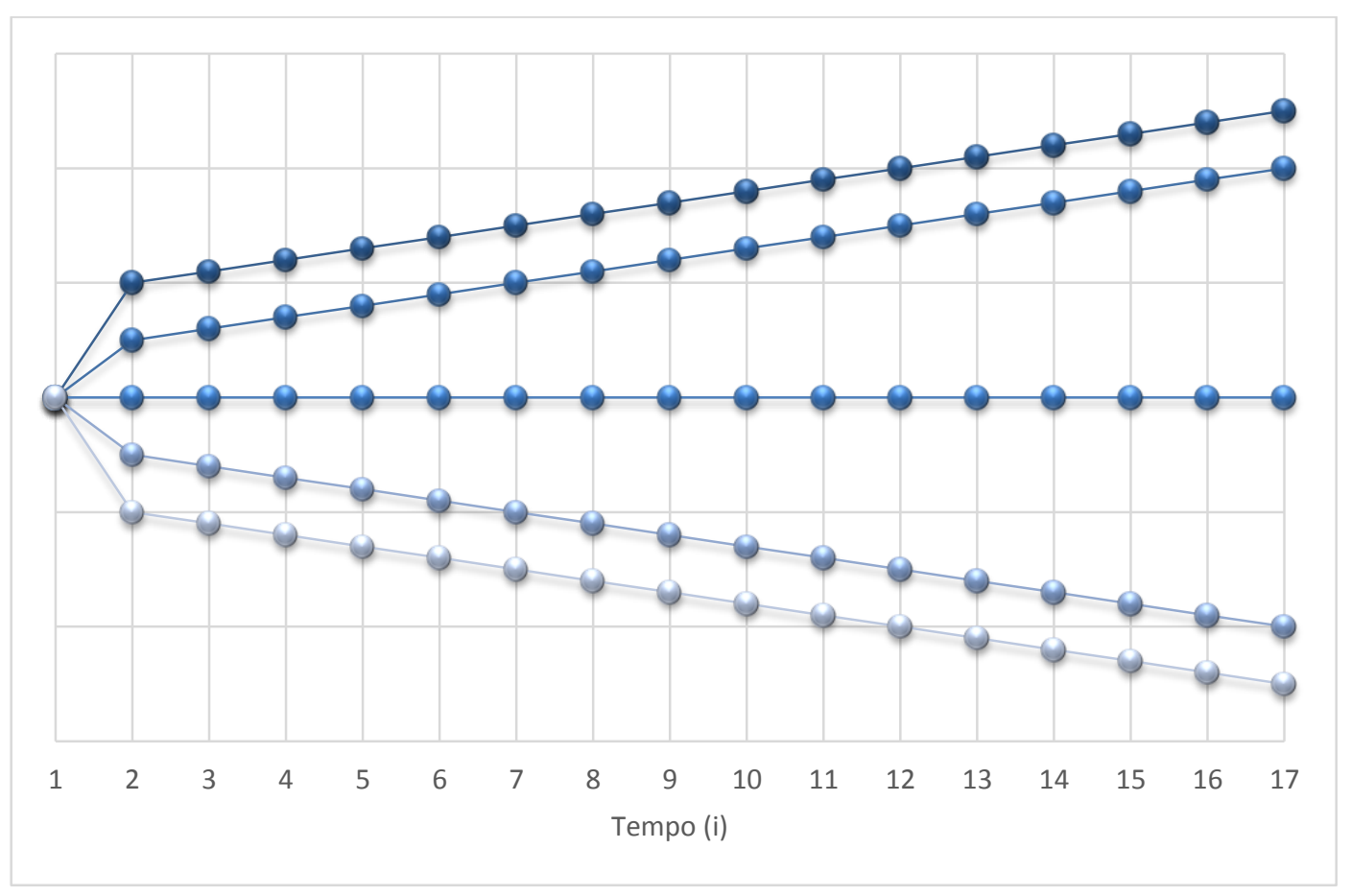

Figura 2: Exemplo da formação de cenários

Desta forma, a função do modelo robusto se constitui de duas funções, chamadas de F1 e F2. A função F1 é a principal função objetivo do problema: ela corresponde à média da complementação quadrática entre a capacidade instalada ou uma demanda objetivo pré-definida menos a energia gerada nos diferentes cenários do modelo, ponderada para os diversos cenários considerados. A função F2 é a soma do desvio padrão dos valores de F1 calculados isoladamente para cada cenário do conjunto. Minimizar o valor de F2 é, portanto, equivalente a minimizar a variância de F1.

Assim, temos como a função objetivo do modelo HIDRO-OR da seguinte maneira:

$$
\min Z_{1}=w_{1} \cdot F 1+w_{2} \cdot F 2
$$

Sendo: 
$\mathrm{w}_{1}$ e $\mathbf{w}_{2}=$ coeficientes de ponderação entre as funções F1 e F2;

$Z_{1}=$ objetivo robusto do modelo HIDRO-OR (106 s.MW'2);

A função $F 1$ pode ser expressa por:

$$
F 1=\frac{\sum_{i=1}^{n i}\left[\sum_{t=1}^{n t} d t_{t} \cdot\left(C-P_{t, i}\right)^{2}\right]}{n i}
$$

Onde:

i = índice do cenário;

ni = número de cenários;

nt = número de intervalos de tempo;

$\mathrm{t}$ = índice de intervalos de tempo;

$d t_{t}=$ duração do intervalo de tempo $\left(10^{6} \mathrm{~s}\right)$;

$\mathrm{C}=$ capacidade instalada ou demanda objetivo (MW);

$\mathrm{P}_{\mathrm{t}, \mathrm{i}}=$ produção de energia $(\mathrm{MW})$.

Já a função F2 é expressa da seguinte forma:

$$
F 2=\sum_{i=1}^{n i} \sigma_{i}
$$

Sendo:

$$
\sigma_{i}=\sqrt{\frac{\sum_{t=1}^{n t}\left[d t_{t} \cdot\left(C-P_{t, i}\right)^{2}-\frac{\sum_{t=1}^{n t} d t_{t} \cdot\left(C-P_{t, i}\right)^{2}}{n t}\right]}{n t-1}}
$$

Onde:

$\sigma_{i}=$ desvio padrão da função $\mathrm{F} 1$, em $10^{6}$ s.MW2

As demais equações e restrições do modelo HIDRO-OR estão apresentadas a seguir.

Equação da produção de energia:

$$
P_{i, t}=\varepsilon_{i} \cdot H b_{i, t} \cdot Q t_{i, t}
$$


Queda bruta:

$$
H b_{i, t}=\frac{H_{i, t}-H_{i, t-1}}{2}--H T_{i}
$$

Vazão no canal de fuga, correspondente à vazão turbinada mais a vazão vertida:

$$
R_{i, t}=R_{i, t}^{\prime}+R^{\prime \prime}{ }_{i, t}
$$

Equação da continuidade:

$$
S_{i, t}=S_{i, t-1}+d t_{t \cdot}\left[I_{i, t}-Q_{i, t}-U C_{i, t}-D T_{i, t}\right]-E_{i, t}
$$

Nível d'água de montante:

$$
H_{i, t}=a_{0, i}+a_{1, i} \cdot S_{i, t}+a_{2, i} \cdot S_{i, t}^{2}+a_{3, i} \cdot S_{i, t}^{3}+a_{4, i} \cdot S_{i, t}^{4}
$$

Nível d'água de jusante:

$$
H T_{i, t}=b_{0, i}+b_{1, i} \cdot R_{i, t}+b_{2, i} \cdot R_{i, t}^{2}+b_{3, i} \cdot R_{i, t}^{3}+b_{4, i} \cdot R_{i, t}^{4}
$$

Área do reservatório:

$$
A_{i, t}=c_{0, i}+c_{1, i} \cdot H_{i, t}+c_{2, i} \cdot H_{i, t}^{2}+c_{3, i} \cdot H_{i, t}^{3}+c_{4, i} \cdot H_{i, t}^{4}
$$

Perdas por evaporação:

$$
E_{i, t}=\frac{A_{i, t}+A_{i, t-1}}{2} \cdot I E_{i, t}
$$

Restrição devido à capacidade máxima de geração:

$$
P_{i, t} \leq P_{i}^{\text {máx }} \cdot I D_{i, t}
$$

Limites de armazenamento, para um reservatório com capacidade variável:

$$
S_{i}^{\text {min }} \leq S_{i, t} \leq S_{i, t}^{\text {máx }}
$$

Armazenamento final:

$$
S_{i, t=n t} \geq S_{\text {end }}
$$

Limites de vazão ambiental e outros usos, turbinada e vertida:

$$
\begin{gathered}
R_{i, t} \geq R_{i}^{\text {min }} \\
R_{i}^{\text {min }} . I D_{i} \leq R_{i, t}^{\prime} \leq R_{i}^{\text {max }} . I D_{i} \\
R^{\prime \prime}{ }_{i, t} \geq 0
\end{gathered}
$$


Condição de operação para o primeiro mês do modelo HIDRO-OR:

$$
\begin{aligned}
& R_{i, t=1}^{\prime}=R_{i=1, t=1}^{\prime} \\
& R_{i, t=1}^{\prime \prime}=R^{\prime \prime}{ }_{i=1, t=1}
\end{aligned}
$$

$P_{i}^{\max }=$ produção maxima de energia $(\mathrm{MW})$

$\varepsilon_{i}=$ produtividade específica líquida $\left(\mathrm{MW} /\left(\mathrm{m}^{3} / \mathrm{s}\right) / \mathrm{m}\right)$

$H b_{i, t}=$ queda bruta da usina $(\mathrm{m})$;

$H_{i, t}=$ nível d'água de montante $(\mathrm{m})$

$H T_{i, t}=$ nível d'água de jusante $(\mathrm{m})$

$R_{i, t}=$ vazão total à jusante $\left(\mathrm{m}^{3} / \mathrm{s}\right)$

$R_{i}^{\text {min }}=$ vazão ambiental, vazão mínima à jusante $\left(\mathrm{m}^{3} / \mathrm{s}\right)$;

$R_{i, t}^{\prime}=$ vazão turbinada $\left(\mathrm{m}^{3} / \mathrm{s}\right)$;

$R_{i}^{\prime}{ }^{m i n}=$ vazão turbinada mínima $\left(\mathrm{m}^{3} / \mathrm{s}\right)$;

$R^{\prime}{ }^{\max }=$ vazão turbinada máxima $\left(\mathrm{m}^{3} / \mathrm{s}\right)$;

$R^{\prime \prime}{ }_{i, t}=$ vazão vertida $\left(\mathrm{m}^{3} / \mathrm{s}\right)$;

$S_{i, t}=$ volume do reservatório $\left(\mathrm{hm}^{3}\right)$;

$S_{i}{ }^{\text {min }}=$ volume mínimo do reservatório $\left(\mathrm{hm}^{3}\right)$;

$S_{i}^{\text {máx }}=$ capacidade máxima do reservatório $\left(\mathrm{hm}^{3}\right)$;

$A_{i, t}=$ área do reservatório $\left(\mathrm{km}^{2}\right)$;

$l_{i, t}=$ vazão natural afluente ao reservatório $\left(\mathrm{m}^{3} / \mathrm{s}\right)$;

$U C_{i, t}=$ usos consuntivos d'água $\left(\mathrm{m}^{3} / \mathrm{s}\right)$;

$D T_{i, t}=$ desvios de vazão, transposição e outros à montante $\left(\mathrm{m}^{3} / \mathrm{s}\right)$;

$E_{i, t}=$ evaporação $\left(10^{6} \mathrm{~m}^{3}\right)$

$I E_{i, t}=$ taxa de evaporação em um determinado período de tempo $t(\mathrm{~m})$

$I D_{i, t}=$ índice de disponibilidade devido à paradas programadas e não programadas no sistema $\left(0 \leq I D_{i, t} \leq 1\right)(-)$

Entretanto, durante os estudos realizados com a formulação descrita anteriormente (apresentados nos Itens 5.2.1, 5.2 .2 e 5.2.3) foi constatado que, com um aumento no peso dado à função F2, o modelo pode criar um comportamento imprevisto, fazendo com que ocorram vertimentos não desejados para diminuir o desvio padrão da função objetivo, diminuindo a energia produzida para aproximar os 
resultados nos cenários com afluências ou armazenamentos mais favoráveis. Uma alternativa para evitar que este comportamento ocorra é realizar a otimização em duas etapas, com duas funções objetivo. Tal solução foi implantada de modo similar ao realizado por Delgado (2006) e Barros et al. (2008b) no modelo SISAGUA, que utilizou um sistema de otimização estocástica em várias etapas (funções objetivo).

No caso do modelo SISAGUA, porém, tratavam-se de prioridades preemptivas, onde novas restrições impediam piorar o resultado dos objetivos anteriores mas obter um novo arranjo com melhoria para os objetivos seguintes a medida em que reduzia o espaço das soluções viáveis pelo acréscimo de novas restrições. Aqui, a técnica foi aplicada para corrigir uma distorção eventualmente observada na primeira etapa.

Neste caso, teremos duas funções objetivo distintas: na função de primeira etapa (Equação 12) são determinados os valores para as variáveis do modelo minimizando o objetivo ponderado da complementação quadrática da energia produzida (F1) e seu desvio padrão (F2). Em uma segunda etapa, fixa-se os valores da tomada de decisão cenário-independente de primeiro estágio, no caso a vazão turbinada no primeiro mês $\left(R^{\prime}(i, t=1)\right)$ e realiza uma nova otimização apenas da função $F 1$ para os demais meses $\left(R^{\prime}(i, t>1)\right)$. Dessa forma, mantém-se a solução robusta no primeiro mês, onde é realizada a tomada de decisão e, subsequentemente, otimiza-se novamente a função para correção dos vertimentos indesejados nos meses futuros, ocasionados pela função F2. Tal formulação pode ser descrita da seguinte forma:

$$
\begin{gathered}
\min Z_{1}=w_{1} \cdot F_{1}+w_{2} \cdot F 2 \\
\text { obtendo } R_{(i, t=1)}^{\prime}, \text { então } \\
\min Z_{2}=F_{1} \\
\text { obtendo } R_{(i, t>1)}^{\prime} e R_{(i, t)}^{\prime \prime}
\end{gathered}
$$

A Figura 3 apresentada a seguir ilustra o modo de funcionamento do modelo HIDRO-OR com a otimização em duas etapas. 


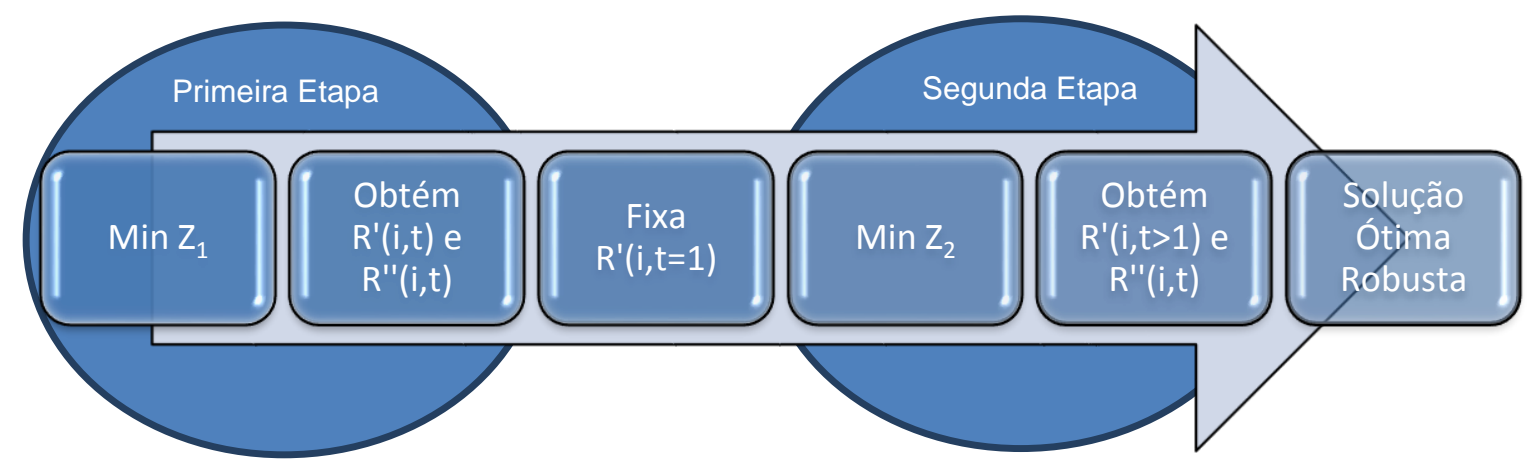

Figura 3: Esquema de funcionamento do modelo HIDRO-OR com a otimização em duas etapas. 


\section{RESULTADOS}

\subsection{Estudo de Caso - UHE Sinop}

Para a análise numérica do modelo de OR serão utilizados os dados numéricos da UHE Sinop, localizada no Rio Teles Pires - MT, prevista na expansão do Sistema Interligado.

A UHE Sinop é composta de um reservatório com capacidade máxima de 3100 hm $^{3}$ e 3 unidades geradoras compostas por turbinas tipo Kaplan, com potência unitária nominal de 136,05 MW cada. A capacidade máxima de geração da UHE Sinop será de 400,00 MW.

Uma peculiaridade da UHE Sinop é sua regra operativa, que considera o nível máximo do reservatório variável. Este fato ocorre devido à presença de lagoas sazonais que se formam durante as secas e servem como berçários para os peixes na área do reservatório. Devido a este fato, o reservatório tem seu nível máximo fixado na cota 300,00 m durante as secas para permitir a formação de tais lagoas. Portanto, a seguinte regra operativa foi adotada para este reservatório

- Durante os meses de cheia (Dezembro a Maio) o reservatório tem seu nível máximo fixado na cota 302,00 , com uma maior capacidade de reserva para acumular um maior volume de água devido às cheias.

- Durante os meses de estiagem (Junho a Novembro) o reservatório tem sua cota máxima fixada a 300,00 m permitindo a formação das lagoas sazonais para a procriação de peixes.

De acordo com EPE (2010b), temos:

- Potência total a ser instalada $\left(P_{\text {Tinst }}\right): 400,00$ MW

- Número de unidades geradoras: 3 unidades geradoras

- Tipo de turbina: Kaplan

- Potência unitária nominal das turbinas: 136,05 MW

- Vazão unitária nominal: 592,20 m³/s 
- Engolimento mínimo: 207,27 m³/s (35\% da vazão unitária nominal)

- Engolimento máximo: 1776,60 m³/s (considerado igual a três vezes a vazão unitária nominal)

- Cota Máxima do Reservatório (NAMax): 302,00m (nos meses de cheia) e $300,00 \mathrm{~m}$ (nos meses de estiagem).

- Cota Mínima do Reservatório (NAMín): 292,00 m

- Capacidade máxima do reservatório: 3100 hm³

- Volume mínimo do reservatório: 1015 hm³

- Capacidade de armazenamento: $2085 \mathrm{hm}^{3}$

- Queda Líquida de Referência (Href): 24,50 m

- Perda Hidráulica considerada: 0,60 m

- Rendimento ponderado do gerador: $98 \%$

- Rendimento médio ponderado do conjunto turbina-gerador: 93,14\%

- Rendimento médio total considerado na modelagem energética: 92,50\%

- Taxa de indisponibilidade forçada: $2,533 \%$

- Taxa de indisponibilidade programada: 8,091\%

- Vazão média de longo termo (MLT): 924 m³/s

- Tempo de enchimento do reservatório, baseado na vazão média de longo termo (considerando do volume mínimo até a capacidade máxima): 26,67 dias

A série histórica de vazões afluentes com os dados para o período de 1931 até 2006 para o aproveitamento Sinop é apresentada na Tabela 1 e na Figura 4. 
Tabela 1: Série História de Vazões Afluentes da UHE Sinop (EPE, 2010b)

\begin{tabular}{|c|c|c|c|c|c|c|c|c|c|c|c|c|c|}
\hline \multicolumn{14}{|c|}{$\operatorname{Vazão~}\left(\mathrm{m}^{3} / \mathrm{s}\right)$} \\
\hline Ano & Jan & Fev. & Mar & Abr. & Mai & Jun. & Jul. & Ago. & Set & Out & Nov. & Dez & Anual \\
\hline 1931 & 1169 & 1485 & 1730 & 936 & 848 & 694 & 562 & 464 & 424 & 661 & 829 & 1108 & 909 \\
\hline 1932 & 1016 & 1251 & 1674 & 869 & 774 & 633 & 546 & 509 & 437 & 477 & 520 & 569 & 773 \\
\hline 1933 & 2212 & 1383 & 943 & 1043 & 735 & 601 & 487 & 397 & 386 & 419 & 599 & 1934 & 928 \\
\hline 1934 & 1276 & 1667 & 1481 & 1064 & 804 & 663 & 537 & 464 & 553 & 537 & 665 & 1328 & 920 \\
\hline 1935 & 3217 & 1037 & 2199 & 1103 & 871 & 706 & 572 & 463 & 393 & 549 & 579 & 1148 & 1070 \\
\hline 1936 & 857 & 2694 & 903 & 834 & 690 & 559 & 453 & 367 & 341 & 312 & 371 & 425 & 734 \\
\hline 1937 & 1115 & 713 & 1675 & 1069 & 722 & 626 & 507 & 410 & 384 & 479 & 493 & 2390 & 882 \\
\hline 1938 & 2635 & 1187 & 1010 & 840 & 733 & 594 & 481 & 389 & 334 & 1073 & 759 & 1103 & 928 \\
\hline 1939 & 918 & 1335 & 985 & 814 & 685 & 611 & 537 & 435 & 418 & 455 & 1065 & 1320 & 798 \\
\hline 1940 & 2184 & 2324 & 2821 & 1527 & 1006 & 815 & 665 & 539 & 470 & 482 & 1073 & 743 & 1221 \\
\hline 1941 & 1256 & 1854 & 2456 & 923 & 801 & 649 & 529 & 532 & 475 & 1016 & 787 & 735 & 1001 \\
\hline 1942 & 1418 & 1483 & 1386 & 1794 & 906 & 739 & 599 & 485 & 476 & 742 & 1086 & 693 & 984 \\
\hline 1943 & 1807 & 1358 & 1559 & 1241 & 825 & 669 & 542 & 439 & 434 & 1114 & 1018 & 1570 & 1048 \\
\hline 1944 & 820 & 1318 & 1223 & 832 & 675 & 559 & 453 & 367 & 345 & 437 & 933 & 738 & 725 \\
\hline 1945 & 1699 & 2052 & 2388 & 1389 & 960 & 778 & 630 & 510 & 458 & 506 & 1149 & 1451 & 1164 \\
\hline 1946 & 945 & 2625 & 1578 & 911 & 1029 & 745 & 634 & 513 & 427 & 447 & 1064 & 1119 & 1003 \\
\hline 1947 & 2675 & 1651 & 2174 & 1094 & 893 & 724 & 586 & 475 & 410 & 580 & 717 & 1475 & 1121 \\
\hline 1948 & 1018 & 1574 & 1194 & 874 & 724 & 587 & 518 & 420 & 470 & 517 & 963 & 4465 & 1110 \\
\hline 1949 & 2066 & 2158 & 1479 & 1015 & 851 & 731 & 592 & 480 & 393 & 904 & 573 & 1986 & 1102 \\
\hline 1950 & 2657 & 1431 & 2108 & 965 & 785 & 636 & 515 & 417 & 338 & 491 & 742 & 2445 & 1128 \\
\hline 1951 & 1662 & 1535 & 3858 & 966 & 931 & 761 & 617 & 503 & 452 & 423 & 810 & 776 & 1108 \\
\hline 1952 & 1260 & 1186 & 1119 & 983 & 725 & 588 & 476 & 385 & 325 & 320 & 476 & 1209 & 754 \\
\hline 1953 & 1068 & 1405 & 2111 & 834 & 722 & 585 & 474 & 384 & 432 & 595 & 562 & 1018 & 849 \\
\hline 1954 & 1300 & 1923 & 2365 & 909 & 768 & 639 & 518 & 419 & 402 & 427 & 1182 & 698 & 963 \\
\hline 1955 & 2244 & 923 & 2369 & 907 & 804 & 664 & 538 & 436 & 353 & 357 & 380 & 1730 & 975 \\
\hline 1956 & 916 & 1458 & 894 & 1149 & 833 & 738 & 599 & 498 & 520 & 510 & 2241 & 1536 & 991 \\
\hline 1957 & 1369 & 2041 & 1344 & 1007 & 818 & 689 & 559 & 480 & 539 & 536 & 707 & 1485 & 965 \\
\hline 1958 & 1540 & 1080 & 1297 & 1123 & 819 & 667 & 564 & 457 & 403 & 449 & 916 & 1815 & 928 \\
\hline 1959 & 3455 & 1431 & 2484 & 1015 & 858 & 709 & 589 & 482 & 399 & 389 & 2011 & 1650 & 1289 \\
\hline 1960 & 1989 & 1949 & 1188 & 1038 & 814 & 659 & 534 & 433 & 351 & 470 & 663 & 1362 & 954 \\
\hline 1961 & 2055 & 1223 & 1962 & 909 & 822 & 669 & 542 & 486 & 403 & 437 & 607 & 1841 & 996 \\
\hline 1962 & 2314 & 1843 & 876 & 1057 & 743 & 611 & 495 & 413 & 494 & 514 & 523 & 2830 & 1059 \\
\hline 1963 & 896 & 2029 & 1196 & 899 & 746 & 604 & 491 & 397 & 341 & 353 & 846 & 623 & 785 \\
\hline 1964 & 1749 & 748 & 1035 & 686 & 617 & 500 & 409 & 331 & 272 & 701 & 1460 & 1001 & 792 \\
\hline 1965 & 1282 & 1559 & 1823 & 999 & 820 & 666 & 539 & 437 & 449 & 1334 & 1413 & 1020 & 1028 \\
\hline 1966 & 1452 & 2245 & 1172 & 922 & 798 & 647 & 524 & 424 & 383 & 893 & 560 & 658 & 890 \\
\hline 1967 & 832 & 923 & 1035 & 929 & 686 & 565 & 458 & 371 & 315 & 516 & 647 & 1263 & 712 \\
\hline 1968 & 750 & 1157 & 718 & 636 & 516 & 418 & 339 & 335 & 343 & 447 & 507 & 1355 & 627 \\
\hline 1969 & 1286 & 814 & 927 & 762 & 651 & 532 & 431 & 349 & 318 & 395 & 841 & 1835 & 762 \\
\hline 1970 & 1797 & 1178 & 911 & 844 & 734 & 595 & 482 & 390 & 324 & 555 & 520 & 511 & 737 \\
\hline
\end{tabular}

Continua 
Conclusão

\begin{tabular}{|c|c|c|c|c|c|c|c|c|c|c|c|c|c|}
\hline \multicolumn{14}{|c|}{ Vazão $\left(\mathrm{m}^{3} / \mathrm{s}\right)$} \\
\hline 1971 & 968 & 1188 & 717 & 671 & 599 & 489 & 428 & 358 & 399 & 487 & 603 & 627 & 628 \\
\hline 1972 & 789 & 1504 & 769 & 690 & 595 & 491 & 430 & 354 & 330 & 399 & 1161 & 1230 & 729 \\
\hline 1973 & 1077 & 1110 & 1005 & 767 & 648 & 547 & 451 & 372 & 341 & 434 & 1272 & 1758 & 815 \\
\hline 1975 & 923 & 1342 & 1003 & 881 & 713 & 579 & 503 & 408 & 333 & 390 & 610 & 626 & 693 \\
\hline 1976 & 952 & 1254 & 1512 & 1169 & 777 & 579 & 444 & 371 & 363 & 470 & 653 & 1264 & 817 \\
\hline 1977 & 1349 & 1653 & 1099 & 1080 & 928 & 736 & 489 & 389 & 388 & 503 & 746 & 1113 & 873 \\
\hline 1981 & 1554 & 1543 & 1449 & 1548 & 1075 & 719 & 579 & 488 & 419 & 509 & 1088 & 1158 & 1011 \\
\hline 1982 & 1905 & 1990 & 1530 & 1612 & 1025 & 770 & 619 & 523 & 514 & 586 & 689 & 1048 & 1068 \\
\hline 1983 & 1407 & 1830 & 1332 & 1149 & 744 & 610 & 479 & 412 & 385 & 524 & 681 & 1017 & 881 \\
\hline 1984 & 1082 & 1038 & 1194 & 1094 & 804 & 557 & 457 & 407 & 417 & 466 & 618 & 1115 & 771 \\
\hline 1985 & 1663 & 1645 & 1458 & 1338 & 925 & 632 & 514 & 428 & 406 & 525 & 627 & 666 & 902 \\
\hline 1986 & 1370 & 1686 & 1469 & 1032 & 757 & 587 & 473 & 450 & 442 & 534 & 539 & 769 & 842 \\
\hline 1987 & 1484 & 1400 & 1351 & 1092 & 736 & 532 & 429 & 381 & 357 & 369 & 673 & 1408 & 851 \\
\hline 1992 & 1079 & 1643 & 1497 & 1360 & 839 & 684 & 548 & 477 & 539 & 579 & 811 & 1477 & 961 \\
\hline 1993 & 1233 & 1628 & 1114 & 912 & 710 & 571 & 458 & 411 & 391 & 430 & 518 & 860 & 770 \\
\hline 1994 & 1577 & 1321 & 1938 & 1317 & 911 & 744 & 573 & 455 & 405 & 468 & 566 & 766 & 920 \\
\hline 1995 & 2328 & 2132 & 2056 & 1784 & 1394 & 887 & 638 & 533 & 486 & 504 & 649 & 1014 & 1200 \\
\hline 1996 & 1423 & 1264 & 1480 & 1239 & 836 & 625 & 480 & 439 & 413 & 439 & 801 & 733 & 848 \\
\hline 1997 & 1384 & 1954 & 1893 & 1285 & 890 & 691 & 524 & 439 & 400 & 424 & 532 & 946 & 947 \\
\hline 1998 & 948 & 1234 & 1348 & 836 & 583 & 451 & 382 & 350 & 337 & 397 & 699 & 1199 & 730 \\
\hline 1999 & 1710 & 1191 & 1584 & 900 & 653 & 493 & 419 & 360 & 361 & 361 & 545 & 888 & 789 \\
\hline 2000 & 1239 & 1488 & 1851 & 1242 & 744 & 541 & 466 & 403 & 406 & 400 & 713 & 894 & 866 \\
\hline 2001 & 901 & 904 & 1225 & 1028 & 699 & 556 & 450 & 391 & 396 & 514 & 642 & 1331 & 753 \\
\hline 2002 & 1596 & 1488 & 1619 & 1174 & 765 & 587 & 493 & 427 & 424 & 431 & 586 & 756 & 862 \\
\hline 2003 & 1464 & 1618 & 1677 & 1900 & 964 & 720 & 576 & 480 & 453 & 556 & 707 & 972 & 1007 \\
\hline 2004 & 1392 & 2998 & 1634 & 1391 & 1013 & 752 & 663 & 556 & 498 & 579 & 770 & 842 & 1091 \\
\hline 2005 & 1314 & 1423 & 1433 & 1158 & 760 & 592 & 513 & 438 & 427 & 514 & 656 & 1341 & 881 \\
\hline
\end{tabular}




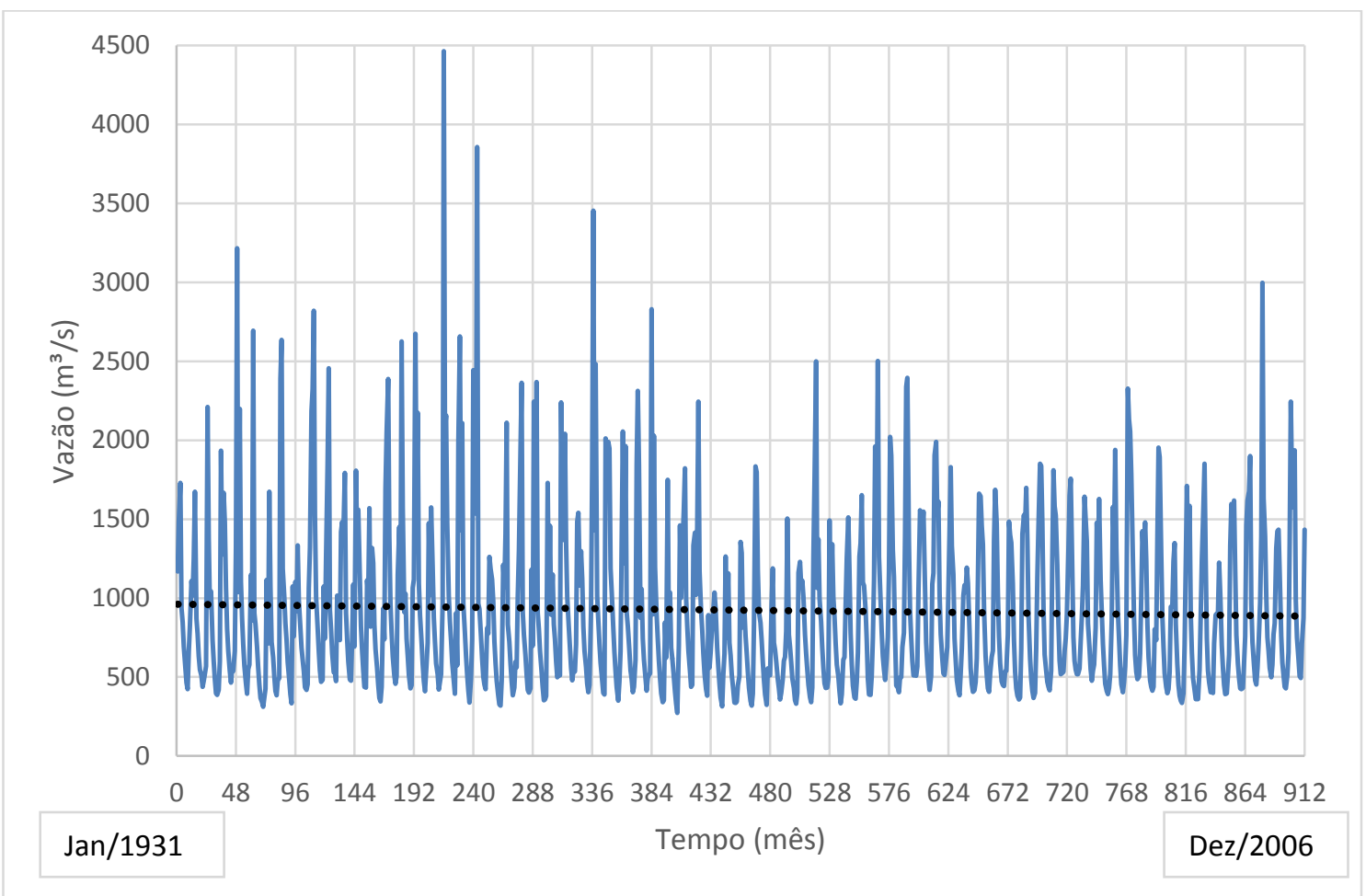

Figura 4: Série histórica de vazões afluentes da UHE Sinop no período de Janeiro/1931 até Dezembro/2006 (EPE, 2010b).

Tabela 2: Valores representativos da série histórica de vazões da UHE Sinop

\begin{tabular}{|c|c|c|c|c|c|c|c|c|c|c|c|c|c|c|}
\hline \multirow{2}{*}{ Dado/Mês } & \multicolumn{13}{|c|}{ Vazão $\left(\mathbf{m}^{3} / \mathbf{s}\right)$} & \multirow{2}{*}{$\%$ MLT } \\
\hline & Jan & Fev & Mar & Abr & Mai & Jun & Jul & Ago & Set & Out & Nov & Dez & MÉDIA & \\
\hline Máximo & 3455.00 & 2998.00 & 3858.00 & 1936.00 & 1394.00 & 887.00 & 665.00 & 556.00 & 553.00 & 1334.00 & 2241.00 & 4465.00 & 2028.50 & 19.61 \\
\hline Quartil 3 & 1807.75 & 1833.25 & 1826.50 & 1241.25 & 887.75 & 706.75 & 566.00 & 480.50 & 454.25 & 554.25 & 842.25 & 1438.25 & 1053.23 & 14.02 \\
\hline Média & 1533.08 & 1547.39 & 1553.58 & 1097.97 & 810.78 & 637.38 & 520.20 & 438.63 & 414.30 & 531.78 & 777.33 & 1221.86 & 923.69 & 100.00 \\
\hline Mediana & 1402.50 & 1486.50 & 1479.50 & 1040.50 & 802.50 & 632.50 & 518.00 & 435.50 & 406.00 & 495.00 & 690.00 & 1117.00 & 875.46 & 94.78 \\
\hline Quartil 1 & 1081.25 & 1246.75 & 1184.00 & 908.50 & 731.00 & 583.50 & 473.75 & 395.50 & 362.50 & 430.75 & 577.50 & 826.50 & 733.46 & 79.41 \\
\hline Mínimo & 750.00 & 713.00 & 717.00 & 636.00 & 516.00 & 418.00 & 339.00 & 331.00 & 272.00 & 312.00 & 371.00 & 425.00 & 483.33 & 52.33 \\
\hline
\end{tabular}




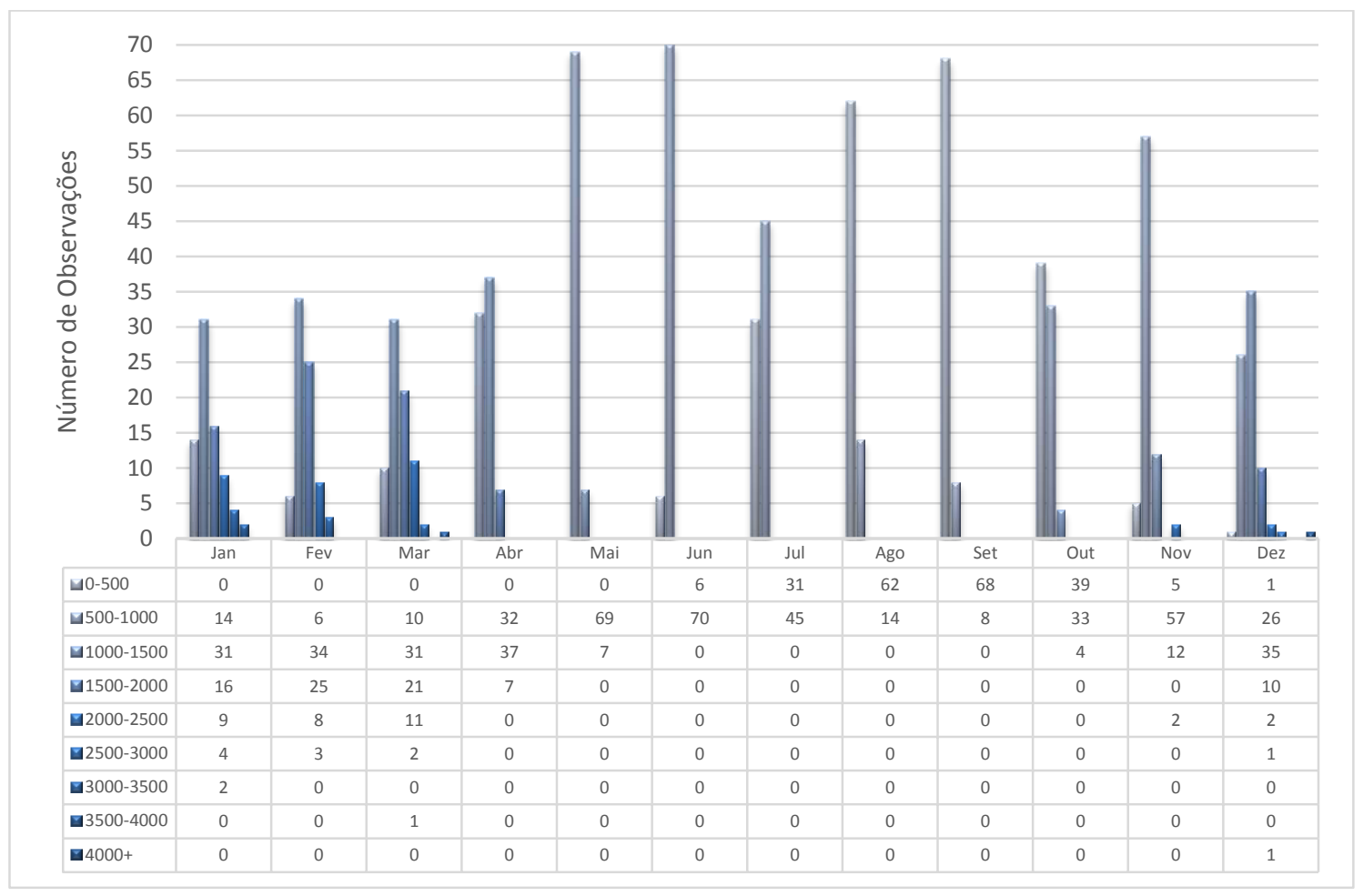

Figura 5: Distribuição de frequência da série de vazões naturais da UHE Sinop.

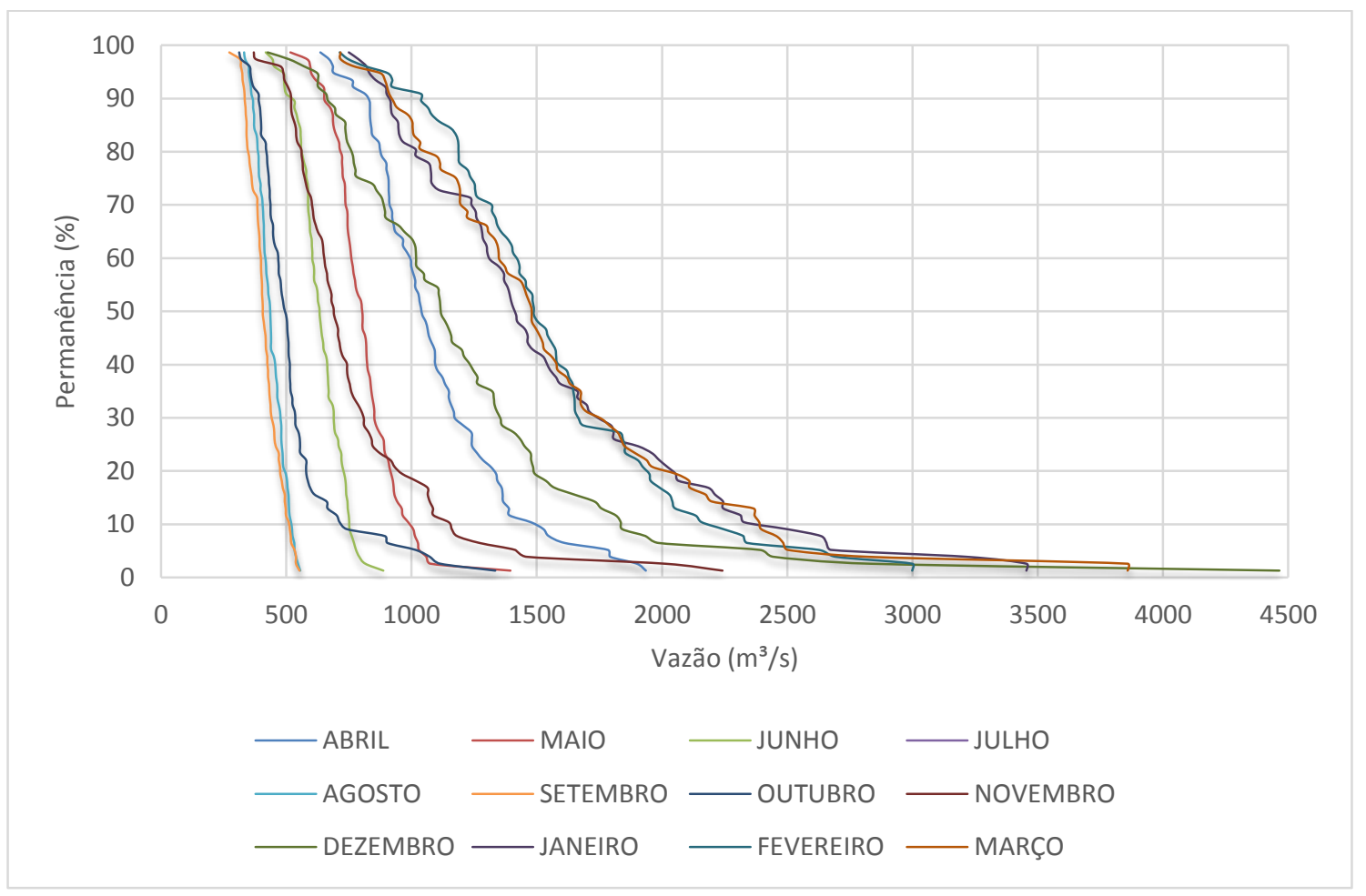

Figura 6: Curvas de permanência mensais para a UHE Sinop. 
A mediana representa a vazão que é superada em $50 \%$ da amostra e, segundo Lopes (2001), pode ser considerada representativa em um cenário de clima normal. Casos de estiagem podem ser considerados valores que são representados no primeiro quartil, ou seja, superados por $75 \%$ da amostra. De maneira análoga, o terceiro quartil índica o cenário úmido, superado por $25 \%$ da amostra.

Os coeficientes dos polinômios para as curvas Cota $\times$ Volume, Cota $\times$ Área e Curva Chave do Canal de Fuga estão apresentados na Tabela 3.

Tabela 3: Coeficientes das curvas Cota x Volume, Cota x Área e Curva do Canal de Fuga (EPE, 2010b)

\begin{tabular}{cccccc}
\hline Curva & Independente & Grau 1 & Grau 2 & Grau 3 & Grau 4 \\
\hline Cota x Volume & $2,8180755 \mathrm{E}+02$ & $1,2946698 \mathrm{E}-02$ & $-3,3665774 \mathrm{E}-06$ & $5,3235843 \mathrm{E}-10$ & $-3,6591819 \mathrm{E}-14$ \\
Cota x Área & $-3,9365578 \mathrm{E}+08$ & $5,2724387 \mathrm{E}+06$ & $-2,6477074 \mathrm{E}+04$ & $5,9084885 \mathrm{E}+01$ & $-4,9435901 \mathrm{E}-02$ \\
Curva Chave & $2,7196675 \mathrm{E}+02$ & $9,2084693 \mathrm{E}-04$ & $2,3795484 \mathrm{E}-07$ & $-7,1196339 \mathrm{E}-11$ & $-5,3060022 \mathrm{E}-15$ \\
\hline
\end{tabular}

Os valores para os coeficientes de evaporação mensal e usos consuntivos da água se encontram na Tabela 4.

Tabela 4: Usos consultivos da água na UHE Sinop (EPE, 2010b)

\begin{tabular}{lcccccccccccc}
\hline Dados/Mês & Jan & Fev. & Mar & Abr. & Mai & Jun. & Jul. & Ago. & Set & Out & Nov. & Dez \\
\hline Evap. $(\mathrm{mm})$ & 26 & 21 & 25 & 2 & 4 & 25 & 32 & 45 & 56 & 23 & 22 & 41 \\
UC. $\left(\mathrm{m}^{3} / \mathrm{s}\right)$ & 7,28 & 7,28 & 14,48 & 17,36 & 20,24 & 23,12 & 20,24 & 20,24 & 11,60 & 7,28 & 7,28 & 7,28 \\
\hline
\end{tabular}




\subsection{Análise dos Resultados Numéricos}

Nesta seção serão apresentados os resultados obtidos de acordo com metodologia proposta no Item 4 - Metodologia. O modelo foi escrito utilizando o software GAMS, utilizando o solver MINOS para resolver o problema de PNL. Cabe ressaltar que, durante a pesquisa, foram também realizados testes com os solvers CONOPT e SISOPT, porém, ambos não foram capazes de resolver o modelo em questão, pois os resultados não convergiram para uma solução factível.

Ao todo foram realizados 5 estudos com o modelo HIDRO-OR. Os primeiros 3 estudos, apresentados nos Itens 5.2.1, 5.2.2 e 5.2.3, correspondem à formulação do modelo considerando apenas a função em uma única etapa (Z1). A partir da análise desses resultados verificou-se a necessidade da adição de uma função objetivo "corretiva", de segunda etapa (Z2), cuja análise de desempenho está apresentada nos itens 5.2 .3 e 5.2 .4 .

Em todos os estudos foram utilizadas três combinações dos coeficientes de ponderação $w_{1}$ e $w_{2}$ da função objetivo $Z_{1}$, para análise de sensibilidade do modelo, conforme demonstrado na Tabela 5.

Tabela 5: Combinações dos coeficientes de ponderação utilizados nos estudos.

\begin{tabular}{ccc}
\hline Combinações & \multicolumn{2}{c}{ Coeficientes } \\
\cline { 2 - 3 } & $\mathrm{W}_{1}$ & $\mathrm{~W}_{2}$ \\
Comb. 1 & 1.00 & 0.00 \\
Comb. 2 & 1.00 & 0.50 \\
Comb. 3 & 1.00 & 1.00 \\
\hline
\end{tabular}

Em todos casos estudados, uma solução inicial viável do modelo foi obtida individualmente para cada cenário de vazões, utilizando um modelo de PNL simplificado onde não foram consideradas as perdas por evaporação. O cálculo da solução inicial foi realizado utilizando uma planilha eletrônica e o pacote de solver presente no MS Excel 2007. 


\subsubsection{Estudo 1 - 20 Cenários com horizonte de 24 meses com otimização em uma única etapa}

Para o Estudo 1, foram realizados 20 cenários de vazões afluentes com um horizonte de planejamento de 24 meses. O valor das vazões para cada cenário foi obtido diretamente da série histórica de vazões (presente na Tabela 1), utilizando combinações diferentes de dois anos consecutivos. $O$ valor da vazão inicial $(t=1)$ foi adotado igual a 1098 m³/s, correspondendo à vazão média para o mês de Abril, que corresponde ao início do período seco na região. Em todos os estudos realizados o volume inicial do reservatório foi considerado $80 \%$ de sua capacidade máxima, 0 que é normalmente encontrado nos reservatórios da região sudeste e oeste.

A composição dos cenários de vazões está apresentada na Tabela 6 e na Figura 7.

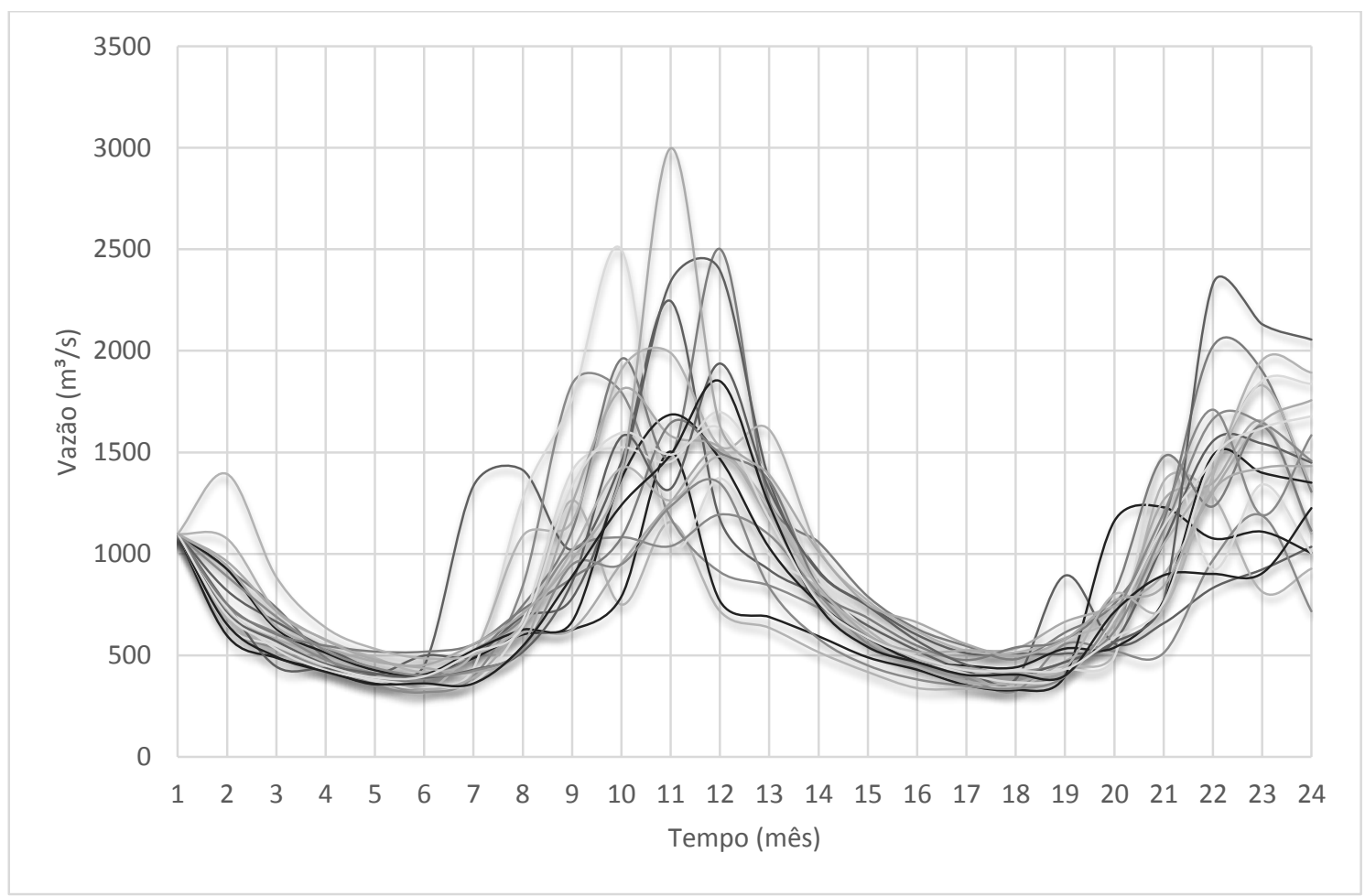

Figura 7: Cenários de Vazões Afluentes - Estudo 1 
Tabela 6: Composição dos Cenários de Vazões (m³/s) - Estudo 1

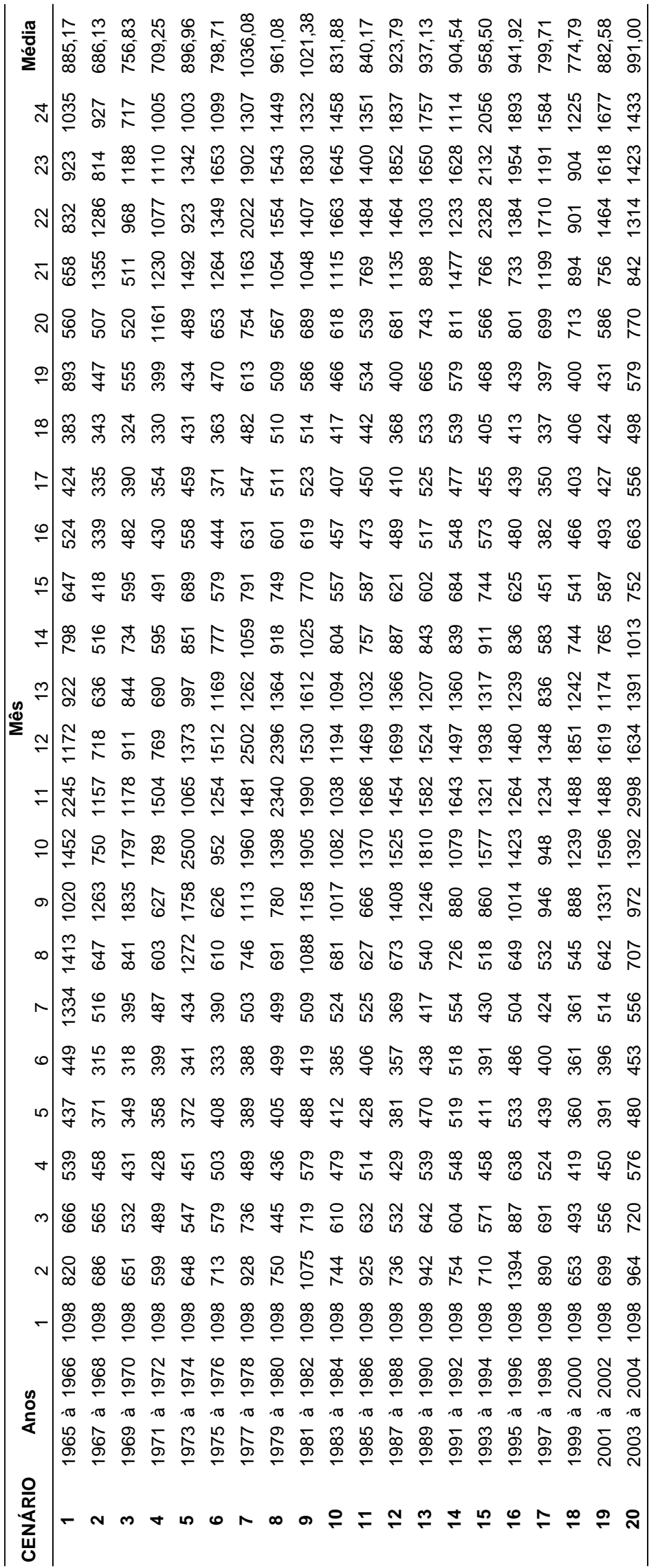


A seguir estão apresentados os resultados obtidos para o Estudo 1.

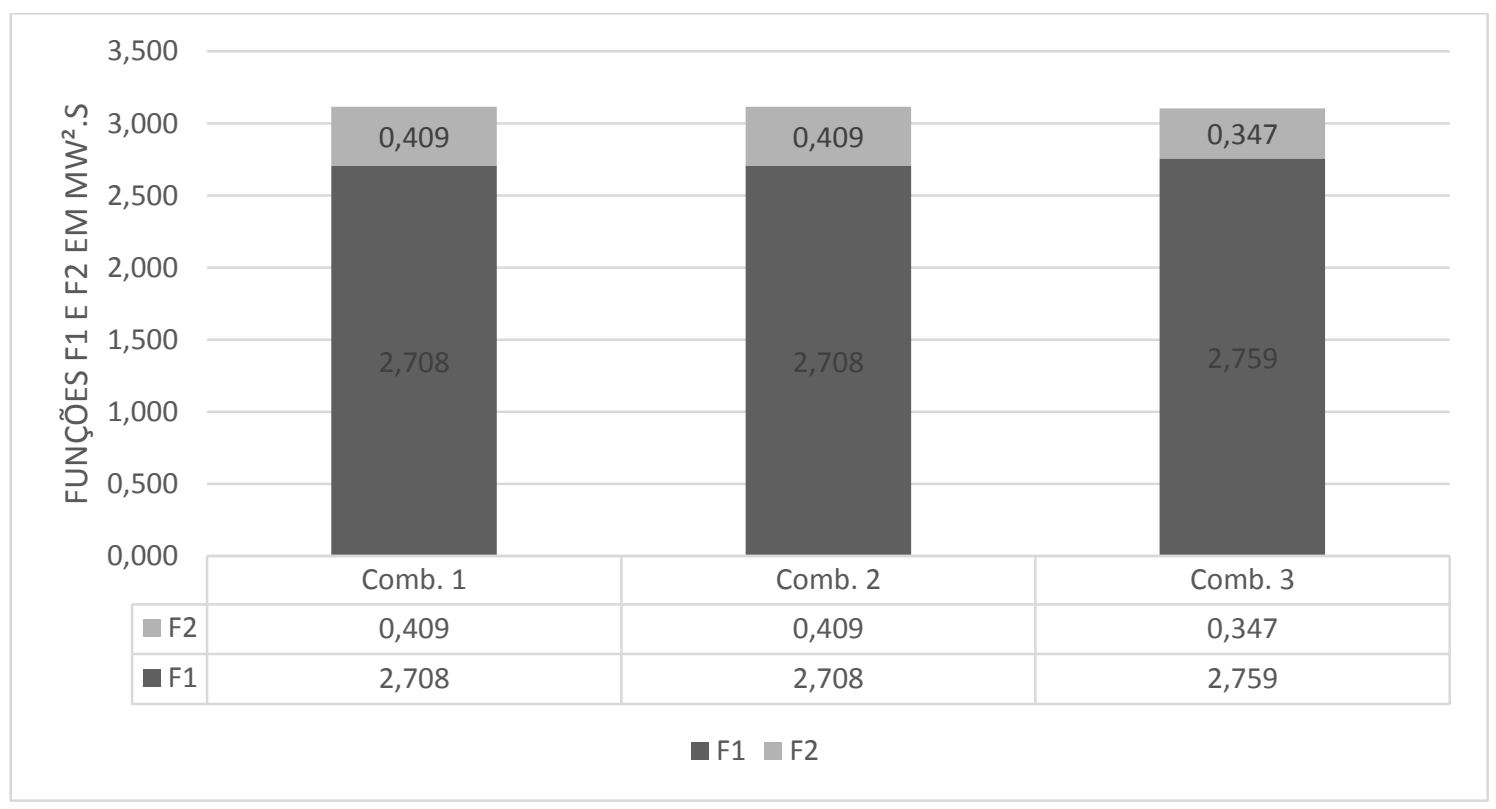

Figura 8: Valores das funções F1 e F2 para o Estudo 1.

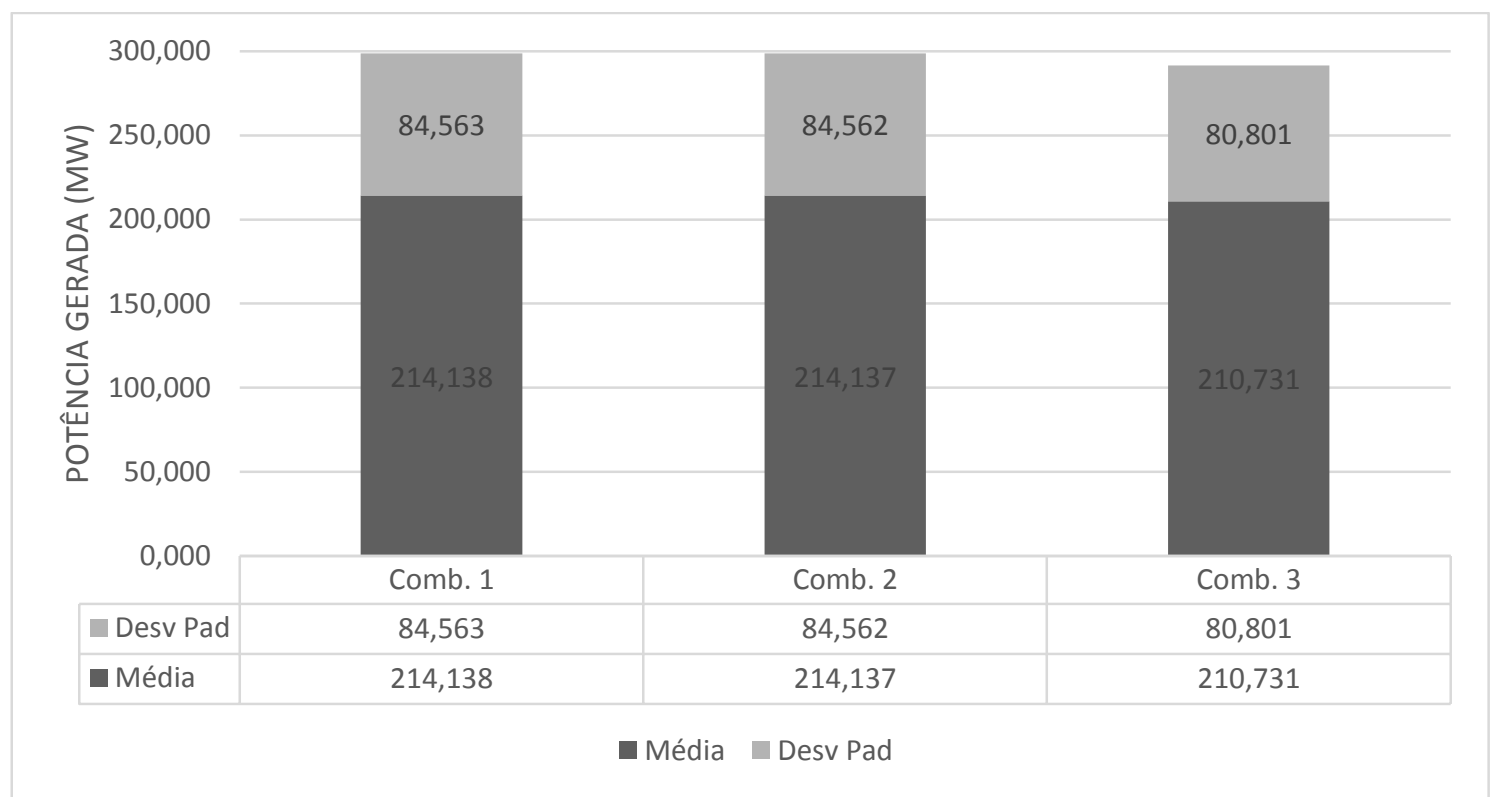

Figura 9: Média de energia produzida e seu desvio padrão no Estudo 1 para diferentes coeficientes de ponderação. 


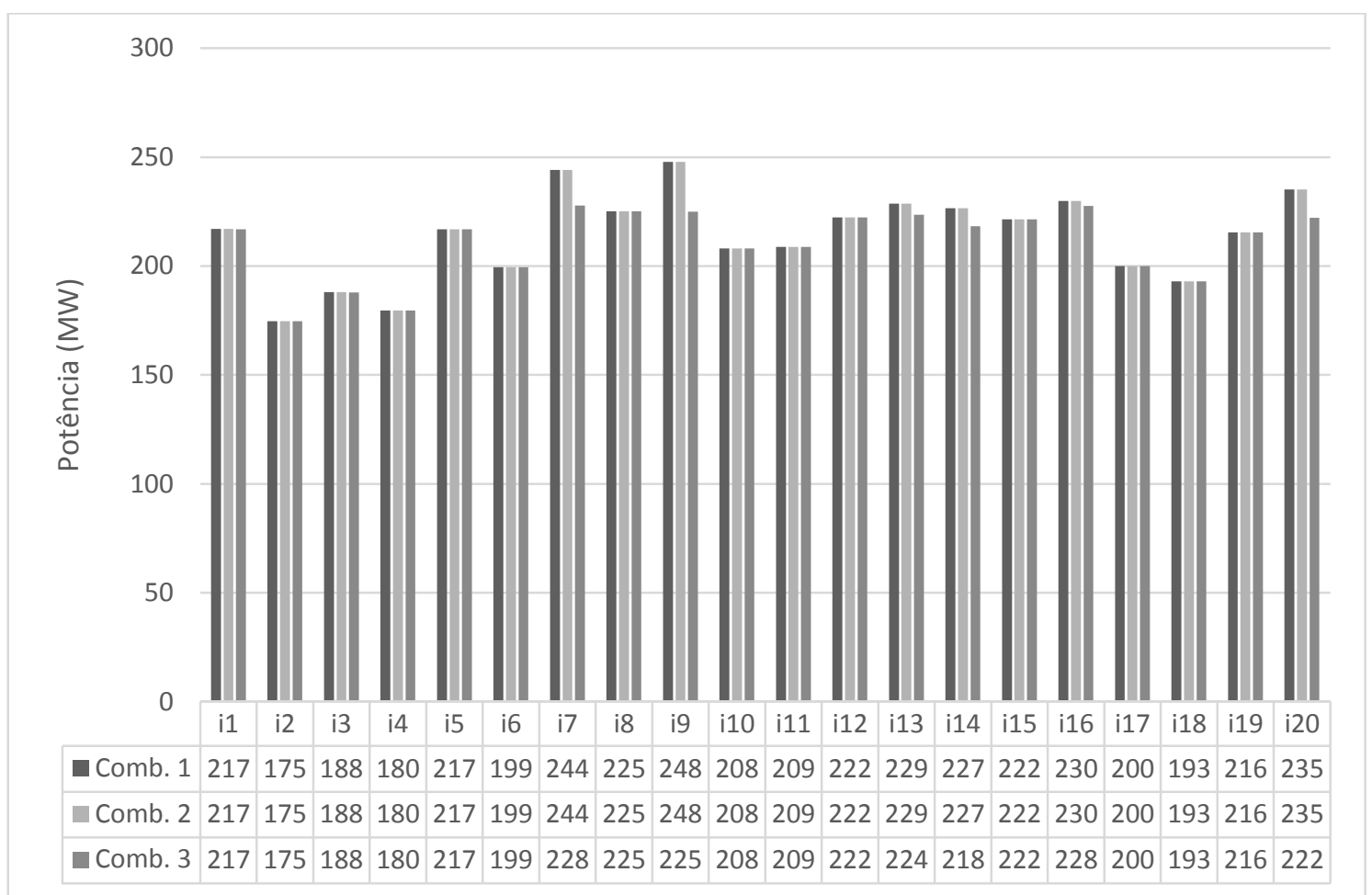

Figura 10: Média da potência por cenário no Estudo 1 para diferentes combinações coeficientes de ponderação.

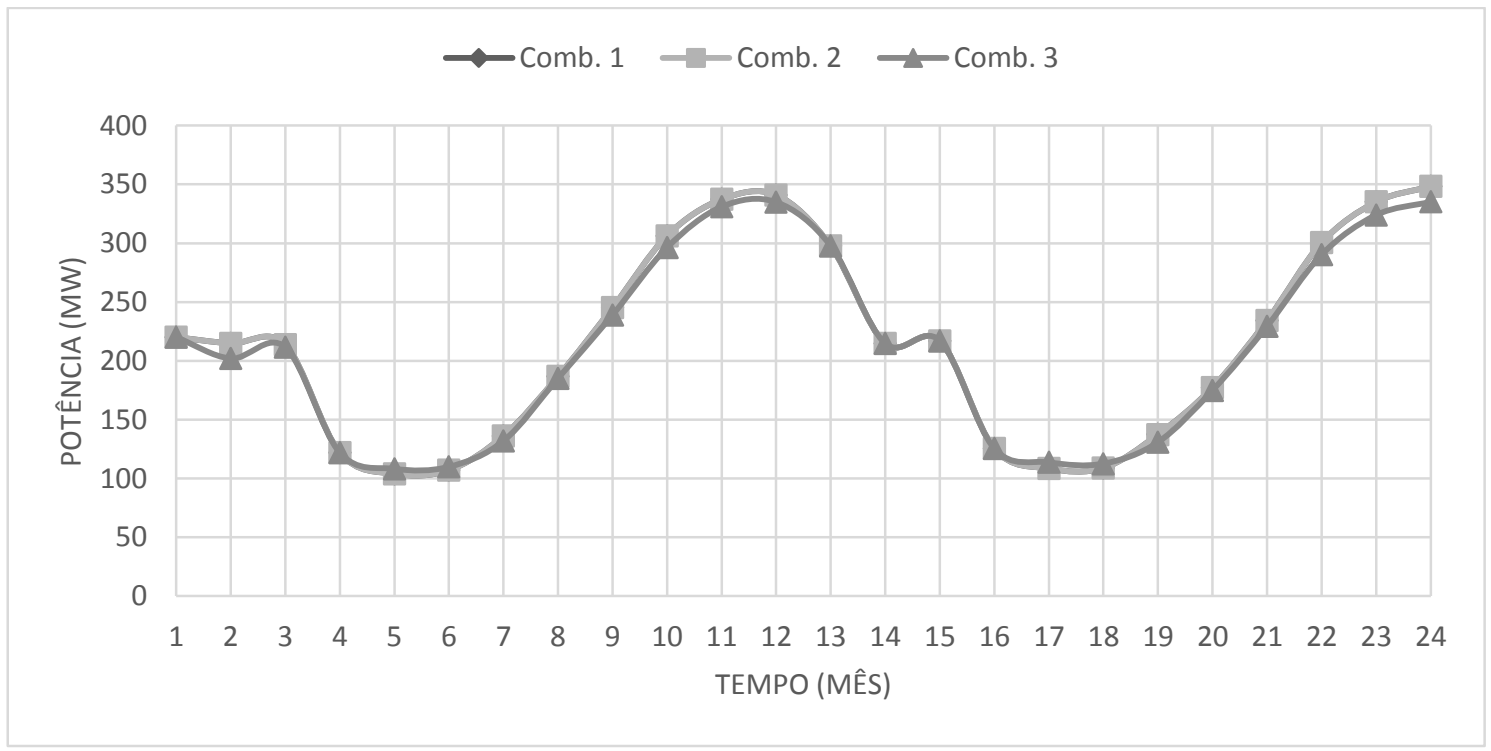

Figura 11: Média mensal de produção do modelo no Estudo 1 para diferentes combinações de coeficientes de ponderação. 


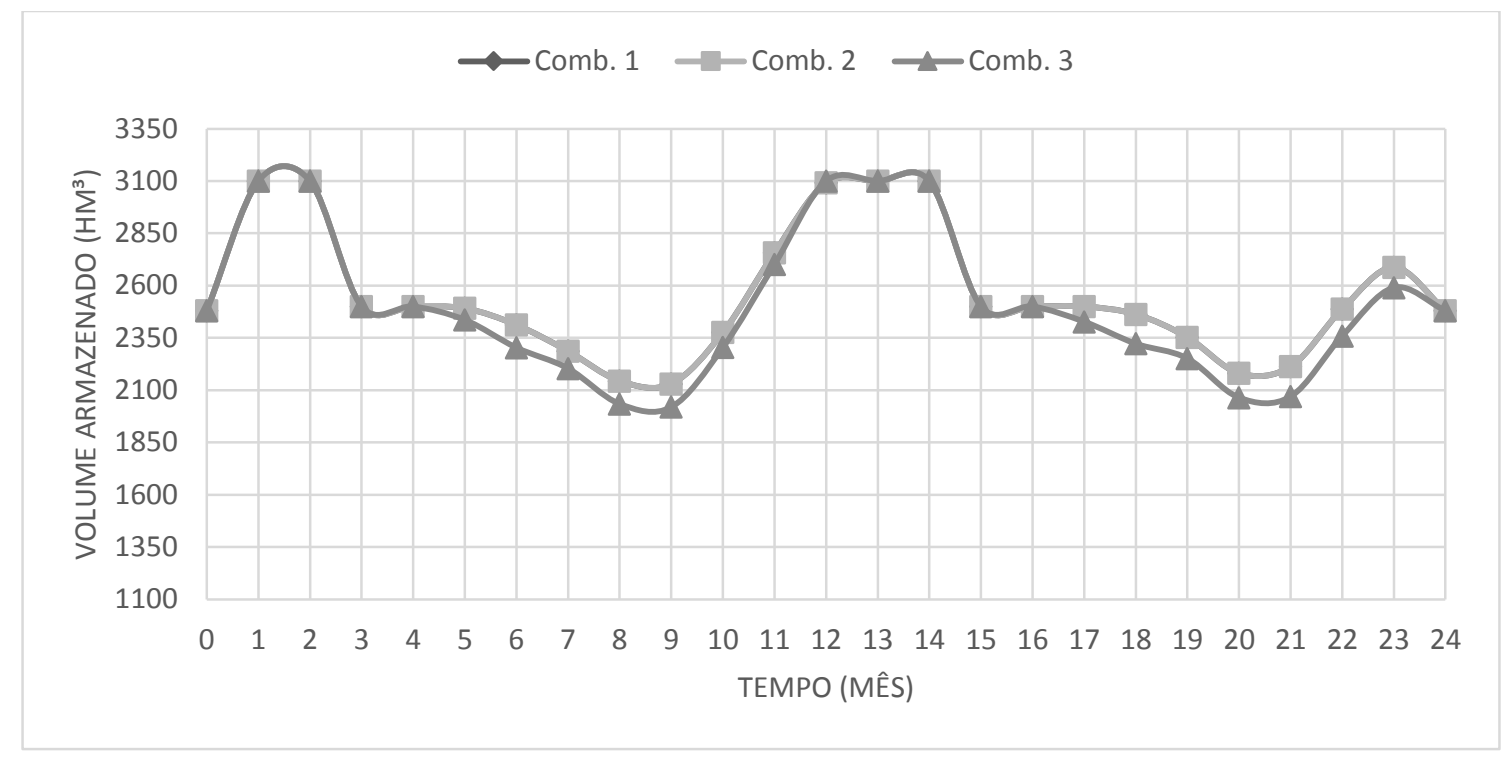

Figura 12: Média do volume armazenado mensalmente no Estudo 1 para diferentes coeficientes de ponderação.

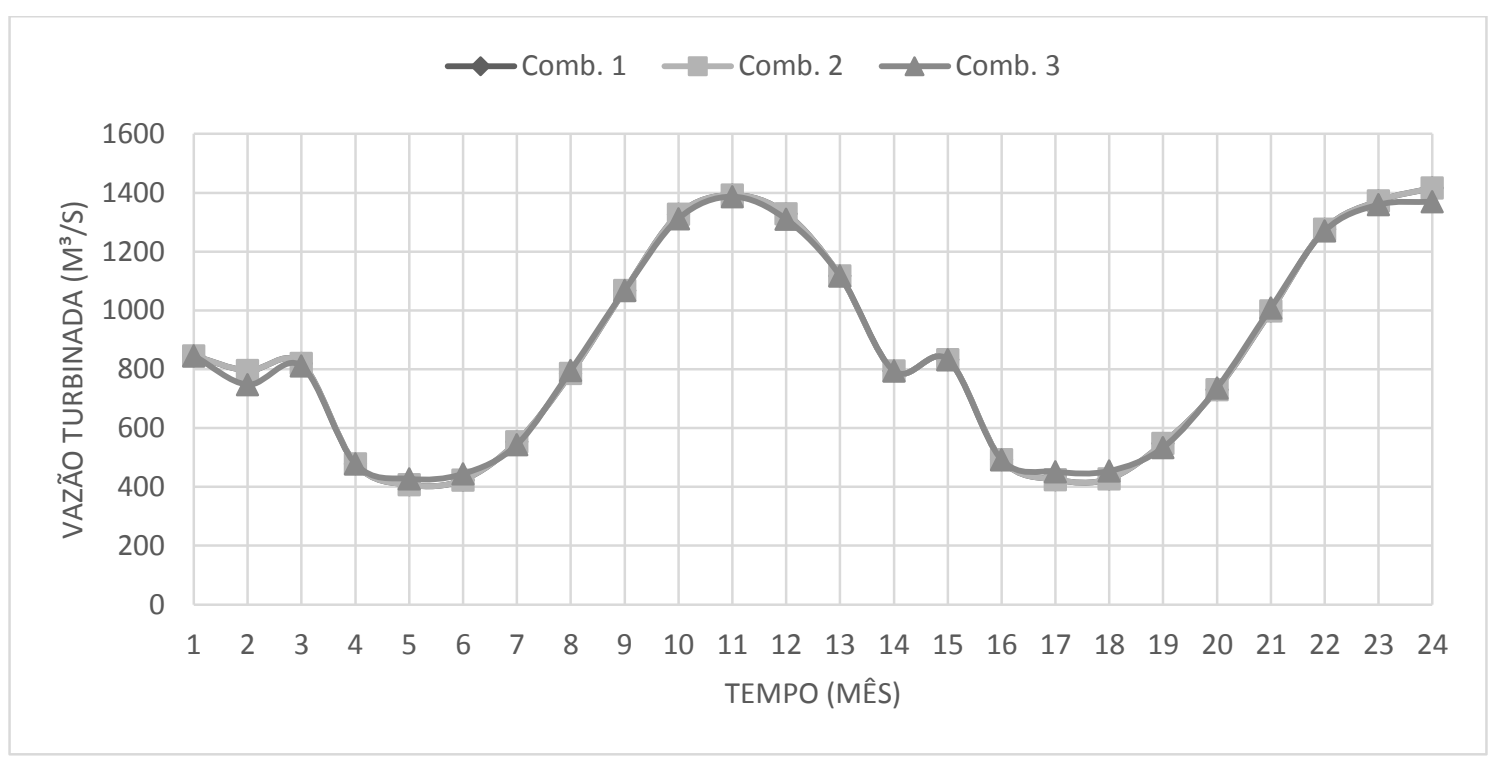

Figura 13: Média da vazão turbinada mensalmente no Estudo 1 para diferentes combinações dos coeficientes de ponderação. 
Tabela 7: Vazões vertidas $\left(\mathrm{m}^{3} / \mathrm{s}\right)$ na Combinação 1 - Estudo 1.

\begin{tabular}{rccccc}
\hline Cenário & \multicolumn{5}{c}{ Mês } \\
i5 & 10 & 11 & 12 & 23 & 24 \\
\cline { 2 - 6 } i7 & 78,525 & - & - & - & - \\
i8 & - & - & 98,631 & - & - \\
i15 & - & - & 580,531 & - & - \\
i20 & - & 425,092 & 88,001 & - & - \\
\hline
\end{tabular}

Tabela 8: Vazões vertidas $\left(\mathrm{m}^{3} / \mathrm{s}\right)$ na Combinação 2 - Estudo 1.

\begin{tabular}{rrrccc}
\hline Cenário & \multicolumn{5}{c}{ Mês } \\
& 10 & 11 & 12 & 23 & 24 \\
\cline { 2 - 6 } i5 & 78,947 & - & - & - & - \\
i7 & - & - & 98,858 & - & - \\
i8 & - & - & 580,278 & - & - \\
i15 & - & - & - & 500,479 & 183,283 \\
i20 & - & 424,656 & 88,001 & - & - \\
\hline
\end{tabular}

Tabela 9: Vazões vertidas $\left(\mathrm{m}^{3} / \mathrm{s}\right)$ na Combinação 3 - Estudo 1.

\begin{tabular}{|c|c|c|c|c|c|c|c|c|c|}
\hline \multirow{2}{*}{ Cenário } & \multicolumn{9}{|c|}{ Mês } \\
\hline & 2 & 3 & 5 & 10 & 11 & 12 & 13 & 23 & 24 \\
\hline i5 & - & - & - & 79,461 & - & - & - & - & - \\
\hline i7 & 404,526 & - & - & - & - & - & - & - & - \\
\hline i8 & - & - & - & - & - & 580,515 & - & - & - \\
\hline i9 & 328,057 & - & - & - & - & - & 66,517 & - & - \\
\hline i13 & 86,311 & - & - & - & - & - & - & - & - \\
\hline i14 & - & - & 8,802 & - & - & - & - & - & - \\
\hline i15 & - & - & - & - & - & - & - & - & - \\
\hline i16 & - & 173,245 & - & - & - & - & - & - & - \\
\hline i20 & 141,648 & - & - & - & 404,502 & 88,001 & - & - & 218,521 \\
\hline
\end{tabular}

Os resultados mostram que, para as Combinações 1 e 2 não ocorreram mudanças nos valores finais da função objetivo, sendo que ambos apresentaram valores de 2,708 $\mathrm{MW}^{2}$.s para a função $\mathrm{F} 1$ e 0,409 $\mathrm{MW}^{2}$.s para a função $\mathrm{F} 2$. A Combinação 3 apresentou um valor superior à das outras duas combinações no 
valor da função $F 1$, com 2,759 $\mathrm{MW}^{2}$.s e um valor inferior para a função $F 2$, com 0,347 $\mathrm{MW}^{2} . \mathrm{s}$ (Figura 8). Estes resultados demonstraram que, conforme aumenta a participação da função F2 no objetivo, temos um maior valor de F1, ou seja, a produção de energia é diminuída. $O$ fato das Combinações 1 e 2 terem apresentado os mesmos resultados deve-se possivelmente às não linearidades de ambas as funções objetivo e também das restrições, que encontraram o mesmo valor ótimo local independente dos valores dos coeficientes de ponderação.

Dessa forma, as Combinações 1 e 2 apresentaram os mesmos valores médios para a energia produzida, com 214,13 $\pm 84,56$ MW. Já a Combinação 3 apresentou valores inferiores na energia média produzida e seu desvio padrão, com $210,731 \pm 80,801$ MW. Para os três casos o modelo apresentou a mesma solução inicial, com uma geração de 220,11 MW.

Apesar da pequena diferença na média, a operação da usina foi bastante similar nas três combinações, sendo que para a Combinação 3 houve um deplecionamento um pouco maior do reservatório devido à um maior vertimento. Com um maior peso para a diminuição do desvio padrão, o modelo acaba optando por diminuir a energia gerada para aproximar os resultados. Dessa forma, ele gera vertimentos em alguns meses diminuindo a queda líquida e a produção de energia e, assim, diminuindo o desvio padrão da função objetivo. 


\subsubsection{Estudo 2 - 35 Cenários com horizonte de planejamento de 24 meses com otimização em uma única etapa.}

Para o Estudo 2, foram realizados 35 cenários de vazões afluentes com um horizonte de planejamento de 24 meses de forma análoga ao Estudo 1. Este estudo foi realizado com o intuito de averiguar a influência de um maior número de cenários no modelo, utilizando praticamente toda a série histórica de vazões.

A composição dos cenários de vazões está apresentada na Tabela 10 e na Figura 14.

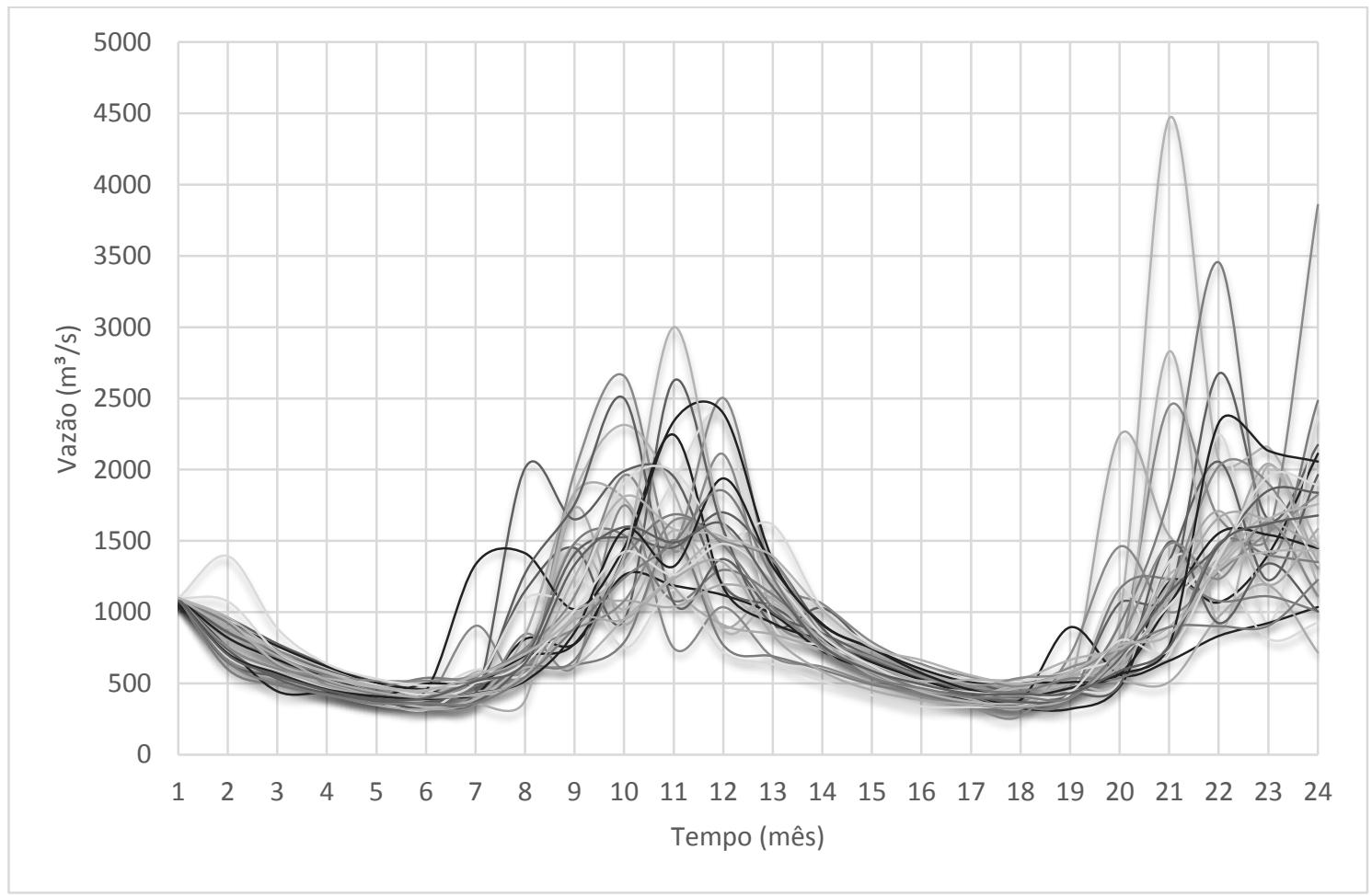

Figura 14: Cenários de Vazões Afluentes - Estudo 4. 
Tabela 10: Composição dos Cenários de Vazões (m³/s) - Estudo 2

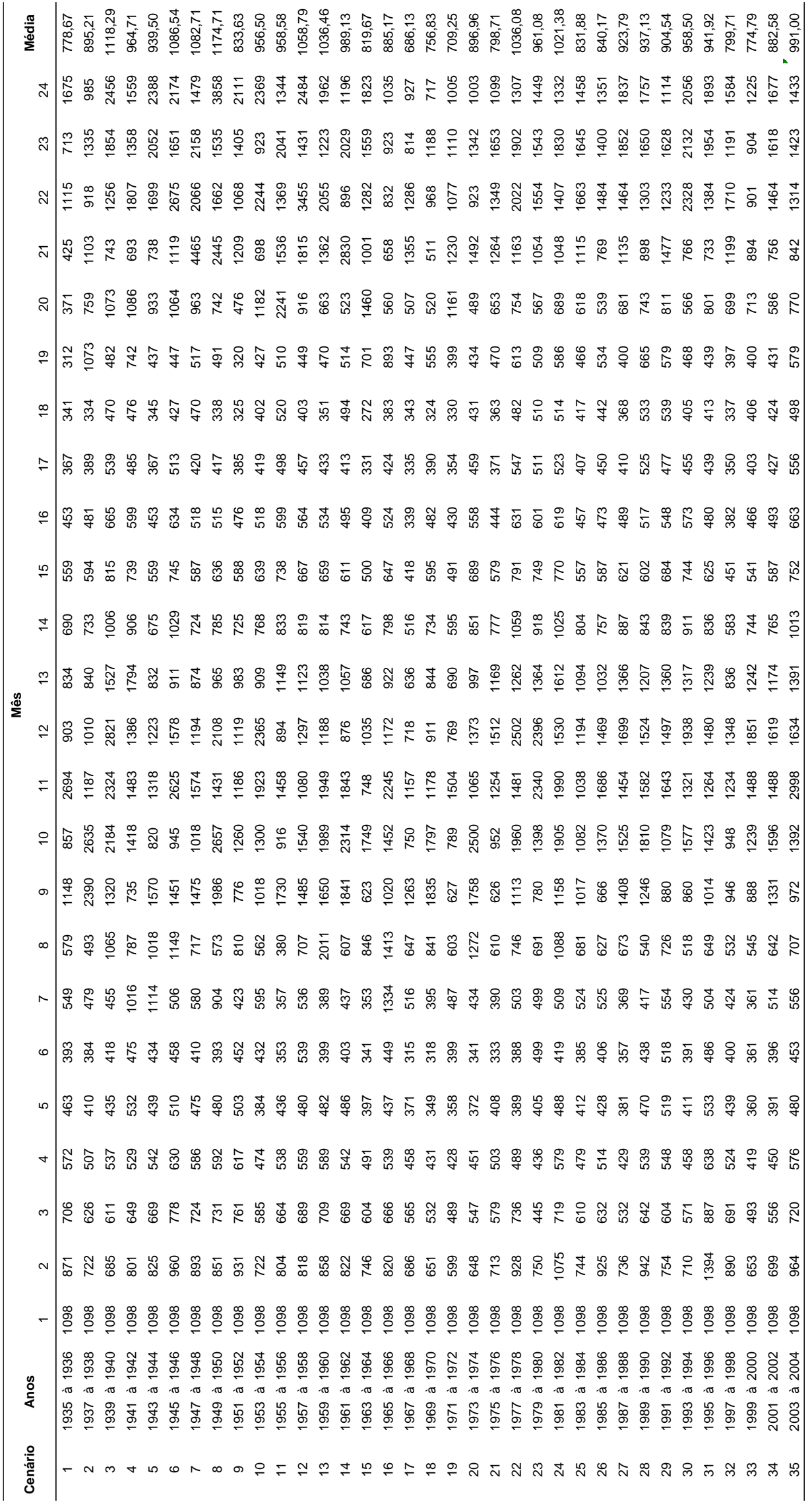




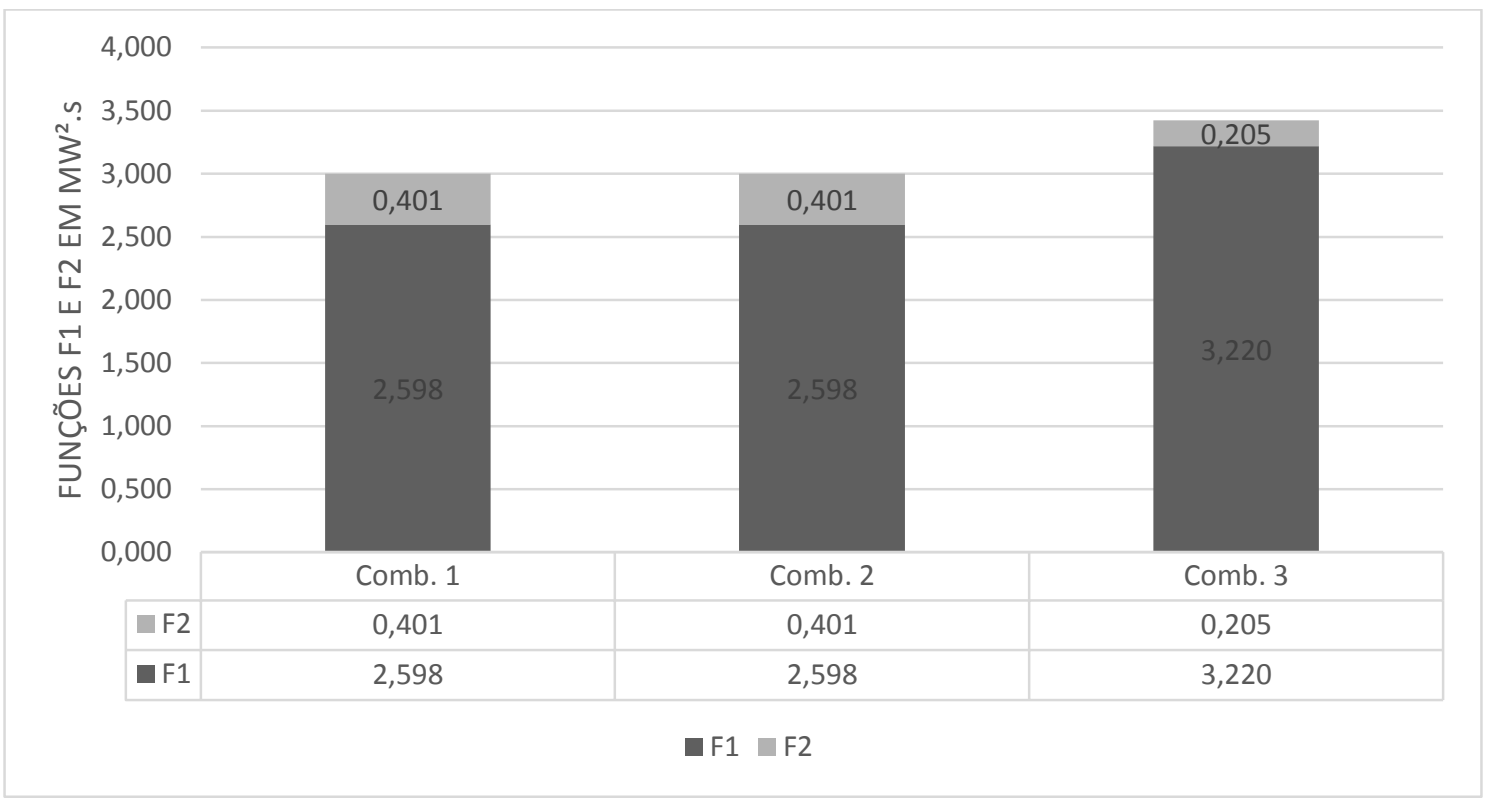

Figura 15: Valores das funções F1 e F2 para o Estudo 2.

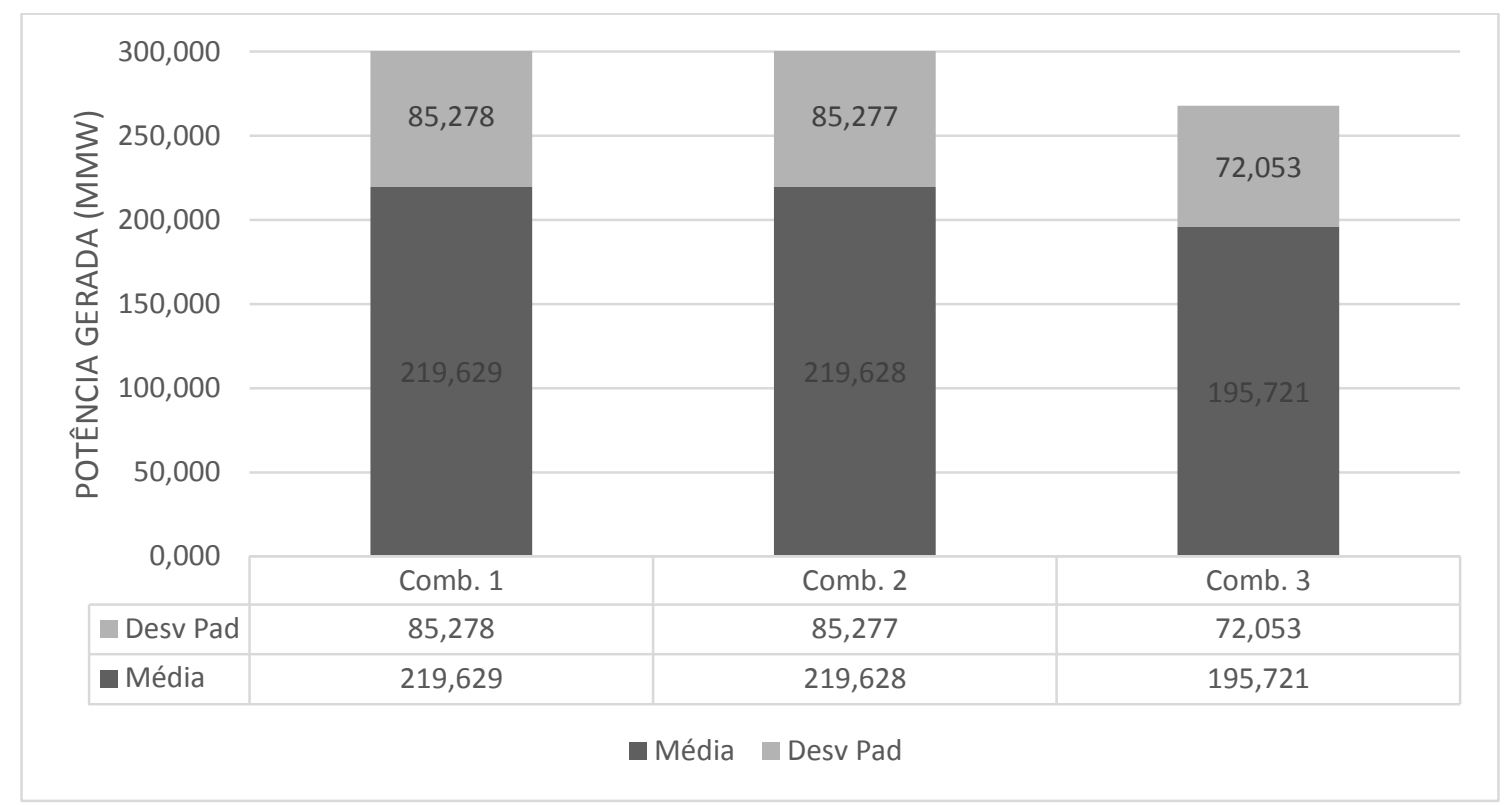

Figura 16: Média de energia produzida e seu desvio padrão no Estudo 2 para diferentes coeficientes de ponderação. 


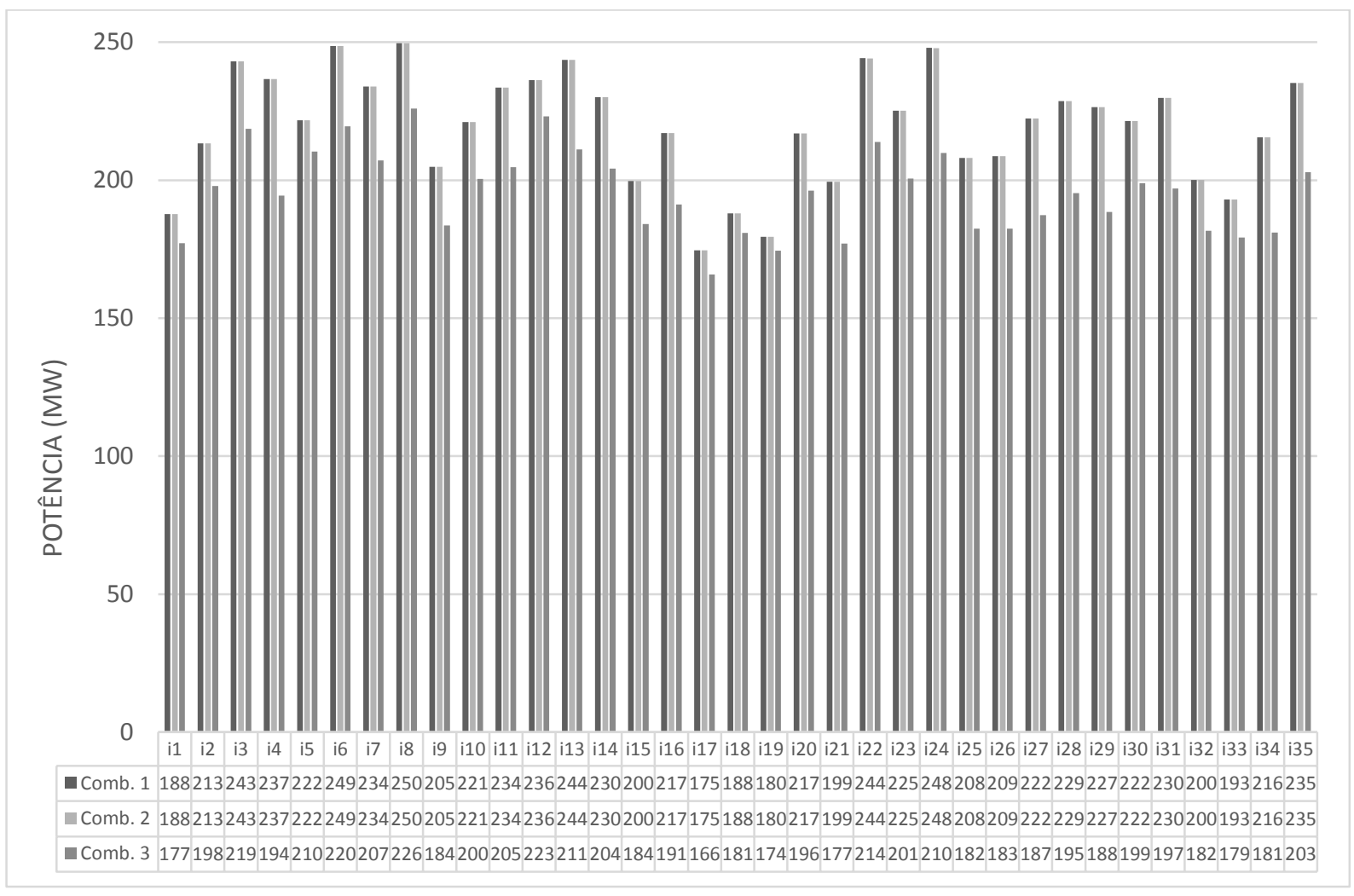

Figura 17: Média da potência por cenário no Estudo 2 para diferentes combinações coeficientes de ponderação.

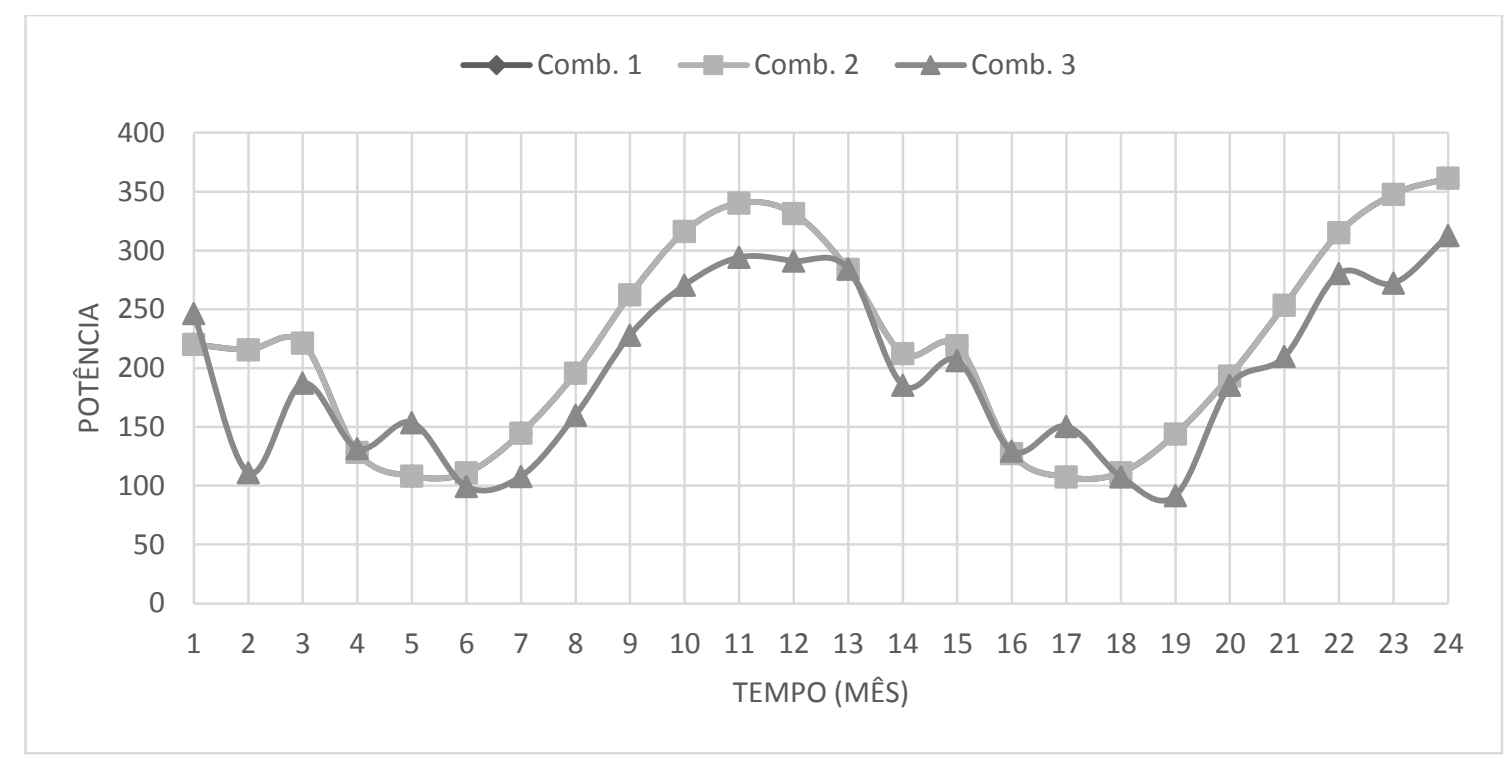

Figura 18: Média mensal de produção de energia do modelo no Estudo 2 para diferentes combinações de coeficientes de ponderação. 


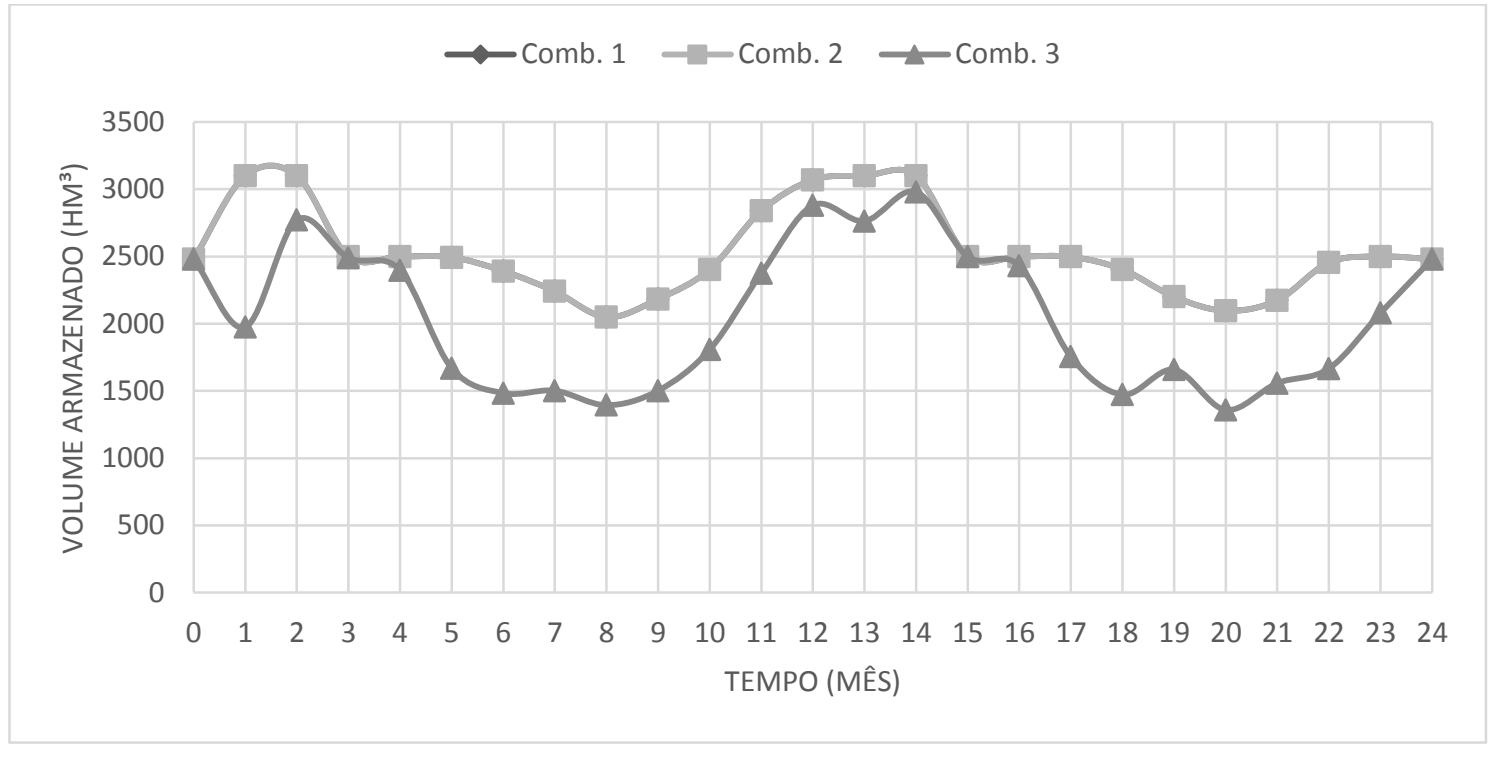

Figura 19: Média mensal do volume armazenado no Estudo 2 para diferentes combinações dos coeficientes de ponderação.

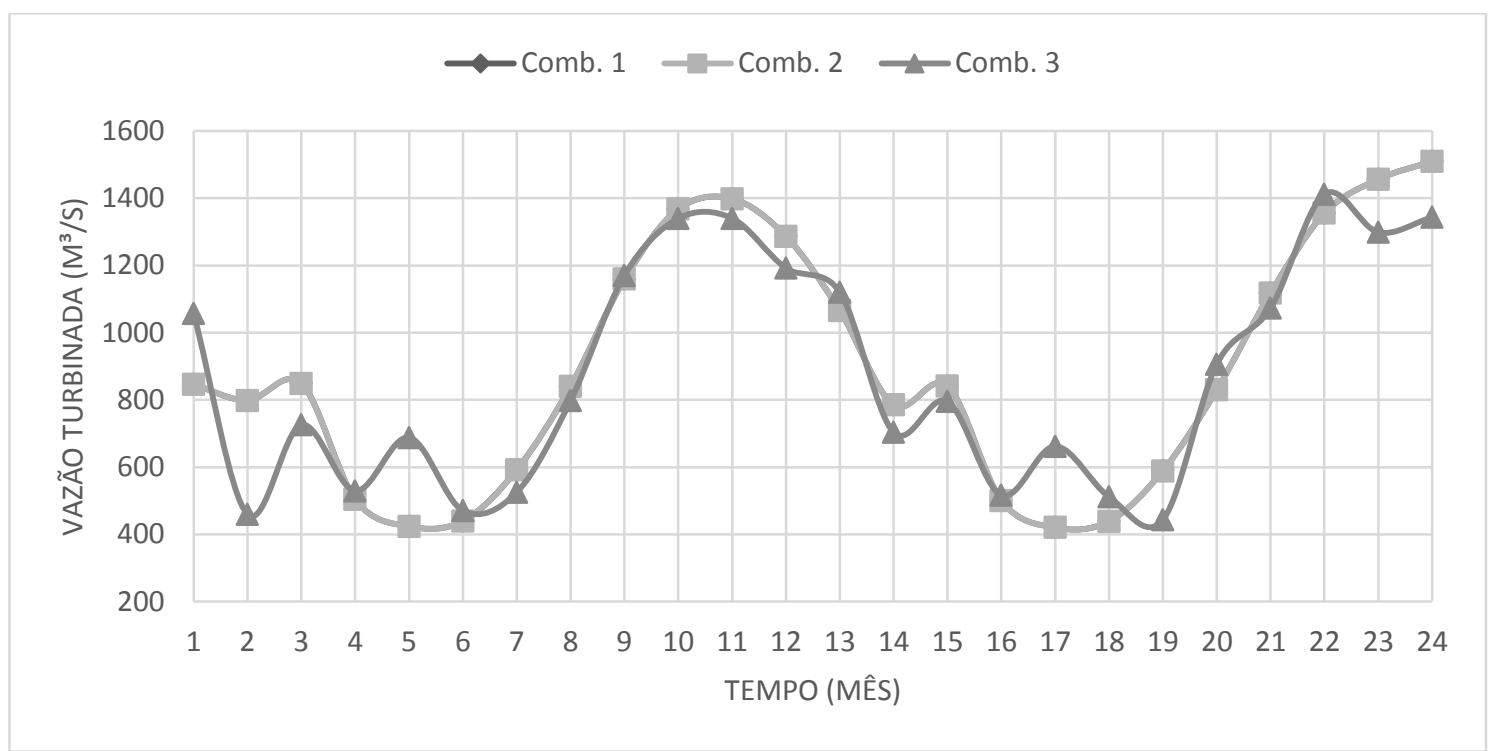

Figura 20: Média mensal da vazão turbinada no Estudo 2 para diferentes combinações dos coeficientes de ponderação. 
Tabela 11: Vazões vertidas $\left(\mathrm{m}^{3} / \mathrm{s}\right)$ na Combinação 1 - Estudo 2.

\begin{tabular}{|c|c|c|c|c|c|c|c|}
\hline \multirow{2}{*}{ Cenário } & \multicolumn{7}{|c|}{ Mês } \\
\hline & 10 & 11 & 12 & 21 & 22 & 23 & 24 \\
\hline i1 & - & 69,194 & - & - & - & - & - \\
\hline i2 & 812,104 & - & - & - & - & - & - \\
\hline i3 & - & 386,64 & 1197,331 & - & - & - & 351,815 \\
\hline i4 & - & - & - & - & - & - & 505,531 \\
\hline i5 & - & 0,194 & 35,701 & - & 103,66 & 413,54 & 221,16 \\
\hline i6 & - & - & - & 1891,803 & 770,494 & 36,114 & 22,185 \\
\hline i7 & 347,184 & - & 387,107 & - & 36,061 & - & 2144,138 \\
\hline i8 & - & - & 176,293 & - & - & - & 139,834 \\
\hline i9 & - & - & - & - & 1028,844 & 222,628 & 477,463 \\
\hline i10 & - & 132,787 & - & 256,803 & - & - & - \\
\hline i11 & 78,519 & - & - & - & - & - & - \\
\hline i12 & - & - & 98,641 & - & - & - & - \\
\hline i13 & - & - & 580,566 & - & - & - & - \\
\hline i14 & - & - & - & - & - & 500,479 & 183,283 \\
\hline i15 & - & 425,093 & 88,001 & - & - & - & - \\
\hline
\end{tabular}

Tabela 12: Vazões vertidas (m³/s) na Combinação 2 - Estudo 2.

\begin{tabular}{|c|c|c|c|c|c|c|c|}
\hline \multirow[t]{2}{*}{ Cenário } & \multicolumn{7}{|c|}{ Mês } \\
\hline & 10 & 11 & 12 & 21 & 22 & 23 & 24 \\
\hline i1 & - & 69,194 & - & - & - & - & - \\
\hline i2 & 812,104 & - & - & - & - & - & - \\
\hline i3 & - & 386,834 & 1197,331 & - & - & - & 351,961 \\
\hline i5 & - & - & - & - & - & - & 505,515 \\
\hline i6 & - & 0,194 & 35,701 & - & 103,66 & 413,54 & 221,16 \\
\hline i7 & - & - & - & 1891,803 & 770,494 & 36,114 & 22,185 \\
\hline i8 & 346,228 & - & 387,107 & - & 36,061 & - & 2144,138 \\
\hline i10 & - & - & 176,389 & - & - & - & 139,567 \\
\hline i12 & - & - & - & - & 1028,52 & 222,628 & 477,463 \\
\hline i14 & - & 132,816 & - & 256,803 & - & - & - \\
\hline $\mathrm{i} 20$ & 78,146 & - & - & - & - & - & - \\
\hline $\mathrm{i} 22$ & - & - & 98,279 & - & - & - & - \\
\hline $\mathrm{i} 23$ & - & - & 580,522 & - & - & - & - \\
\hline i30 & - & - & - & - & - & 500,479 & 183,283 \\
\hline i35 & - & 424,374 & 88,001 & - & - & - & - \\
\hline
\end{tabular}


Tabela 13: Vazões vertidas $\left(\mathrm{m}^{3} / \mathrm{s}\right)$ na Combinação 3 - Estudo 2

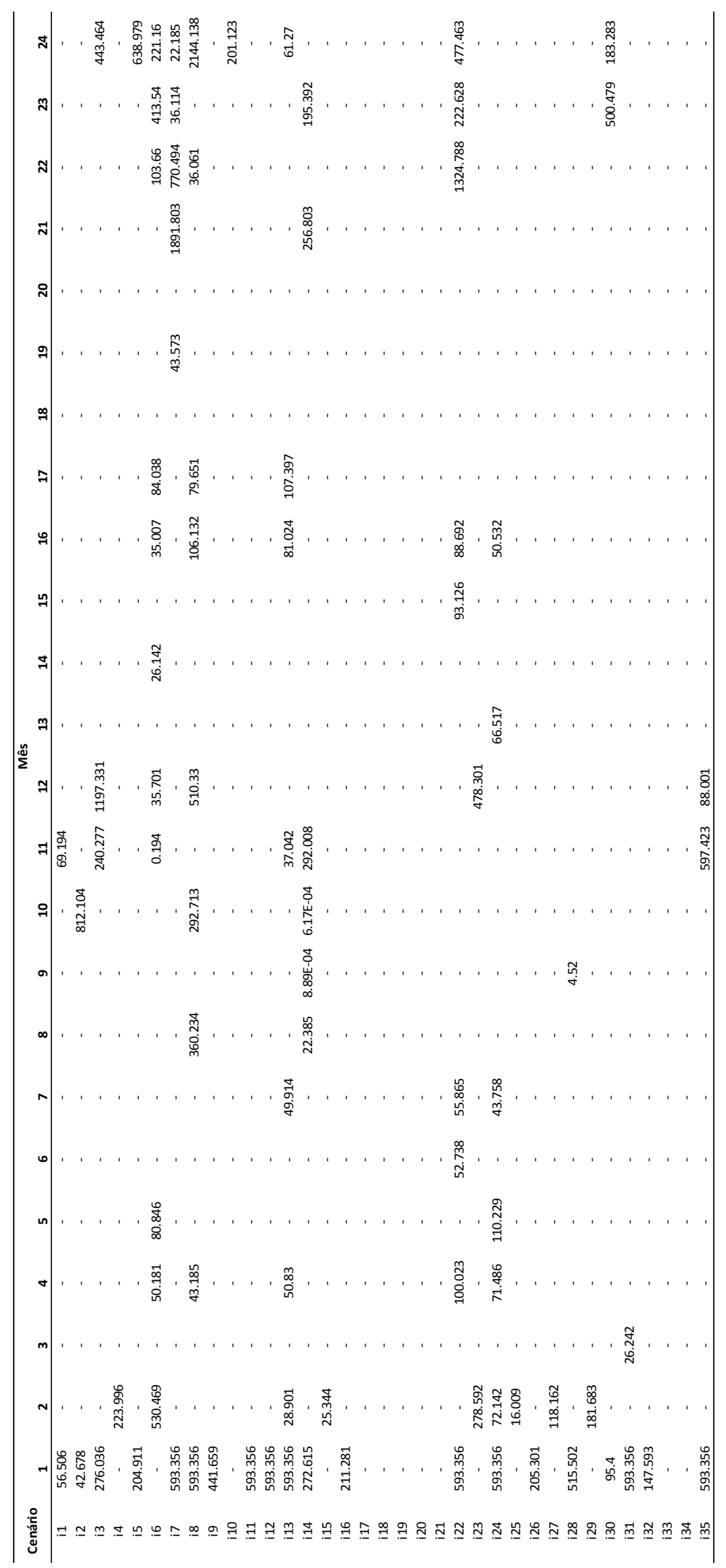


Neste estudos o comportamento do modelo foi o mesmo observado no Estudo 2. As Combinações 1 e 2 apresentaram praticamente os mesmos resultados, conforme evidenciados nas Figuras 15 a 20 e Tabelas 11 e 12.

A maior diferença, entretanto, ocorreu na Combinação 3. A primeira diferença que se pode notar foi uma maior variação dos valores da função $Z_{1}$ se comparados com as outras duas combinações, sendo que $\mathrm{F} 1$ igual a 3,220 $\mathrm{MW}^{2}$.s e F2 igual a 0,205 MW2.s. A geração média foi de 195,721 $\pm 72,053 \mathrm{MW}$, um valor bem menor do que o das Combinações 1 e 2, que apresentaram uma geração média de 219,629 \pm $85,278 \mathrm{MW}$.

Apesar da Combinação 3 ter diminuído consideravelmente o desvio padrão da função objetivo principal, isso ocorreu às custas da energia produzida. Novamente notamos que o modelo acaba deplecionando bastante o reservatório, conforme mostrado na Figura 19 e Tabela 13. É interessante notar que, entretanto, na Combinação 3 a solução para $\mathrm{t}=1$ apresentou uma geração de energia superior à das duas outras combinações, devido à um maior valor da vazão turbinada.

\subsubsection{Estudo 3 - 10 cenários abaixo de $50 \%$ de permanência, com horizonte de 24 meses com otimização em uma única etapa}

Para este foram utilizados 10 cenários de vazões, compostos por vazões inferiores à $50 \%$ da curva de permanência, para observação do comportamento do modelo utilizando apenas a função objetivo $Z_{1}$ em casos de estiagem.

Cada cenário apresenta um horizonte de planejamento de 24 meses, com a vazão inicial correspondente à 50\% da permanência (mediana) para o mês de Abril, com um valor de 1040,50 m³/s. Para os demais meses foram adotados valores da permanência mensais, conforme apresentados na Tabela 14 e na Figura 21. Devido aos resultados apresentados nos estudos anteriores, onde as Combinações 1 e 2 apresentaram resultados praticamente iguais, para este estudo serão analisados apenas as Combinações 1 e 3. 
Tabela 14: Cenários de vazões afluentes $\left(\mathrm{m}^{3} / \mathrm{s}\right)$ - Estudo 3

\begin{tabular}{|c|c|c|c|c|c|c|c|c|c|c|}
\hline \multirow{2}{*}{ Permanência } & \multicolumn{10}{|c|}{ Cenário } \\
\hline & i1 - 50\% & i2 - $45 \%$ & i3 - 40\% & $\mathrm{i} 4-35 \%$ & i5 - 30\% & i6 - $25 \%$ & i7 - $20 \%$ & i8 - $15 \%$ & i9 - 10\% & $i 10-5 \%$ \\
\hline 1 & 1040,50 & 1040,50 & 1040,50 & 1040,50 & 1040,50 & 1040,50 & 1040,50 & 1040,50 & 1040,50 & 1040,50 \\
\hline 2 & 802,50 & 775,95 & 759,40 & 745,90 & 736,70 & 731,00 & 716,60 & 688,20 & 652,40 & 598,40 \\
\hline 3 & 632,50 & 617,50 & 604,00 & 594,95 & 587,10 & 583,50 & 561,40 & 551,95 & 522,40 & 483,30 \\
\hline 4 & 518,00 & 513,65 & 494,60 & 488,90 & 480,10 & 473,75 & 457,40 & 450,55 & 430,70 & 417,50 \\
\hline 5 & 435,50 & 425,95 & 416,20 & 410,00 & 405,20 & 395,50 & 386,60 & 371,55 & 364,90 & 349,85 \\
\hline 6 & 406,00 & 402,65 & 398,40 & 390,85 & 384,10 & 362,50 & 347,40 & 341,00 & 333,70 & 323,10 \\
\hline 7 & 495,00 & 478,30 & 467,60 & 447,00 & 437,00 & 430,75 & 420,60 & 399,55 & 389,70 & 356,40 \\
\hline 8 & 690,00 & 670,20 & 652,20 & 626,55 & 603,40 & 577,50 & 560,80 & 535,85 & 519,40 & 487,05 \\
\hline 9 & 1117,00 & 1085,85 & 1017,80 & 970,70 & 888,60 & 826,50 & 760,00 & 734,10 & 663,60 & 614,90 \\
\hline 10 & 1412,50 & 1379,10 & 1311,80 & 1281,70 & 1240,70 & 1081,25 & 1016,80 & 946,65 & 911,50 & 830,20 \\
\hline 11 & 1488,00 & 1456,60 & 1419,40 & 1357,20 & 1318,30 & 1246,75 & 1187,40 & 1135,85 & 1037,70 & 890,50 \\
\hline 12 & 1479,50 & 1443,40 & 1350,40 & 1306,50 & 1198,70 & 1184,00 & 1060,60 & 1004,10 & 922,20 & 859,95 \\
\hline 13 & 1040,50 & 1015,00 & 994,20 & 935,65 & 913,00 & 908,50 & 876,80 & 838,20 & 826,60 & 689,40 \\
\hline 14 & 802,50 & 775,95 & 759,40 & 745,90 & 736,70 & 731,00 & 716,60 & 688,20 & 652,40 & 598,40 \\
\hline 15 & 632,50 & 617,50 & 604,00 & 594,95 & 587,10 & 583,50 & 561,40 & 551,95 & 522,40 & 483,30 \\
\hline 16 & 518,00 & 513,65 & 494,60 & 488,90 & 480,10 & 473,75 & 457,40 & 450,55 & 430,70 & 417,50 \\
\hline 17 & 435,50 & 425,95 & 416,20 & 410,00 & 405,20 & 395,50 & 386,60 & 371,55 & 364,90 & 349,85 \\
\hline 18 & 406,00 & 402,65 & 398,40 & 390,85 & 384,10 & 362,50 & 347,40 & 341,00 & 333,70 & 323,10 \\
\hline 19 & 495,00 & 478,30 & 467,60 & 447,00 & 437,00 & 430,75 & 420,60 & 399,55 & 389,70 & 356,40 \\
\hline 20 & 690,00 & 670,20 & 652,20 & 626,55 & 603,40 & 577,50 & 560,80 & 535,85 & 519,40 & 487,05 \\
\hline 21 & 1117,00 & 1085,85 & 1017,80 & 970,70 & 888,60 & 826,50 & 760,00 & 734,10 & 663,60 & 614,90 \\
\hline 22 & 1412,50 & 1379,10 & 1311,80 & 1281,70 & 1240,70 & 1081,25 & 1016,80 & 946,65 & 911,50 & 830,20 \\
\hline 23 & 1488,00 & 1456,60 & 1419,40 & 1357,20 & 1318,30 & 1246,75 & 1187,40 & 1135,85 & 1037,70 & 890,50 \\
\hline 24 & 1479,50 & 1443,40 & 1350,40 & 1306,50 & 1198,70 & 1184,00 & 1060,60 & 1004,10 & 922,20 & 859,95 \\
\hline Média & 876,42 & 856,41 & 825,76 & 800,69 & 771,39 & 738,96 & 702,85 & 674,89 & 640,15 & 589,68 \\
\hline
\end{tabular}




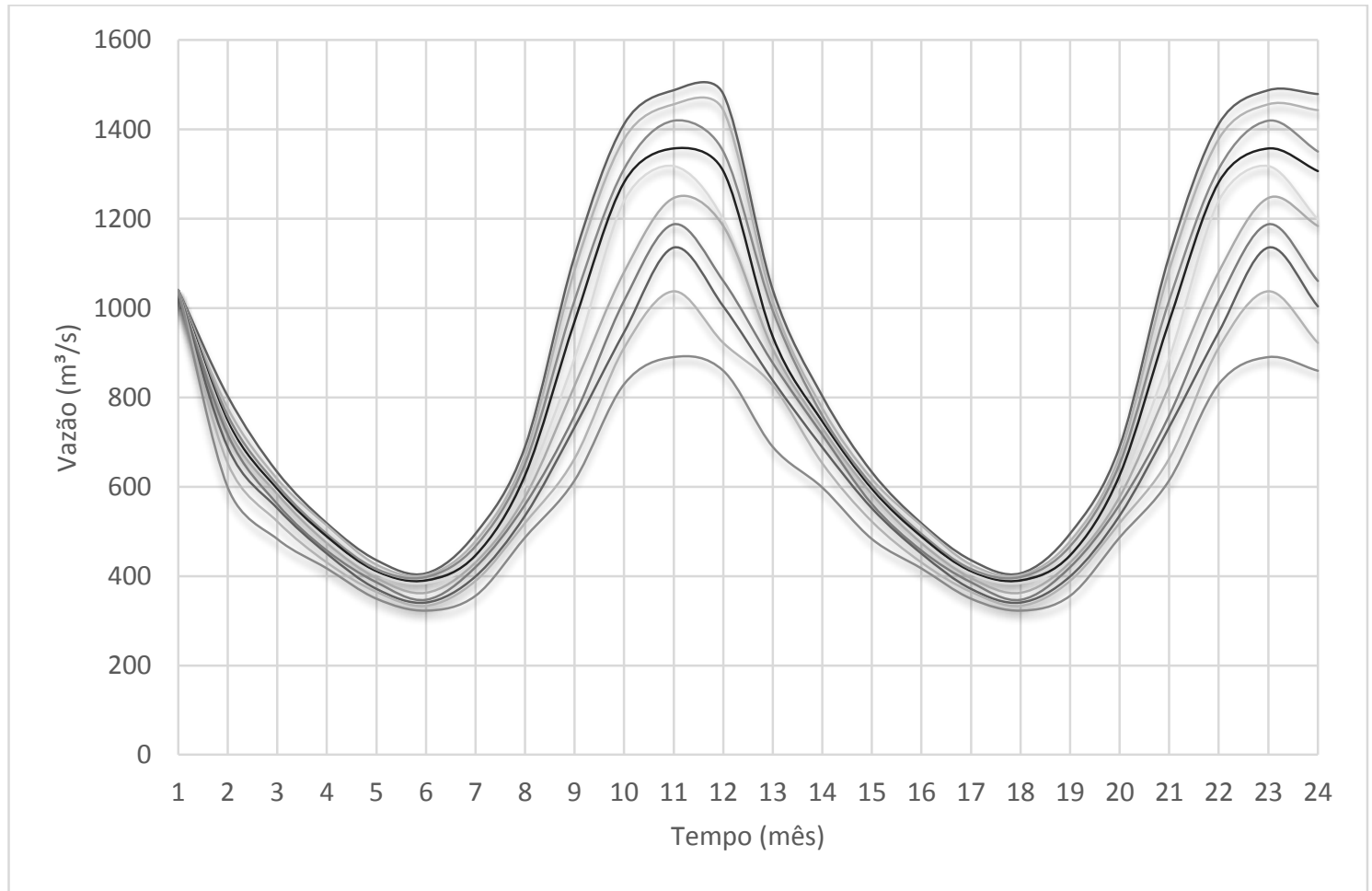

Figura 21: Cenários de vazões afluentes - Estudo 3.

Dessa forma foram obtidos os seguintes resultados:

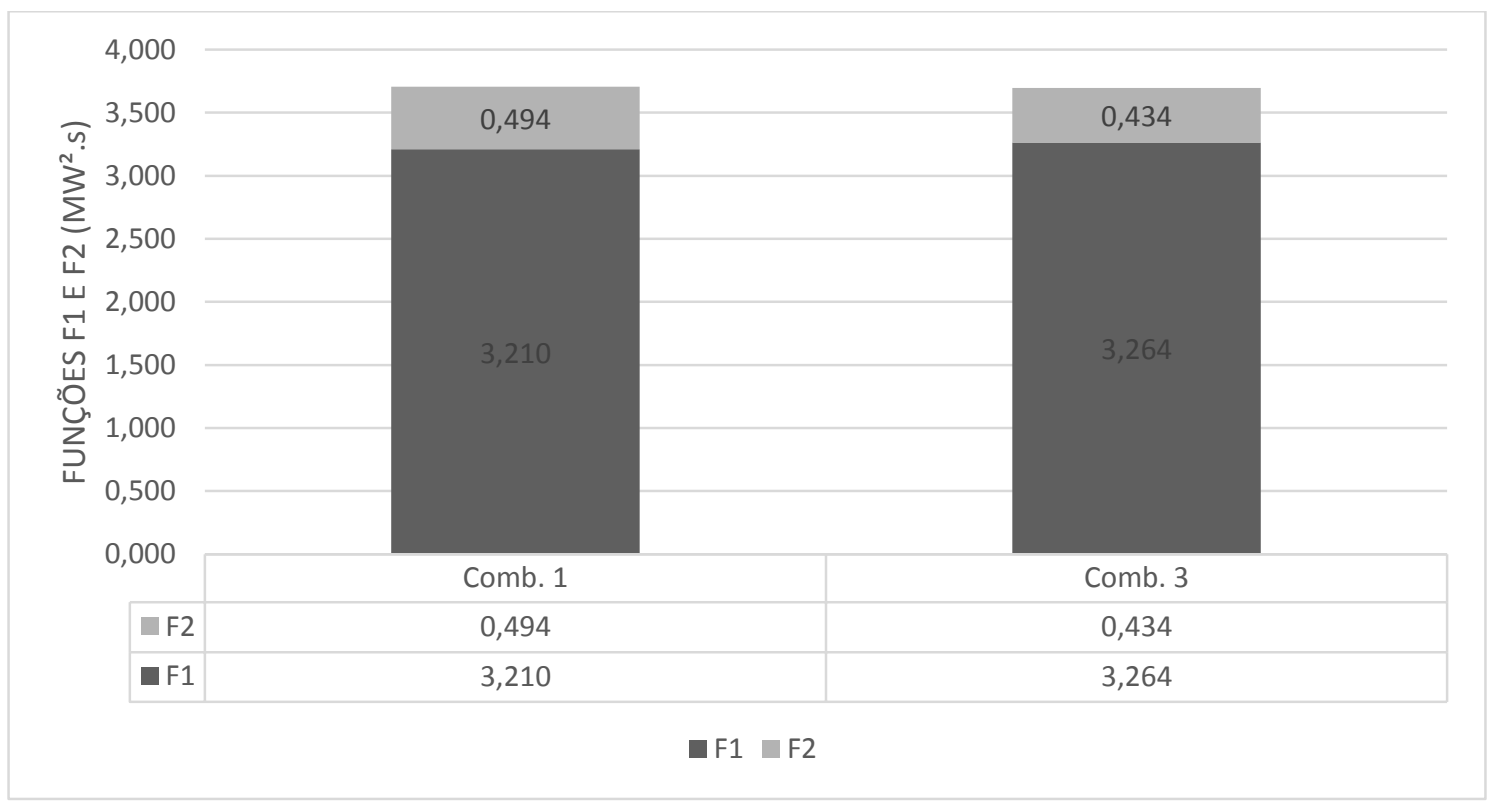

Figura 22: Média de energia produzida e seu desvio padrão no Estudo 3 para diferentes coeficientes de ponderação. 


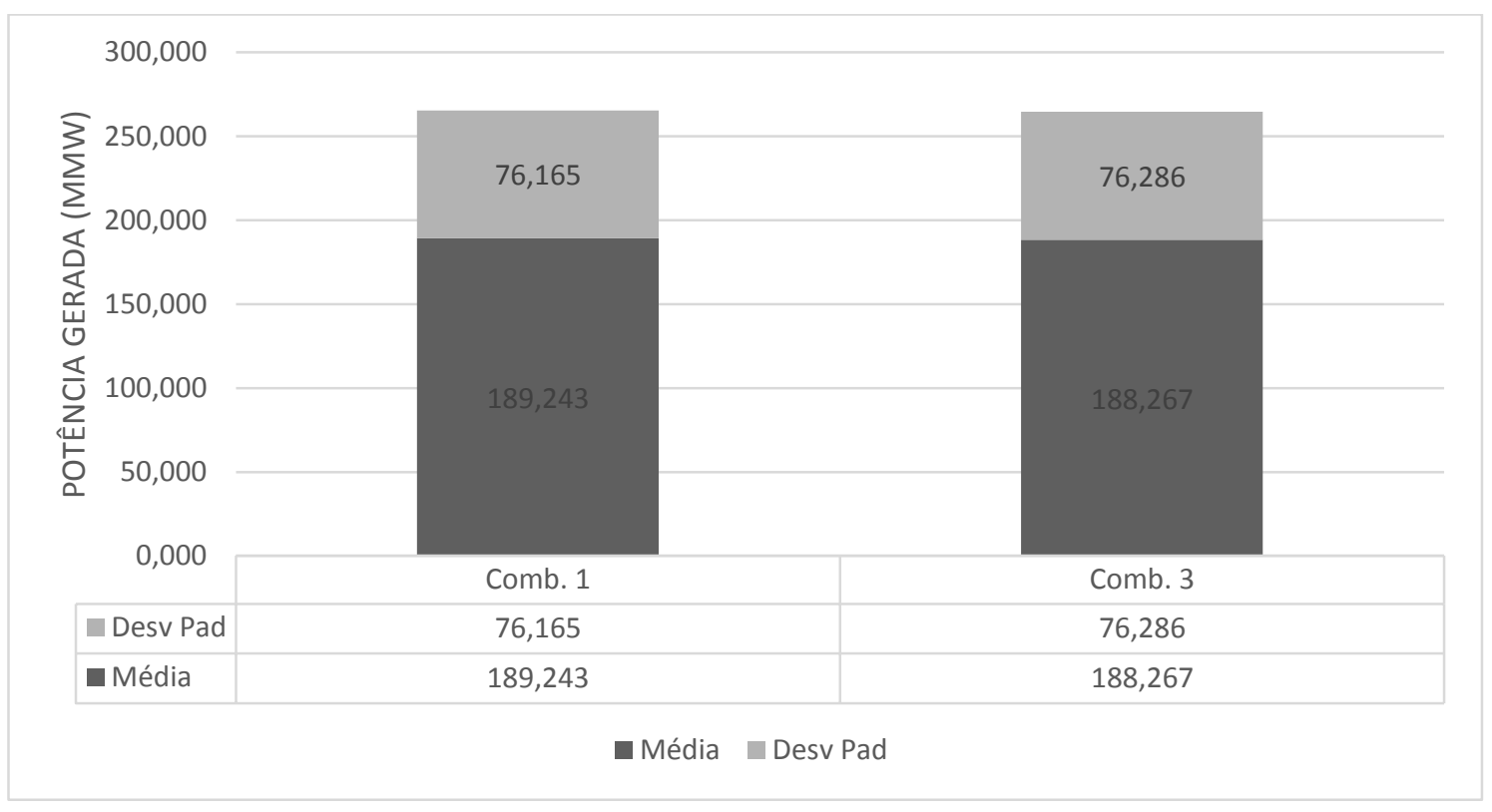

Figura 23: Média de energia produzida e seu desvio padrão no Estudo 2 para diferentes coeficientes de ponderação.

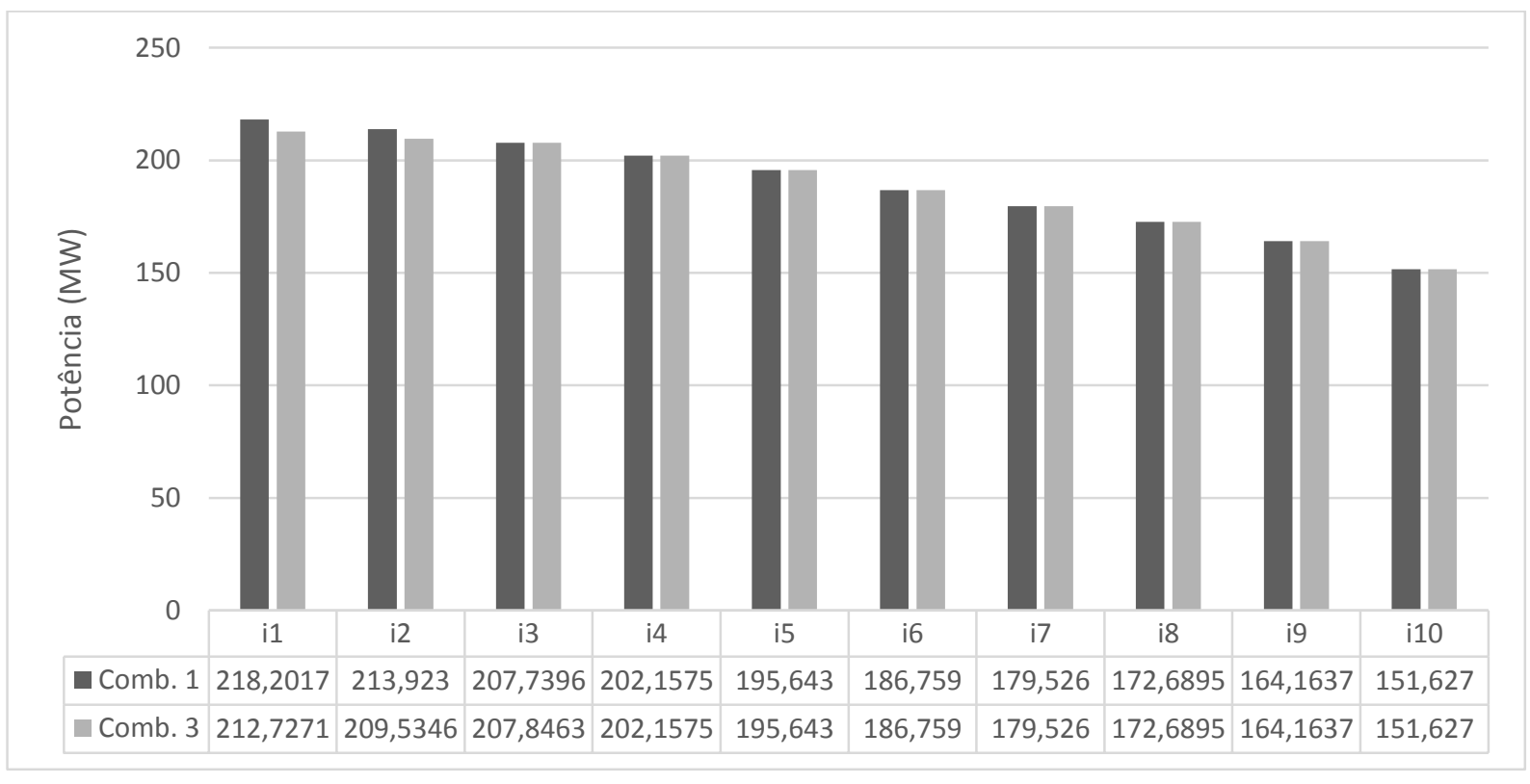

Figura 24: Média da potência por cenário no Estudo 3 para diferentes combinações coeficientes de ponderação. 


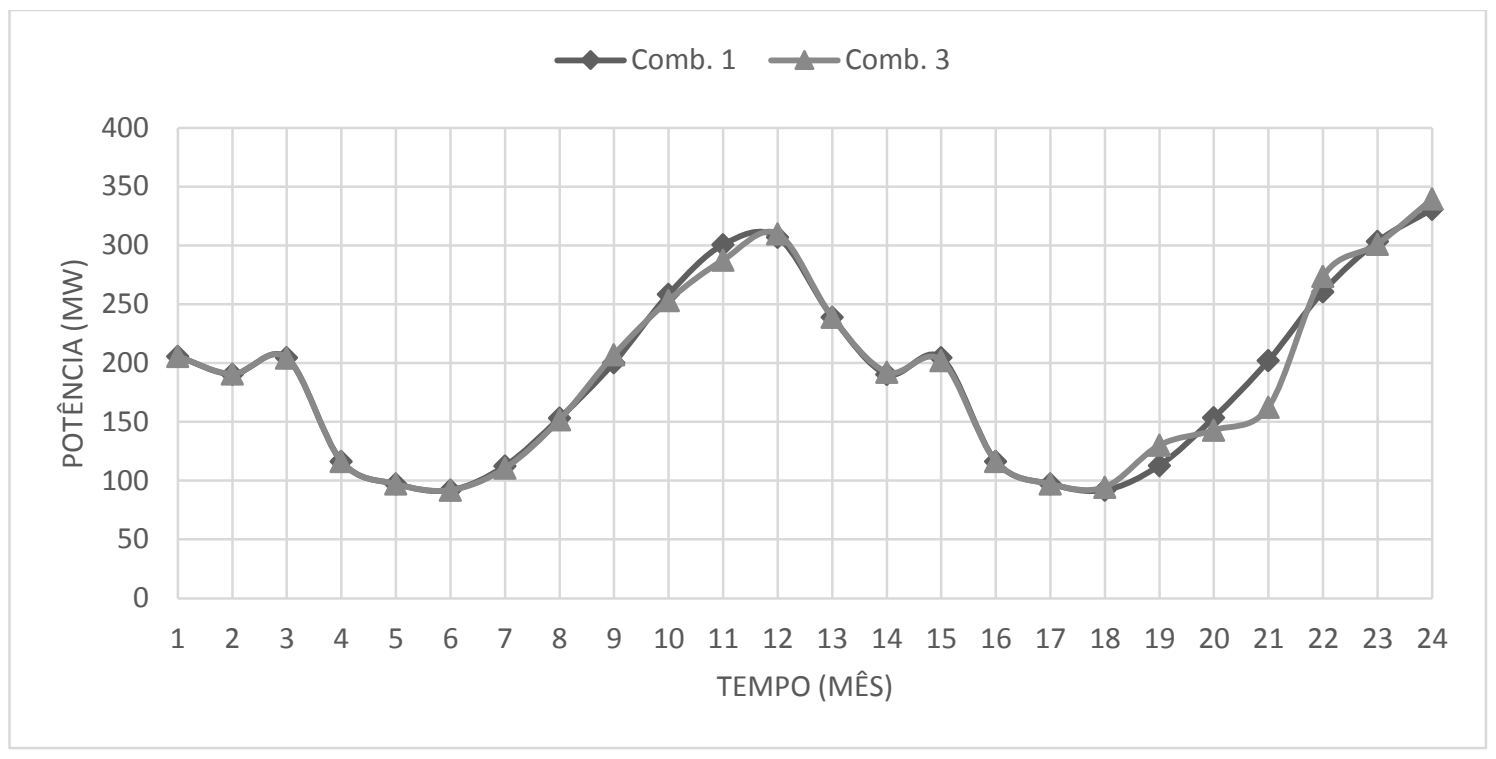

Figura 25: Média mensal de produção de energia do modelo no Estudo 3 para diferentes combinações dos coeficientes de ponderação.

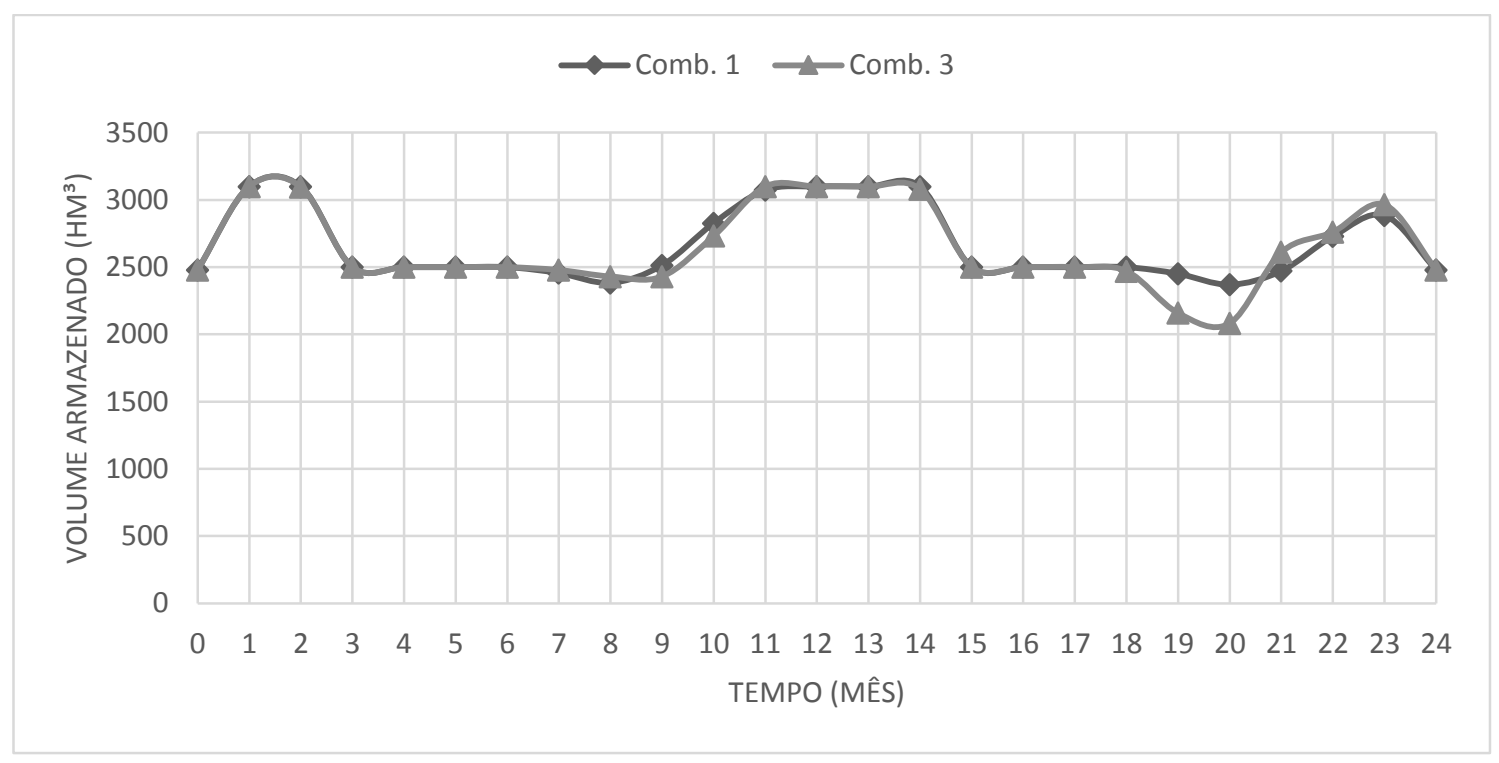

Figura 26: Média mensal do volume armazenado do modelo no Estudo 3 para diferentes combinações dos coeficientes de ponderação. 


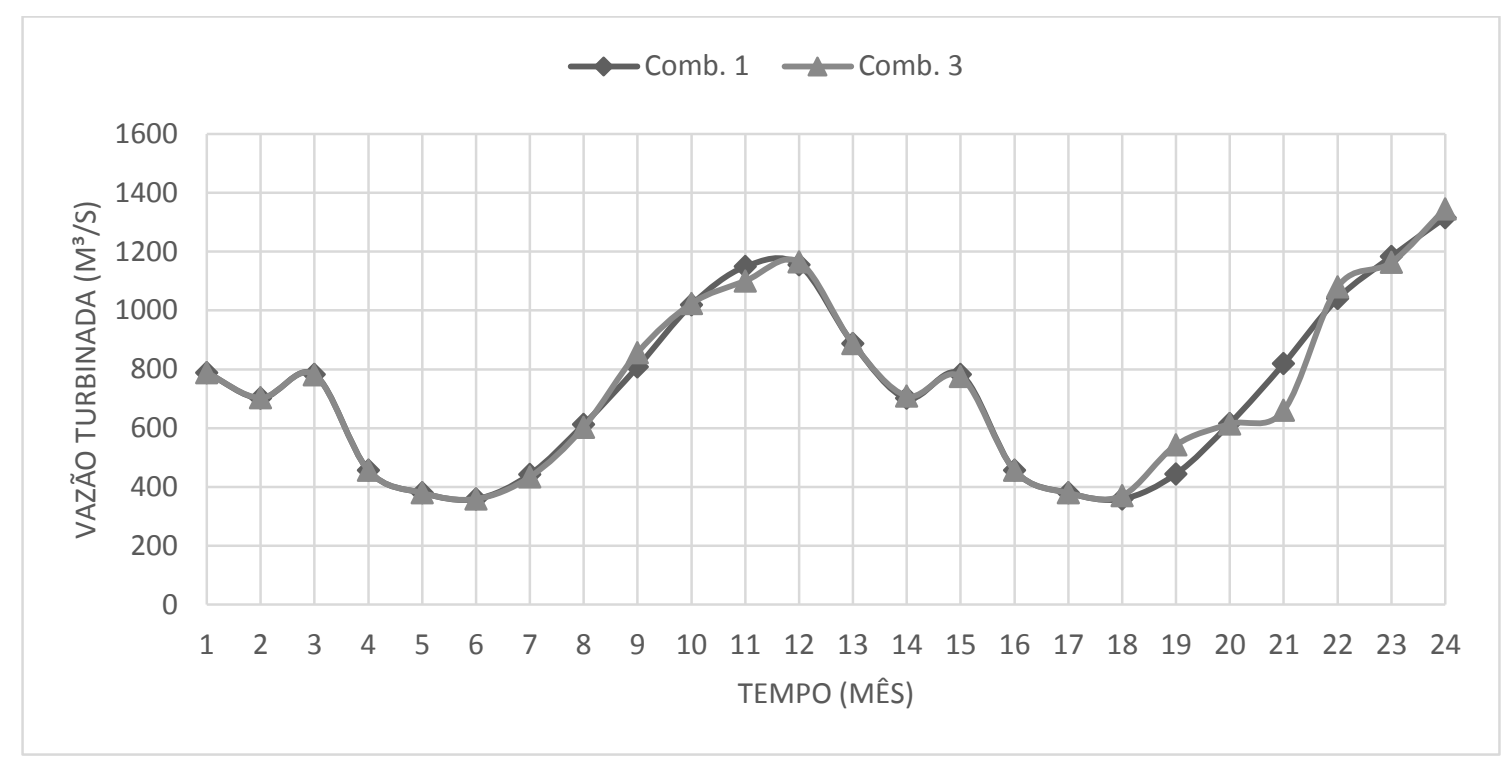

Figura 27: Média mensal da vazão turbinada do modelo no Estudo 3 para diferentes combinações dos coeficientes de ponderação.

Neste estudo, utilizando cenários de estiagem, não ocorreram vertimentos em nenhum dos cenários. Como as vazões deste estudo foram consideravelmente menores, não existe a possibilidade de vertimentos para as combinações dos coeficientes de ponderação estudados. Entretanto, não existe nenhum impedimento da ocorrência de vertimentos no caso se aumente o valor do coeficiente $w_{2}$, o que foi verificado em testes hipotéticos/preliminares realizados.

A Combinação 1 apresentou valores 3,210 e 0,494 MW's para as funções F1 e F2 respectivamente. A Combinação 3 apresentou valores próximos, com 3,264 e 0,434 $\mathrm{MW}^{2}$.s para as funções F1 e F2. Apesar do valor da função F2 ter sido inferior para a Combinação 3, a média de produção de energia apresentou um desvio padrão um pouco superior ao da Combinação 1, com 188,267 \pm 76,286 MW contra $189,243 \pm 76,165 \mathrm{MW}$.

Os resultados da operação nos meses iniciais foram idênticas para as duas combinações estudadas. As diferenças ocorreram apenas nos meses seguintes, com um maior turbinamento em alguns meses para a Combinação 2. Caso fosse aplicada a otimização em duas etapas, os resultados seriam exatamente os mesmos para ambas as combinações estudadas. 


\subsubsection{Estudo 4-20 Cenários com horizonte de 24 meses com otimização em duas etapas}

Neste estudo será avaliada a alternativa de realizar a OR em duas etapas, utilizando as mesmas condições estabelecidas no Estudo 1.

Dessa forma, o modelo apresentou os seguintes resultados:

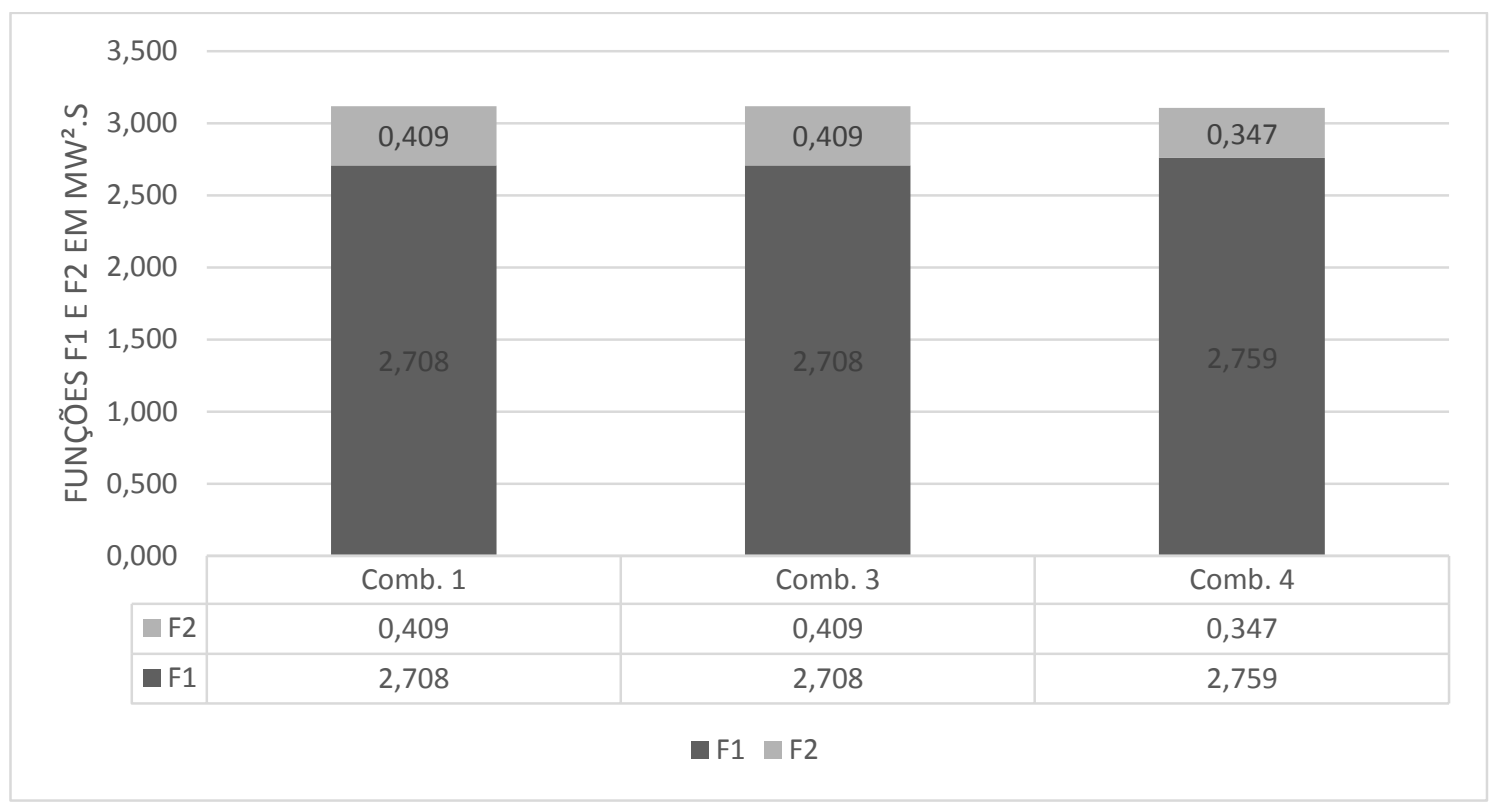

Figura 28: Valores das funções F1 e F2 para o Estudo 4. 


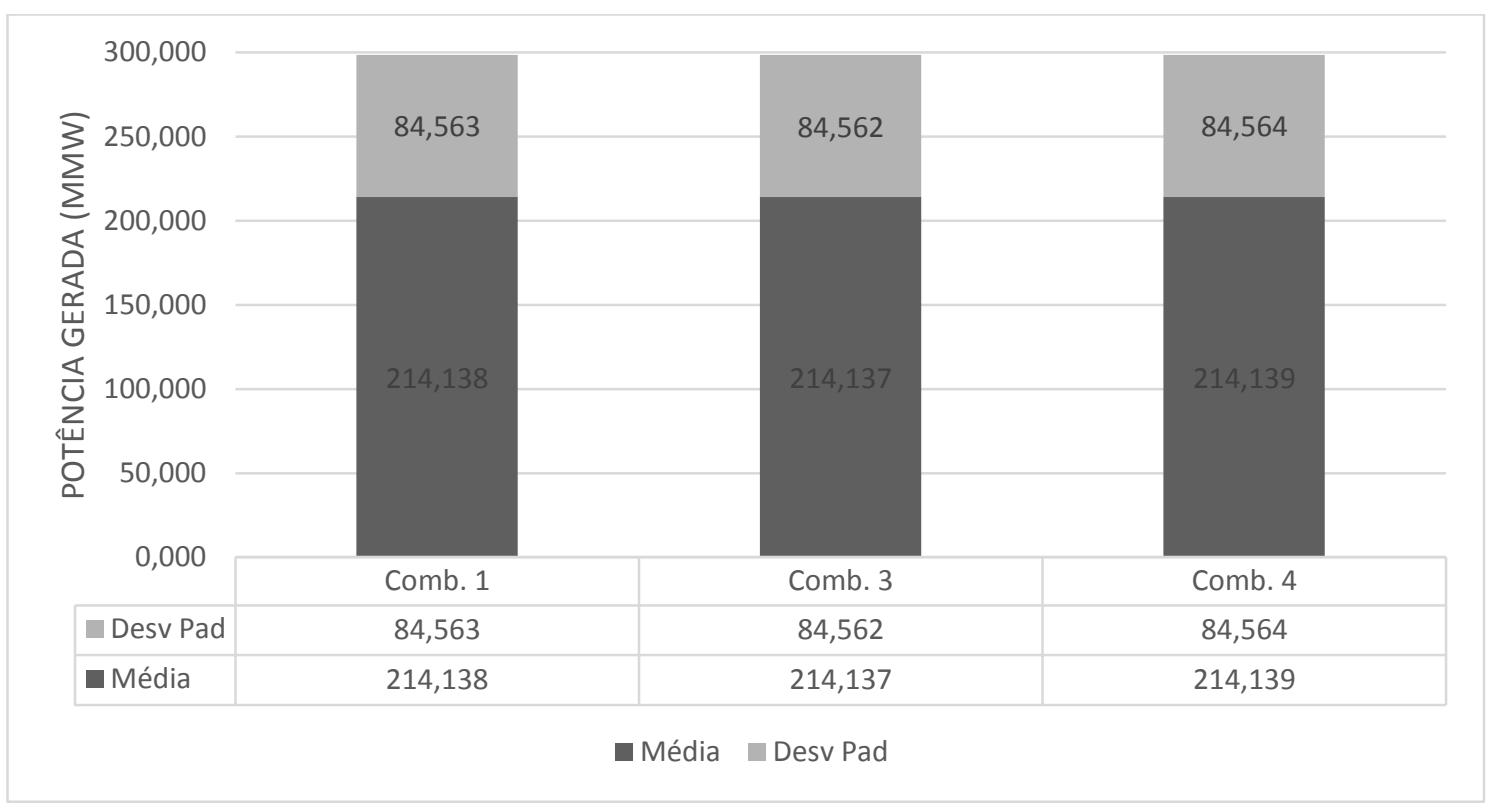

Figura 29: Média de energia produzida e seu desvio padrão no Estudo 4 para diferentes coeficientes de ponderação.

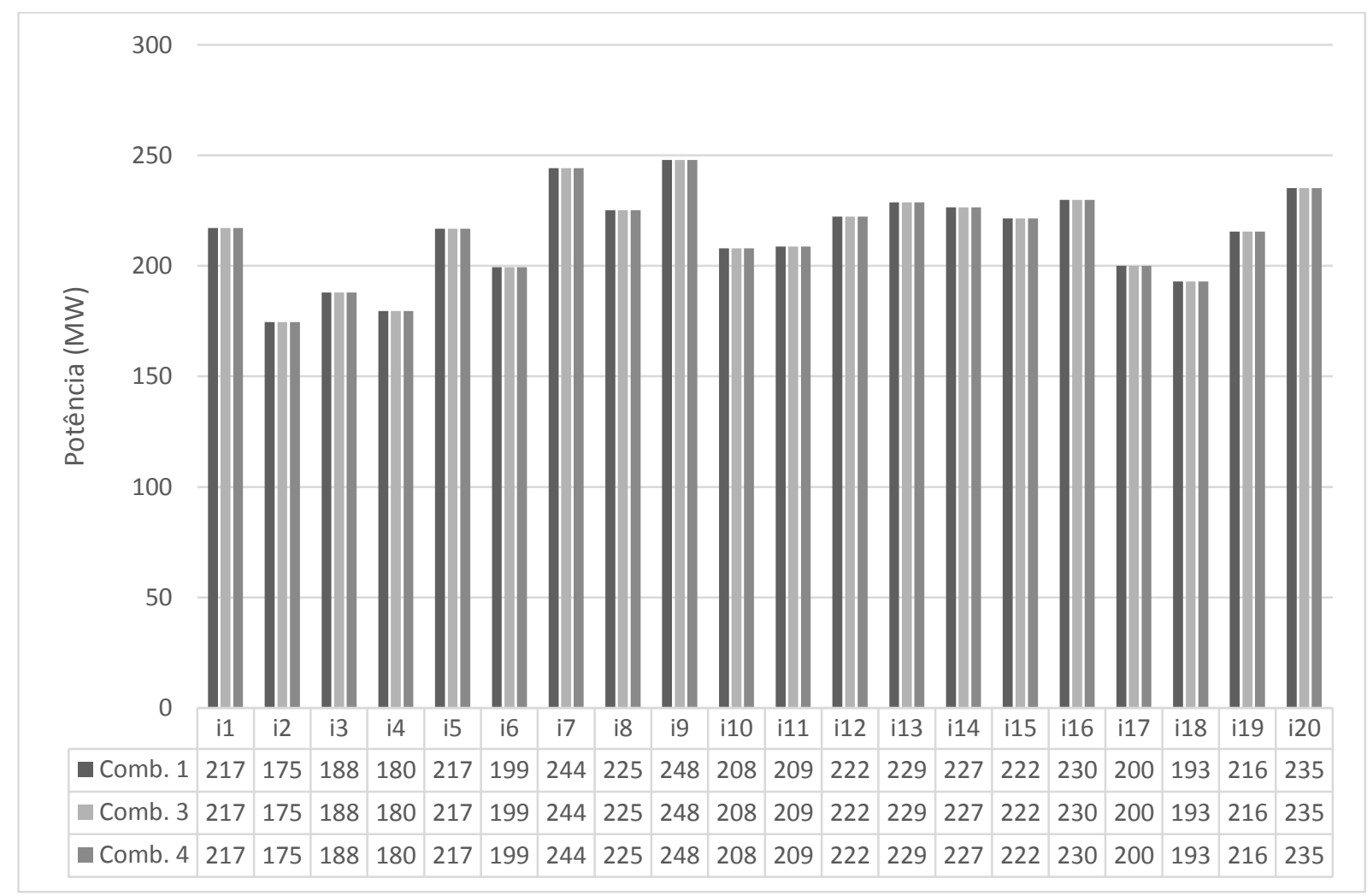

Figura 30: Média da potência por cenário no Estudo 4 para diferentes combinações coeficientes de ponderação. 


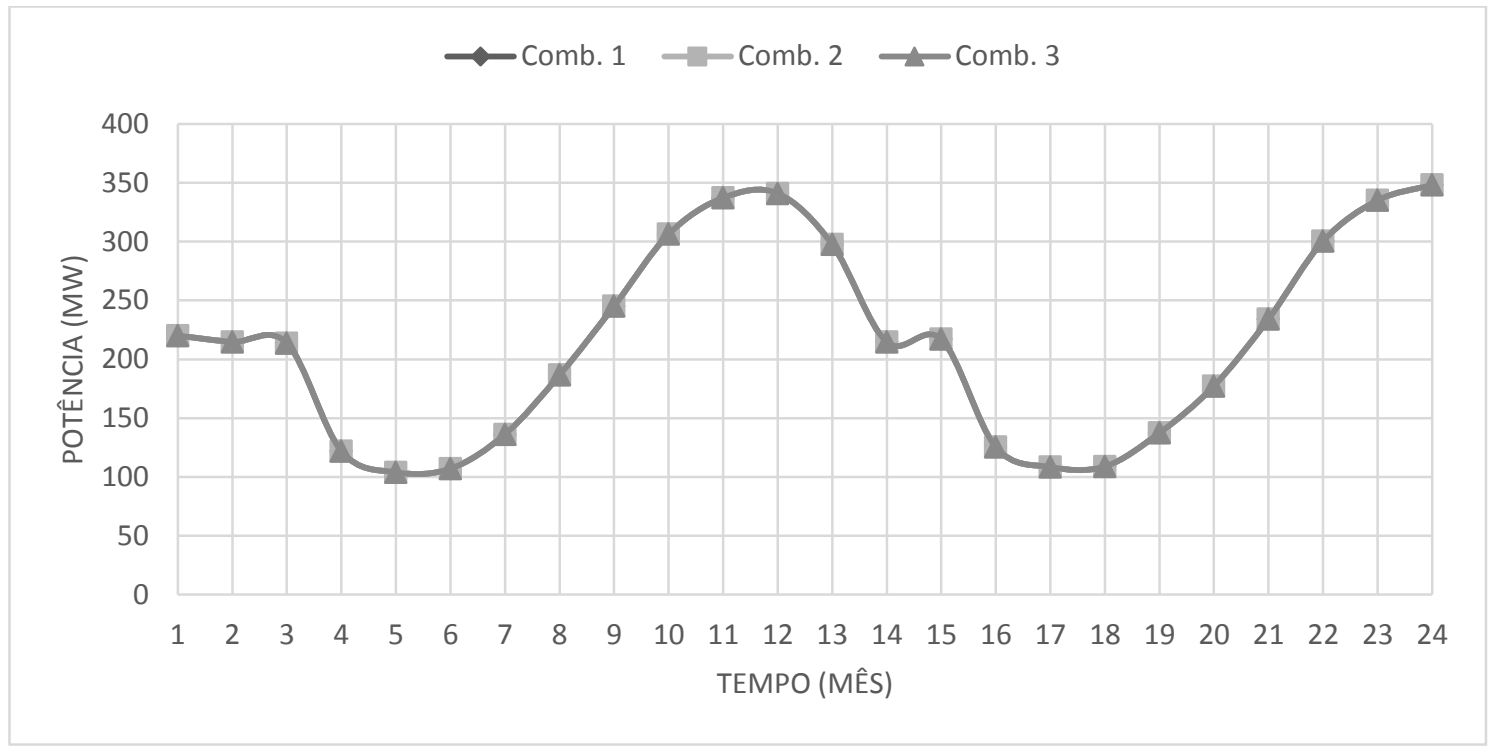

Figura 31: Média mensal de produção de energia do modelo no Estudo 4 para diferentes combinações dos coeficientes de ponderação.

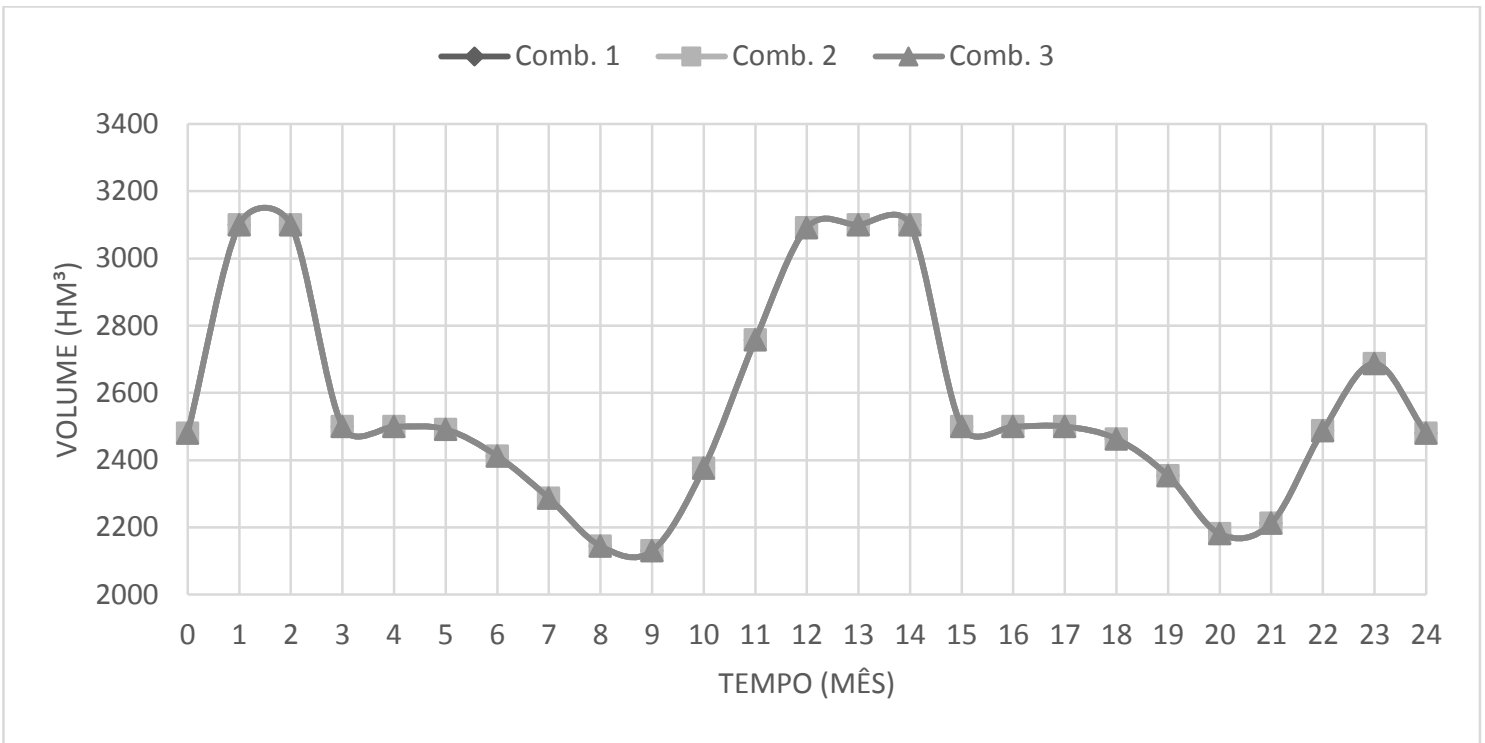

Figura 32: Média mensal do volume armazenado do modelo no Estudo 4 para diferentes combinações dos coeficientes de ponderação. 


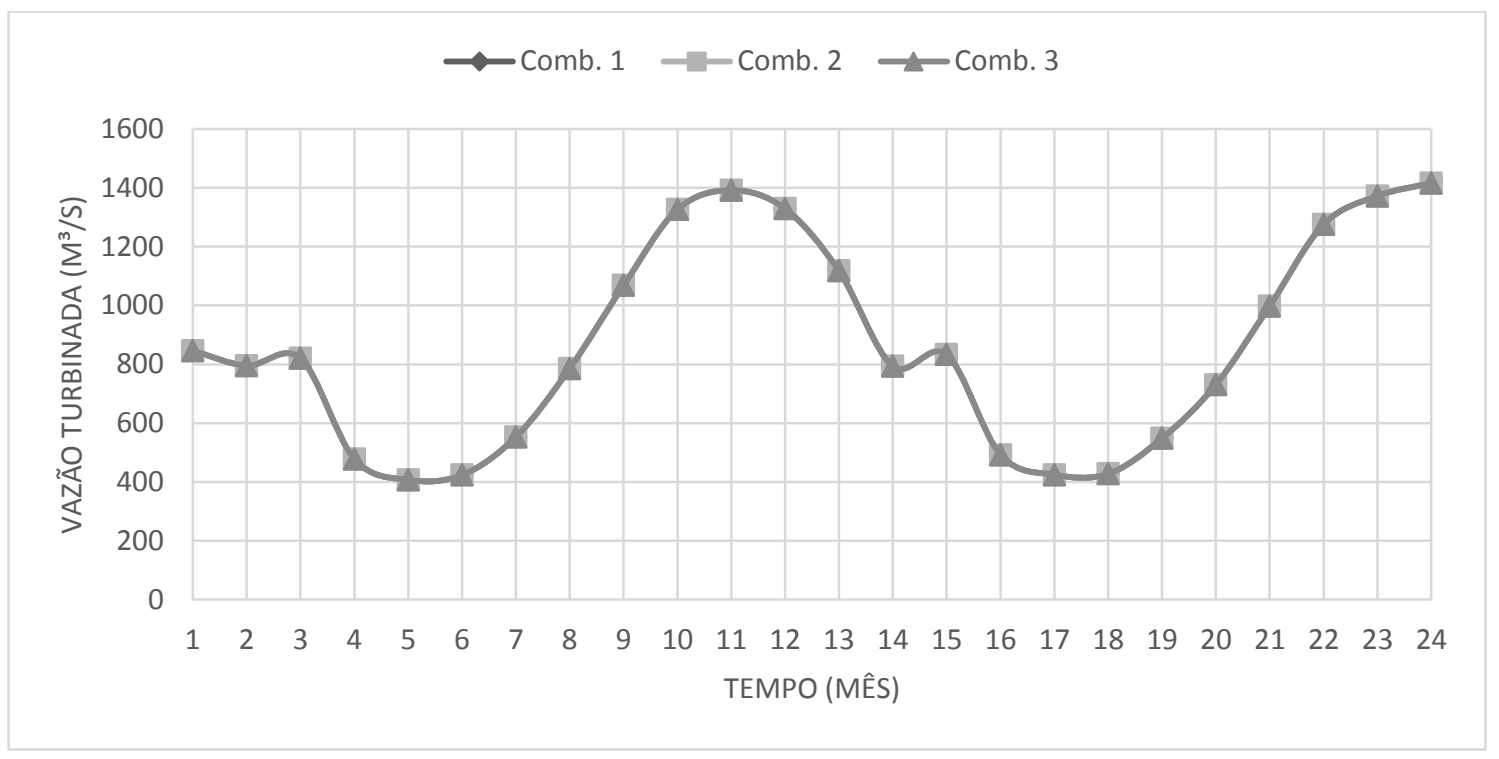

Figura 33: Média mensal do volume armazenado do modelo no Estudo 4 para diferentes combinações dos coeficientes de ponderação.

Tabela 15: Vazões vertidas ( $\left.\mathrm{m}^{3} / \mathrm{s}\right)$ no Estudo 4.

\begin{tabular}{rccccc}
\hline Cenário & \multicolumn{5}{c}{ Mês } \\
i5 & $\mathbf{1 0}$ & $\mathbf{1 1}$ & $\mathbf{1 2}$ & $\mathbf{2 3}$ & $\mathbf{2 4}$ \\
\cline { 2 - 6 } i7 & 78,525 & - & - & - & - \\
i8 & - & - & 98,631 & - & - \\
i15 & - & - & 580,531 & - & - \\
i20 & - & 425,092 & 88,001 & - & - \\
\hline
\end{tabular}

Neste primeiro estudo utilizando o modelo com otimização em duas etapas fica evidente que 0 modelo apresentou 0 mesmo resultado para as três combinações, com diferenças mínimas.

Este estudo mostrou que, mesmo com diferentes variações do peso dado à minimização da função F2 (desvio padrão) na otimização da primeira etapa, não causou impactos nas variáveis do primeiro mês e, consequentemente, tornou o resultado da otimização de segundo estágio igual para os três casos. Isto sugere que o modelo possa estar encontrando para o primeiro mês de operação um valor ótimo local. Dessa forma, independente da utilização da minimização do desvio padrão, é possível inferir que tal resultado é, de fato, robusto. Conforme explanado 
no Item 4.1, de acordo com Mulvey (1995), uma solução pode ser considerada robusta se permanecer próxima a ideal para qualquer realização dos cenários.

A Figura 33 e a Tabela 15 mostram que a utilização de uma segunda função de otimização após a fixação eliminou o problema dos vertimentos indesejados nos meses subsequentes.

\subsubsection{Estudo 5 - 35 Cenários com horizonte de 24 meses com otimização em duas etapas}

O Estudo 5 contempla os resultados obtidos utilizando a OR em duas etapas, utilizando a mesma composição de cenários realizada no Estudo 2.

Dessa forma temos:

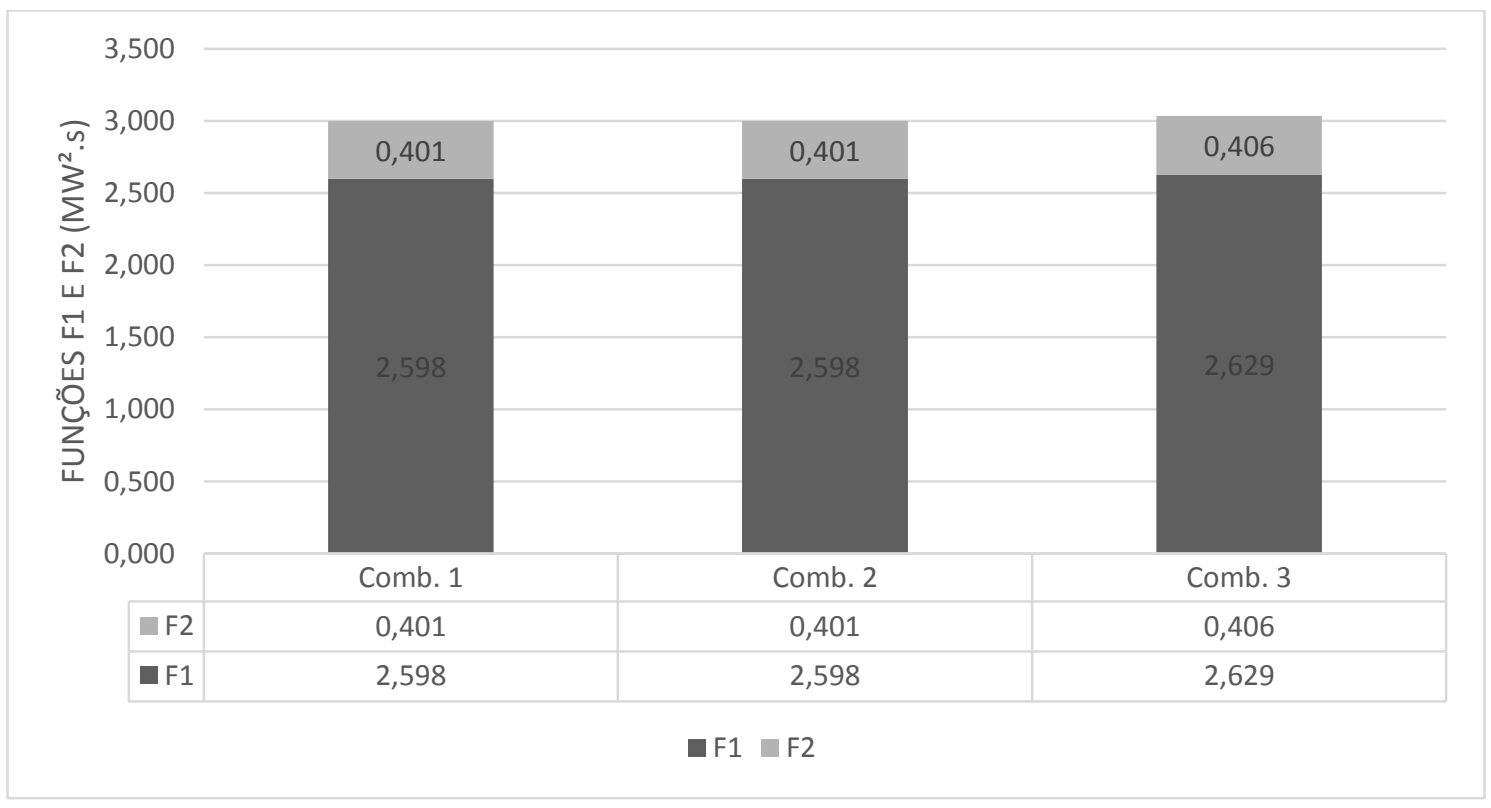

Figura 34: Valores das funções F1 e F2 para o Estudo 5. 


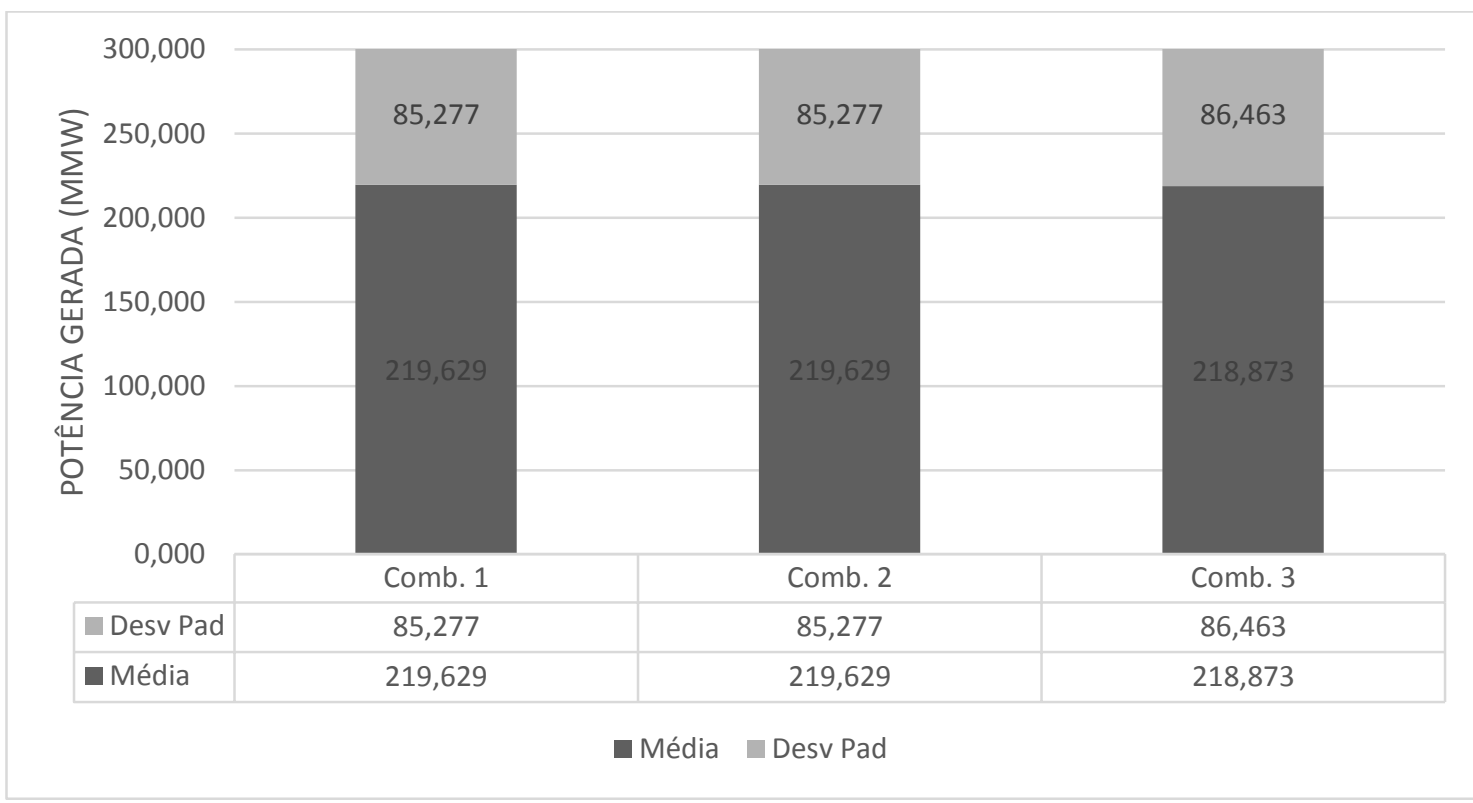

Figura 35: Média de energia produzida e seu desvio padrão no Estudo 4 para diferentes coeficientes de ponderação.

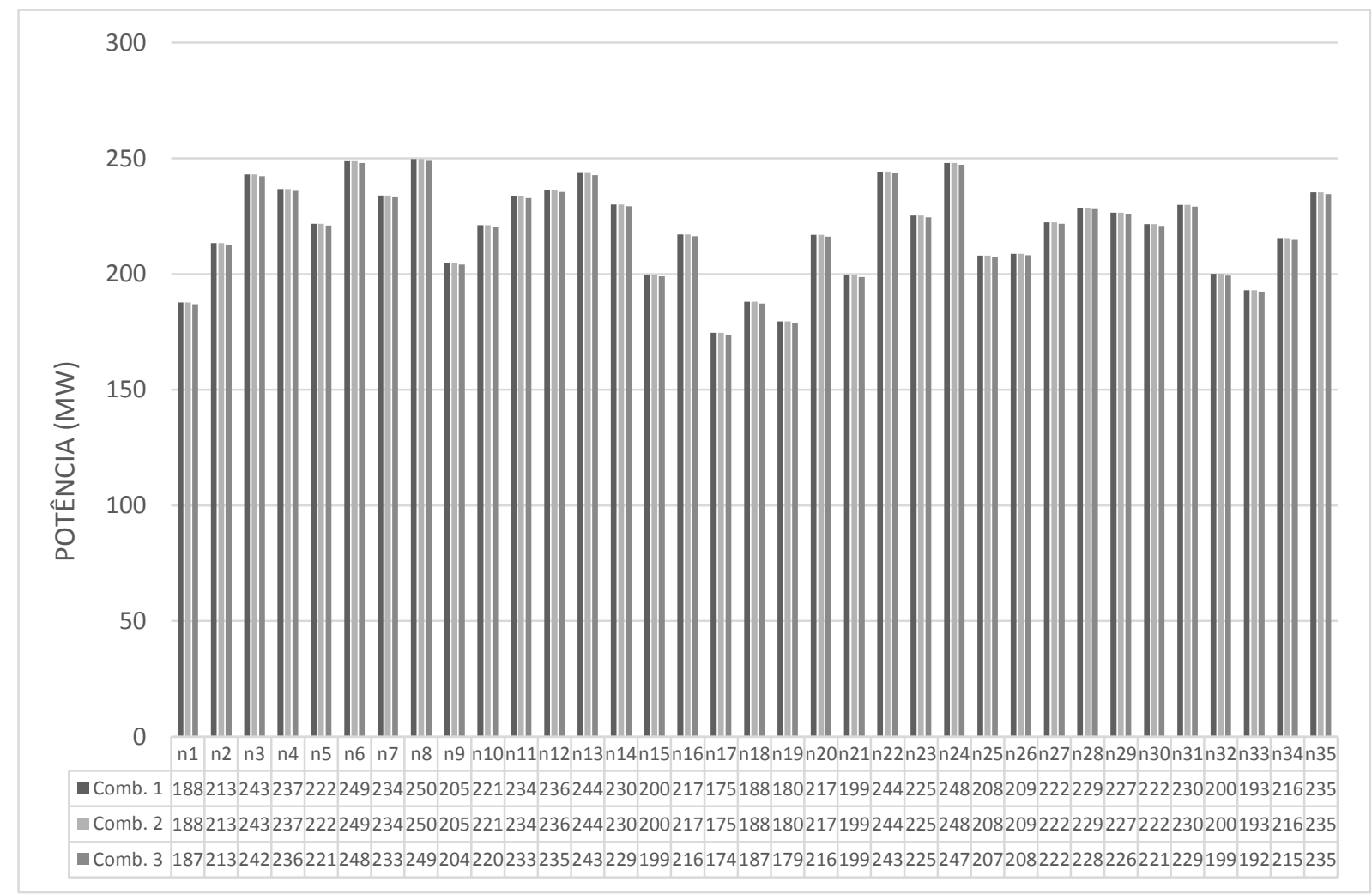

Figura 36: Média da potência por cenário no Estudo 5 para diferentes combinações coeficientes de ponderação. 


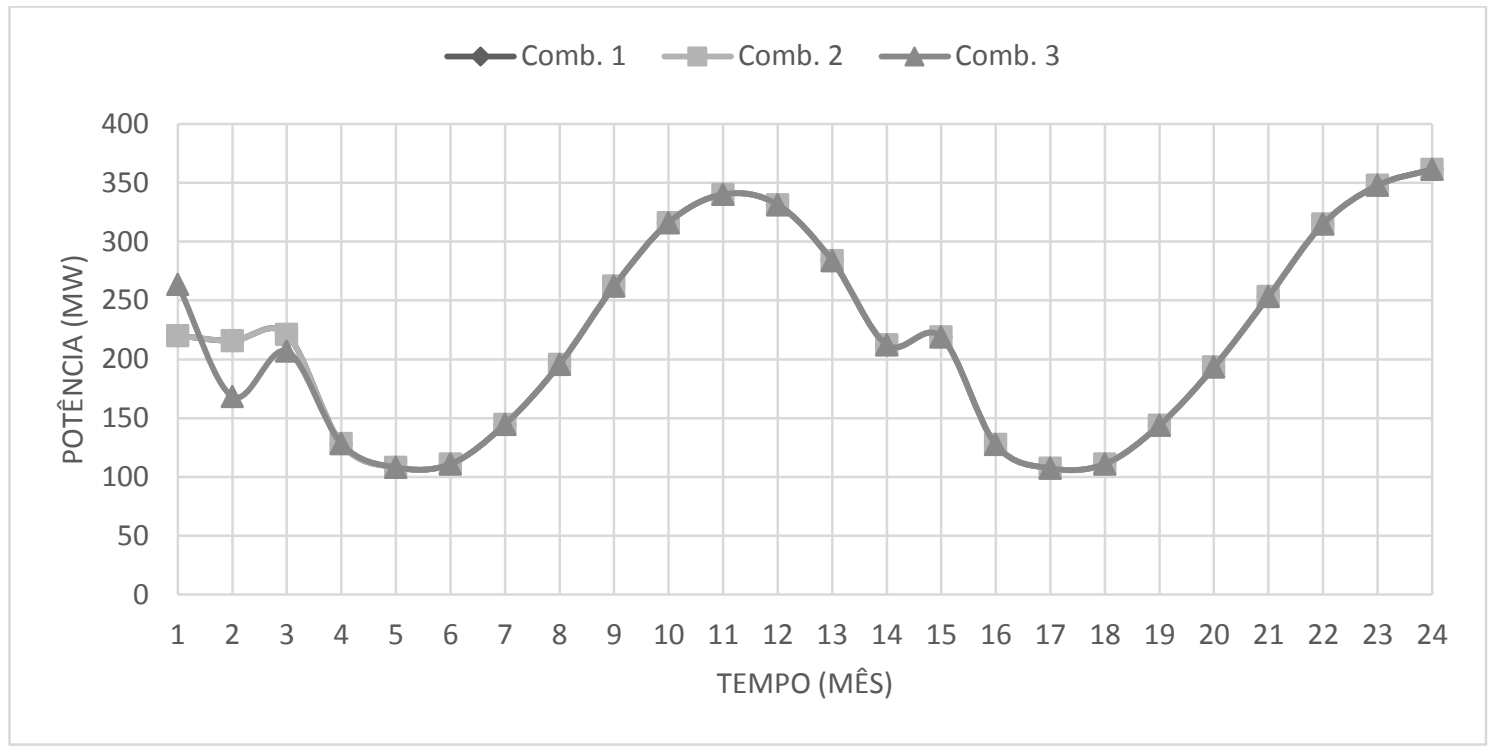

Figura 37: Média mensal de produção de energia do modelo no Estudo 5 para diferentes combinações dos coeficientes de ponderação.

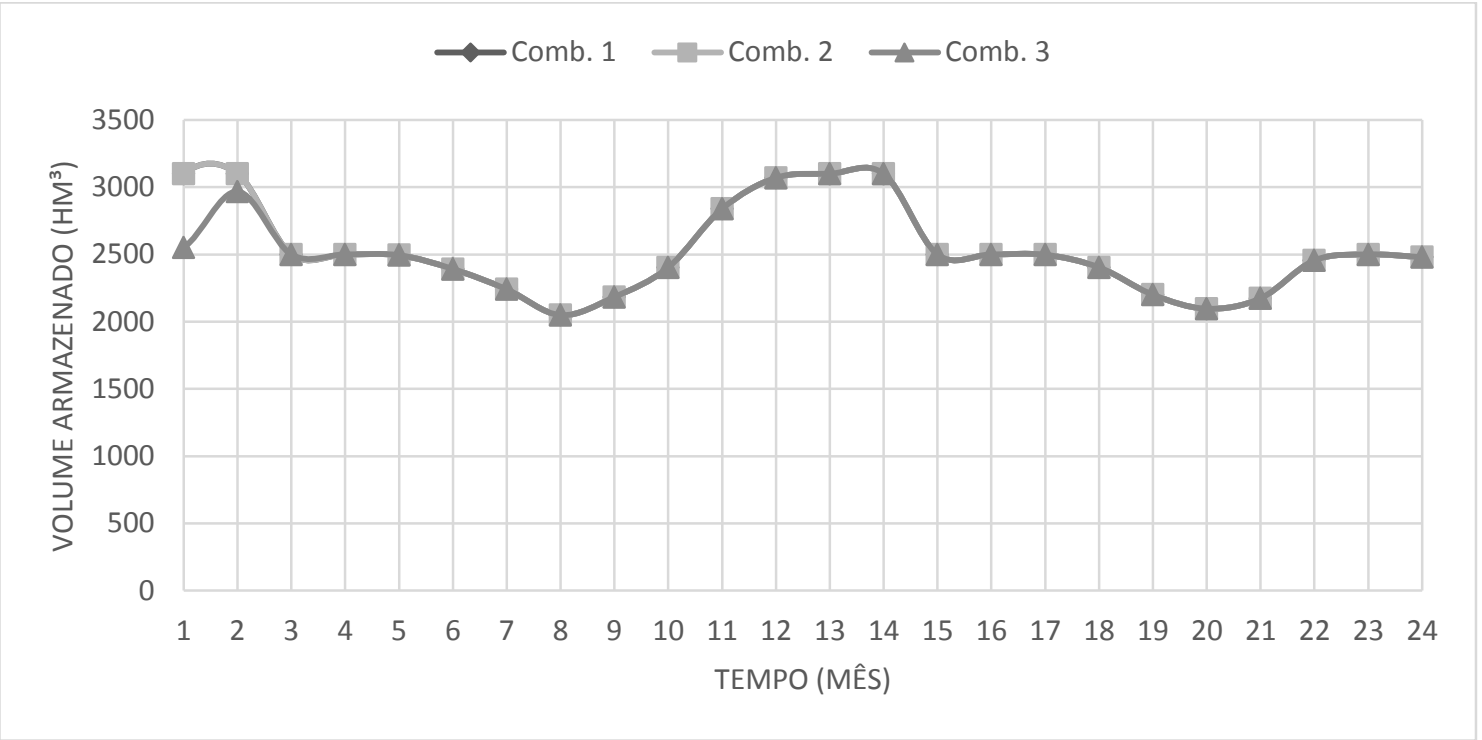

Figura 38: Média mensal do volume armazenado do modelo no Estudo 5 para diferentes combinações dos coeficientes de ponderação. 


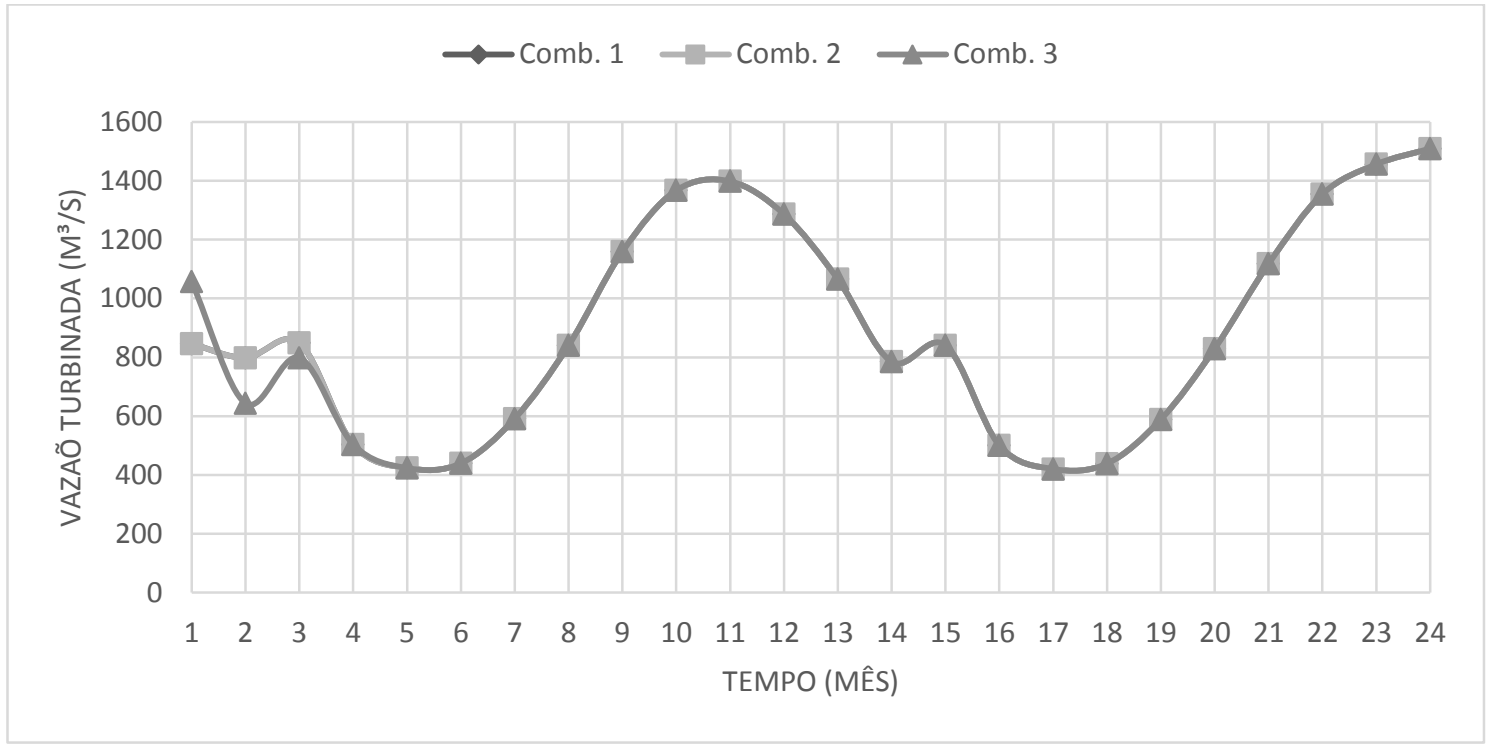

Figura 39: Média mensal da vazão turbinada do modelo no Estudo 5 para diferentes combinações dos coeficientes de ponderação.

Tabela 16: Vazões vertidas no Estudo 5, para as Combinações 1 e 2.

\begin{tabular}{|c|c|c|c|c|c|c|c|}
\hline \multirow{2}{*}{ Cenário } & \multicolumn{7}{|c|}{ Mês } \\
\hline & 10 & 11 & 12 & 21 & 22 & 23 & 24 \\
\hline i1 & - & 69.,194 & - & - & - & - & - \\
\hline i2 & 812,104 & - & - & - & - & - & - \\
\hline i3 & - & 386,627 & 1197,331 & - & - & - & 351,824 \\
\hline ¡5 & - & - & - & - & - & - & 505,532 \\
\hline i6 & - & 0,194 & 35,701 & - & 103,66 & 413,54 & 221,16 \\
\hline i7 & - & - & - & 1891,803 & 770,494 & 36,114 & 22,185 \\
\hline i8 & 346,485 & - & 387,107 & - & 36,061 & - & 2144,138 \\
\hline i10 & - & - & 176,123 & - & - & - & 139,984 \\
\hline i12 & - & - & - & - & 1028,943 & 222,628 & 477,463 \\
\hline i14 & - & 132,822 & - & 256,803 & - & - & - \\
\hline i20 & 78,527 & - & - & - & - & - & - \\
\hline i22 & - & - & 98,86 & - & - & - & - \\
\hline i23 & - & - & 580,505 & - & - & - & - \\
\hline i30 & - & - & - & - & - & 500,479 & 183,283 \\
\hline i35 & - & 425,117 & 88,001 & - & - & - & - \\
\hline
\end{tabular}


Tabela 17: Vazões turbinadas ( $\left.\mathrm{m}^{3} / \mathrm{s}\right)$ no Estudo 5 para a Combinação 3.

\begin{tabular}{|c|c|c|c|c|c|c|c|}
\hline \multirow{2}{*}{ Cenário } & \multicolumn{7}{|c|}{ Mês } \\
\hline & 10 & 11 & 12 & 21 & 22 & 23 & 24 \\
\hline i1 & - & 69,194 & - & - & - & - & - \\
\hline i2 & 812,104 & - & - & - & - & - & - \\
\hline i3 & - & 386,692 & 1197,331 & - & - & - & 351,894 \\
\hline i5 & - & - & - & - & - & - & 505,424 \\
\hline i6 & - & 0,194 & 35,701 & - & 103,66 & 413,54 & 221,16 \\
\hline ¡7 & - & - & - & 1891,803 & 770,494 & 36,114 & 22,185 \\
\hline i8 & 346,939 & - & 387,107 & - & 36,061 & - & 2144,138 \\
\hline ¡10 & - & - & 176,262 & - & - & - & 139,79 \\
\hline i12 & - & - & - & - & 1029,096 & 222,628 & 477,463 \\
\hline i14 & - & 132,936 & - & 256,803 & - & - & - \\
\hline i20 & 78,621 & - & - & - & - & - & - \\
\hline i22 & - & - & 98,601 & - & - & - & - \\
\hline i23 & - & - & 580,567 & - & - & - & - \\
\hline i30 & - & - & - & - & - & 500,479 & 183,283 \\
\hline i35 & - & 424,876 & 88,001 & - & - & - & - \\
\hline
\end{tabular}

Da mesma forma que no Estudo 3, no Estudo 5 para a Combinação 3 também ocorreu um maior turbinamento durante o primeiro mês de operação. Dessa forma, a segunda etapa realizou a correção da operação para evitar o vertimento desnecessário nos meses subsequentes como o ocorrido no Estudo 3, Combinação 3. Entretanto, a maior geração no primeiro mês não resultou, necessariamente, em uma diminuição do desvio padrão já que o mesmo ocorria por conta de uma diminuição na potência gerada para aproximar os resultados.

Diferentemente do Estudo 4 e das Combinações 1 e 2 deste estudo, a solução encontrada na Combinação 3 mostrou uma pequena piora nos objetivos, certamente efeito da convergência da PNL para um ótimo local um pouco inferior. Entretanto ela pode ser, de certa forma, considerada também uma solução robusta, já que seu resultado é factível e relativamente próximo do ótimo para todos os cenários. 


\section{CONCLUSÃO}

O objetivo principal desta pesquisa foi a aplicação e análise de desempenho da otimização robusta $(\mathrm{OR})$ aplicada à operação de um reservatório para geração de energia.

Uma revisão do estado da arte, envolvendo a utilização de técnicas de otimização para o planejamento de sistemas hidrotérmicos foi desenvolvida para dar embasamento ao trabalho dentro deste contexto. Foi também realizada uma análise teórica da OR e suas aplicações, chegando-se à conclusão que o tema ainda foi pouco explorado quando aplicado na área de recursos hídricos, sendo que não foram encontrados trabalhos publicados referentes à $O R$ aplicada à operação de usinas hidrelétricas.

A formulação matemática teve como base a formulação geral de um problema de OR de acordo com Mulvey et al. (1995). Para o equacionamento da produção de energia em uma usina hidrelétrica foi utilizado como base o modelo HIDRO, desenvolvido por Zambon (2008). Dessa forma foi desenvolvido o modelo HIDROOR que consiste em um problema de PNL, em dois estágios com dois objetivos distintos ponderados: minimizar a complementação quadrática entre a capacidade da usina e a energia produzida mensalmente e o desvio padrão deste resultado para os diferentes cenários avaliados, e em duas etapas.

Para a obtenção de resultados numéricos e análise do modelo foram escolhidos os dados da UHE - Sinop, no MT, cujos estudos de modelagem energética foram disponibilizados pela EPE (2010). A UHE Sinop conta com uma particularidade de operação, que mantém o nível máximo do seu reservatório variável, podendo chegar à cota máxima (302 m) nos meses de cheia e, durante a estiagem tendo um nível inferior (300 m). Tal restrição operativa se deve à fatores ambientais para a conservação de lagoas sazonais utilizadas pela ictiofauna local como berçário.

Foram realizados primeiramente 3 estudos de análise de sensibilidade do modelo, sendo que para cada estudo foram testadas 3 diferentes combinações dos coeficientes de ponderação da função objetivo. Os resultados dos Estudos 1, 2 e 3 
demonstraram que aumentando o peso dado à minimização do desvio padrão do objetivo principal o modelo, se por um lado pode evitar situações de armazenamento muito reduzido e risco de déficit, em cenários de maiores afluências pode ocasionar vertimentos indesejados para diminuir a energia produzida e assim minimizar o desvio padrão. Dessa forma foi proposta a realização da otimização em duas etapas: a primeira minimizando o desvio padrão e obtendo os resultados para a vazão turbinada no primeiro mês para todos os cenários e, na segunda etapa, realizando a otimização da geração de energia para os meses subsequentes mantendo constantes os resultados obtidos no mês inicial da etapa anterior.

Os resultados dos Estudos 4 e 5 demonstraram que a otimização de segunda etapa de fato corrigiu a questão dos vertimentos porém o resultado da operação foi bastante similar, senão praticamente o mesmo, para as três combinações dos coeficientes de ponderação estudados. Se considerarmos a definição de Mulvey para uma solução robusta, estes resultados podem ser considerados robustos, mesmo sem a minimização explícita do desvio padrão.

Cabe salientar que a aplicação de técnicas de OR na operação de reservatórios é um tema que foi pouco estudado, sendo recomendada a continuidade das pesquisas sobre o tema.

Também seria interessante a avaliação da técnica proposta para diferentes reservatórios, com maior capacidade de regularização. Alguns dos problemas encontrados podem ser inerentes dos dados numéricos da UHE Sinop.

Apesar da aplicação de uma função objetivo de segunda etapa para a correção dos vertimentos indesejados, a mesma ainda não é a solução ideal, pois após sua aplicação pode-se perder a minimização do desvio padrão ocasionada na etapa anterior. Uma outra abordagem sugerida como pesquisa futura é o desenvolvimento de funções objetivo "aninhadas", ou seja, fazendo com que otimização de segunda etapa ocorra ao mesmo tempo e internamente à otimização de primeira etapa e não após ela. Com a utilização de funções "aninhadas" também poderá ser interessante testar o desempenho de diferentes funções objetivo principais, como a maximização da produção, minimização dos custos de operação ou do vertimento, apenas para citar alguns exemplos. 


\section{REFERÊNCIAS BIBLIOGRÁFICAS}

BARROS, M. T. L., TSAI, F., LOPES, J. E. G., YEH, W. Optimization of large scale hydropower system operations. Journal of Water Resources Planning and Management, v. 129, n. 3, p. 178-188, 2003.

BARROS, M. T. L., ZAMBON, R. C., LOPES, J. E. G. Sistema de suporte à decisão para 0 planejamento da operação hidráulica de sistemas hidroenergéticos. In: III Simpósio de Recursos Hídricos Del Cono Sur, Mendoza, 2005.

BARROS, M. T. L, ZAMBON, R. C., LOPES, J. E. G., BARBOSA, P. S. F., FRANCATO, A. L. F., YEH, W. Model to optimize large hydrothermal system operation considering water and environment sustainability. In: World Environmental \& Water Resources Congress, Honolulu, Hawaii, 2008a.

BARROS, M. T. L., ZAMBON, R. C., BARBOSA, P. S., YEH, W. Planning and Operation of Large-Scale Water Distribution Systems with Preemptive Priorities. Journal of Water Resources Planning and Management, v. 134, n. 3, p. 247-256, 2008b.

BARROS, M. T. L., ZAMBON, R. C., LOPES, J. E. G., BARBOSA, P. S. F., FRANCATO, A. L. F., YEH, W. Impacts of the upstream storage reservoirs on Itaipu hydropower plant operation. In: World Environmental \& Water Resources Congress, Kansas City, Missouri, 2009.

BEN-TAL, A., EL-GHAOUI, L. NEMIROVSKI, A. Robust Optimization. Princeton Series in Applied Mathematics. 2009. 564 p.

BERTSIMAS, D., SIM, M. Robust discrete optimization and network flows. Mathematical Programming Series B, v. 98, n. 1-3, p. 49-71, 2003.

BERTSIMAS, D., SIM, M. The price of robustness. Operations Research, v. 52, n. 1, p. 35-53, 2004.

BERTSIMAS, D., PACHAMANOVA, D., SIM, M. Robust linear optimization under general norms. Operations Research Letters, v. 32, n. 6, p. 510-516, 2004.

BERTSIMAS, D., THIELE, A. A robust optimization approach to inventory theory. Operations Resarch, v. 54, n. 1, p. 150-168, 2006.

BEYER, H., SANDHOFF, B. Robust optimization - a comprehensive survey. Computation Methods Applied to Mechanical Engineering, v. 196, n. 33-34, p. 31903218, 2007.

BRANDÃO, J. L. B. Modelo para operação de reservatórios com usos múltiplos. Tese de Doutorado. São Paulo: Universidade de São Paulo - Escola Politécnica, 2004. 160p. 
CICOGNA, M. A. Planejamento e a programação da operação de sistemas de energia elétrica. Tese de Doutorado. Campinas: Universidade Estadual de Campinas - Faculdade de Engenharia Elétrica e Computação, 2003. 220 p.

DELGADO, D. M. Otimização Estocástica de Sistemas Urbanos de Suprimento Hídrico. Dissertação de Mestrado. Campinas: Universidade Estadual de Campinas Faculdade de Engenharia Civil, Arquitetura e Urbanismo, 2006. 116p.

FRAGNIÈRE, E., GONDZIO, J. Stochastic Programming from Modeling Languages, in: Applications of Stochastic Programming. H. Gassmann, S. Wallace and W. Ziemba (eds), 1-21, 2002.

EL-GHAOUI, L., LEBRET, H. Robust solutions to least-square problems to uncertain data matrices. Journal on Matrix Analysis and Applications, v. 18, p. 1035-1064, 1997.

EL-GHAOUI, L., OUSTRY, F., LEBRET, H. Robust solutions to uncertain semi definite programs. SIAM Journal of Optimization, v. 9, p. 33-52, 1998.

EPE. Relatório de Impacto Ambiental. Relatório Técnico realizado pela Themag Engenharia. 2010a.

EPE. Modelagem energética da UHE SINOP. Nota Técnica. Brasília: EPE, 07 de Outubro de 2010b, 29p. Disponível em: <http://www.epe.gov.br>. Acesso em: 05 de Maio de 2011.

ERDOGAN, E., IYENGAR, G. Ambiguous chance constrained problems and robust optimization. Mathematical Programming Series B, v.107, p. 37-61, 2006.

GAMS - Generic Algebraic Modeling System. www.gams.com, 2012.

LABADIE, J. Optimal operation of multireservoir systems: state of art review. Journal of Water Resources Planning and Management, v. 130, n. 2, p. 93-111, 2004.

LEITE, P. T. Aplicação de técnicas de inteligência artificial no planejamento da operação de sistemas hidrotérmicos de potência. Tese de Doutorado. São Carlos: Universidade de São Paulo - Escola de Engenharia de São Carlos, 2003.

LOPES, J. E. G. Otimização de sistemas hidroenergéticos. Dissertação de Mestrado. São Paulo: Universidade de São Paulo - Escola Politécnica, 2001.

LOPES, J. E. G. Modelo de planejamento da operação de sistemas hidrotérmicos de produção de energia elétrica. Tese de Doutorado. São Paulo: Universidade de São Paulo: Escola Politécnica, 2007.

LUND, J. R., ISRAEL, M. Optimization of transfers in urban water supply planning. Journal of Water Resources Planning and Management, v. 121, n. 1, p. 41-48, 1995.

MARQUES, F. G. Modelo de otimização não linear para programação de manutenção em sistemas hidrelétricos. Dissertação de Mestrado. Campinas: 
Universidade Estadual de Campinas - Faculdade de Engenharia Civil, Arquitetura e Urbanismo, 2006. 80p.

MOMOH, J. A., EL-HAWARY, M. E., ADAPA, R. A review of selected optimal power flow literature to 1993, Part I: Nonlinear and quadratic programming approaches. IEEE Trans. Syst, v. 14, n. 1, p. 96-104, 1999a.

MOMOH, J. A., EL-HAWARY, M. E., ADAPA, R. A review of selected optimal power flow literature to 1993, Part II: Newton, linear programming and interior point methods. IEEE Trans, v. 14, n. 1, p. 96-104, 1999b.

MULVEY, J. M., VANDERBEI, R. J., ZENIOS, S. A. Robust optimization of largescale systems. Operations Research, v. 43, n. 2, p. 264-281, 1995.

MURTAGH, B., SAUNDERS, M. MINOS 5.1. User's guide. Technical Report n.50 L83-20R, Dept. of Operations Research, Stanford University, CA, 1987.

PAIVA, R. P. O. Modelagem do planejamento agregado da produção em usinas cooperadas do setor sucroenergético utilizando programação matemática e otimização robusta. Tese de Doutorado. São Carlos: Universidade Federal de São Carlos. 2009. 241p.

PEREIRA, M. V. F. Optimal scheduling of hydrothermal systems - an overview, In: IFAC Symposium on Planning and Operation of Electric Energy Systems, Rio de Janeiro, Brasil, 1985.

PEREIRA, M. V. F. Optimal stochastic operations of large hydroelectric systems. Electrical Power \& Energy Systems, v. 11, n.3, p. 161-169, 1989.

PEREIRA, M. V. F., PINTO, L. M. V. G. Stochastic Optimization of a Multireservoir Hydroelectric System: A Decomposition Approach. Water Resources Research, Vol. 21, n.6, p. 779-792, 1985.

RAY, P. A., VOGEL, R. M., WATKINS, D. W. Robust optimization using a variety of performance indices. In: World Environmental and Water Resources Congress, Providence, Rhode Island, p. 4710-4719, 2010.

SIMONOVIC, S. P. Reservoir systems analysis: closing gap between theory and practice. Journal of Water Resources Planning and Management, 118(3), p. 262280, 1992.

TOSCANO, A. E. Comparação entre os modelos NEWAVE e ODIN no planejamento energético do sistema interligado nacional. Dissertação de Mestrado. Campinas: Universidade Estadual de Campinas - Faculdade de Engenharia Elétrica e Computação, 2009. 116 p.

UNITED STATES DEPARTMENT OF ENERGY. < http://energy.gov/>. 2011.

WATKINS, D. W.; MCKINNEY, D. C. Robust optimization for incorporating risk and uncertainty in sustainable water resources planning. Modelling and Management of Sustainable Basin-scale Water Resource Systems (Proceedings of a 
Boulder Symposium, July 1995). IAHS XXI General Assembly of IUGG, Boulder, CO, p. 225-232, 1995.

WATKINS, D. W., MCKINNEY, D. C. Finding robust solutions to water resources problems. Journal of Water Resources Planning and Management, v. 123, n. 1, p. 49-58, 1997.

WURBS, R. Reservoir-system simulation and optimization models. Journal of Water Resources Planning and Management, v. 119, n. 4, p. 455-472, 1993.

YAMASHITA, D. S., ARMENTANO, V. A., LAGUNA, M. Robust optimization models for subject scheduling with resource availability cost. Journal of Scheduling, v. 10, p. 67-76, 2007.

YEH, W. W-G. Reservoir management and operations models: a state of art review. Water Resources Research, v. 21, n.2, 1797-1818, 1985.

YEH, W. W-G., BECKER, L. HUA, S-Q., WEN, D-P., LIU, J-M. Optimization of realtime hydrothermal system operation. Journal of Water Resources Planning and Management, v. 118, n. 6, p. 636-653, 1992.

ZAMBON, R. C. Planejamento da operação de sistemas hidrotérmicos de grande porte. Tese de Doutorado. São Paulo: Universidade de São Paulo - Escola Politécnica, 2008. 104p.

ZAMBON, R. C., BARROS, M. T. L., LOPES, J. E. G., BARBOSA, P. S. F., FRANCATO, A. L. F., YEH, W. Economical Impacts on the Brazilian Hydrothermal System Production Due to the Newly Imposed Constraints on Storage Reservoirs. In: World Environmental \& Water Resources Congress, Providence, Rhode Island, 2010.

ZAMBON, R. C., BARROS, M. T. L., LOPES, J. E. G., BARBOSA, P. S. F., FRANCATO, A. L. F., YEH, W. Planning operation of large-scale hydrothermal system. In: World Environmental \& Water Resources Congress, Palm Springs, California, 2011.

ZAMBON, R. C., BARROS, M. T. L., LOPES, J. E. G., BARBOSA, P.S.F., FRANCATO, A. L., YEH, W. Optimization of large-scale hydrothermal system operation. Journal of Water Resources Planning and Management, Vol. 138, $\mathrm{N}^{\circ} 2$, 135-143p. doi:10.1061/(ASCE)WR.1943-5452.000149, 2012.

ZAMBON, R. C., BARROS, M. T. L., BARBOSA, P. S. F., FRANCATO, A. L. F., LOPES, J. E. G., NOGUEIRA, L. F. A. M., YEH, W. A Stochastic Hydrothermal Decision Support System for Planning Operation: New Developments for the HIDROTERM model. In: World Environmental \& Water Resources Congress, Cincinnati, Ohio, 2013. 


\section{APÊNDICE A}

Segue-se abaixo o código fonte utilizado para modelo HIDRO-OR com a otimização em 2 estágios. O exemplo ilustrado é o do Estudo 5 (Item 5.2.5).

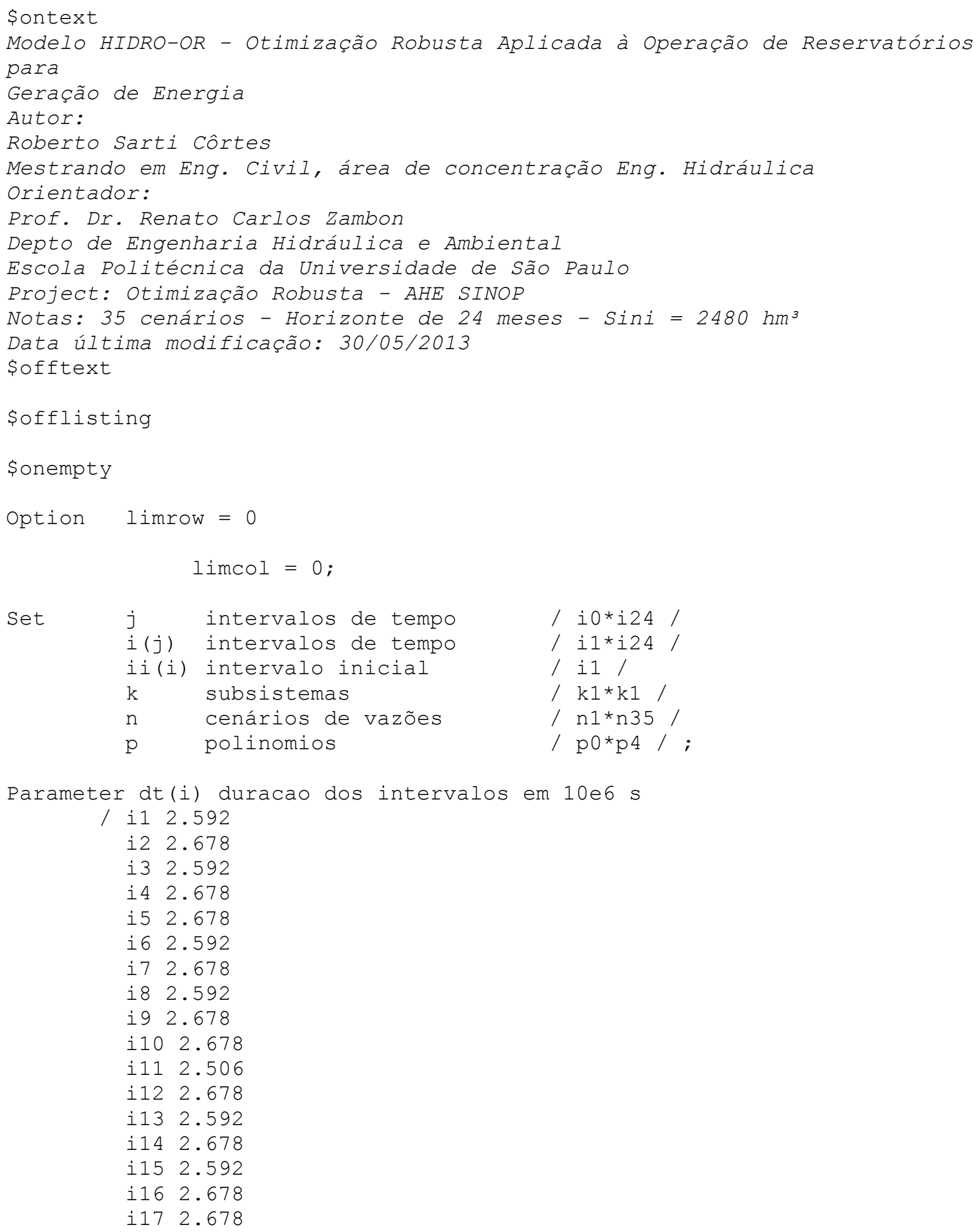




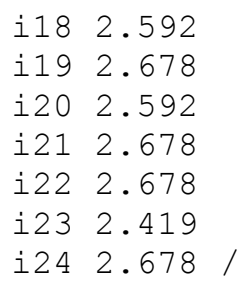

Table DD $(k, i)$ demanda objetivo

\$ondelim

$k$, i1, i2, i3, i4, i5, i6, i7, i8, i9, i10, i11, i12, i13, i14, i15, i16, i17, i18, i19, i20, i2 $1, i 22, i 23, i 24$

$\mathrm{k} 1,400,400,400,400,400,400,400,400,400,400,400,400,400,400,400,400,400,400$, $400,400,400,400,400,400$

soffdelim

Table QI (n, i) vazao afluente

\$ondelim

$k, i 1, i 2, i 3, i 4, i 5, i 6, i 7, i 8, i 9, i 10, i 11, i 12, i 13, i 14, i 15, i 16, i 17, i 18, i 19, i 20, i 2$ $1, i 22, i 23, i 24$

$\mathrm{n} 1,1098,871,706,572,463,393,549,579,1148,857,2694,903,834,690,559,453,367,3$ $41,312,371,425,1115,713,1675$

$\mathrm{n} 2,1098,722,626,507,410,384,479,493,2390,2635,1187,1010,840,733,594,481,389$ ,334,1073,759,1103,918,1335,985

$\mathrm{n} 3,1098,685,611,537,435,418,455,1065,1320,2184,2324,2821,1527,1006,815,665$, $539,470,482,1073,743,1256,1854,2456$

$\mathrm{n} 4,1098,801,649,529,532,475,1016,787,735,1418,1483,1386,1794,906,739,599,48$ $5,476,742,1086,693,1807,1358,1559$

$\mathrm{n} 5,1098,825,669,542,439,434,1114,1018,1570,820,1318,1223,832,675,559,453,36$ $7,345,437,933,738,1699,2052,2388$

$\mathrm{n} 6,1098,960,778,630,510,458,506,1149,1451,945,2625,1578,911,1029,745,634,51$ $3,427,447,1064,1119,2675,1651,2174$

$\mathrm{n} 7,1098,893,724,586,475,410,580,717,1475,1018,1574,1194,874,724,587,518,420$ $, 470,517,963,4465,2066,2158,1479$

$\mathrm{n} 8,1098,851,731,592,480,393,904,573,1986,2657,1431,2108,965,785,636,515,417$ , 338,491,742,2445,1662,1535,3858

$\mathrm{n} 9,1098,931,761,617,503,452,423,810,776,1260,1186,1119,983,725,588,476,385$, $325,320,476,1209,1068,1405,2111$

n10,1098,722,585,474,384,432,595,562,1018,1300,1923,2365,909, 768,639,518,41 $9,402,427,1182,698,2244,923,2369$

$\mathrm{n} 11,1098,804,664,538,436,353,357,380,1730,916,1458,894,1149,833,738,599,498$ ,520,510,2241,1536,1369,2041,1344

$\mathrm{n} 12,1098,818,689,559,480,539,536,707,1485,1540,1080,1297,1123,819,667,564,4$ $57,403,449,916,1815,3455,1431,2484$

$\mathrm{n} 13,1098,858,709,589,482,399,389,2011,1650,1989,1949,1188,1038,814,659,534$, $433,351,470,663,1362,2055,1223,1962$

$\mathrm{n} 14,1098,822,669,542,486,403,437,607,1841,2314,1843,876,1057,743,611,495,41$ $3,494,514,523,2830,896,2029,1196$

$\mathrm{n} 15,1098,746,604,491,397,341,353,846,623,1749,748,1035,686,617,500,409,331$, $272,701,1460,1001,1282,1559,1823$

$\mathrm{n} 16,1098,820,666,539,437,449,1334,1413,1020,1452,2245,1172,922,798,647,524$, $424,383,893,560,658,832,923,1035$

$\mathrm{n} 17,1098,686,565,458,371,315,516,647,1263,750,1157,718,636,516,418,339,335$, $343,447,507,1355,1286,814,927$

$\mathrm{n} 18,1098,651,532,431,349,318,395,841,1835,1797,1178,911,844,734,595,482,390$ , 324,555,520,511,968, 1188,717

n19,1098,599,489,428,358,399,487,603,627,789,1504,769,690,595,491,430,354,3 $30,399,1161,1230,1077,1110,1005$ 
$\mathrm{n} 20,1098,648,547,451,372,341,434,1272,1758,2500,1065,1373,997,851,689,558,4$ $59,431,434,489,1492,923,1342,1003$

$\mathrm{n} 21,1098,713,579,503,408,333,390,610,626,952,1254,1512,1169,777,579,444,371$ , 363,470,653,1264,1349,1653,1099

$\mathrm{n} 22,1098,928,736,489,389,388,503,746,1113,1960,1481,2502,1262,1059,791,631$, $547,482,613,754,1163,2022,1902,1307$

$\mathrm{n} 23,1098,750,445,436,405,499,499,691,780,1398,2340,2396,1364,918,749,601,51$ $1,510,509,567,1054,1554,1543,1449$

n24,1098,1075,719,579,488,419,509,1088,1158,1905,1990,1530,1612,1025,770,61 $9,523,514,586,689,1048,1407,1830,1332$

n25,1098,744,610,479,412,385,524,681,1017,1082,1038,1194,1094,804,557,457,4 $07,417,466,618,1115,1663,1645,1458$

n26,1098,925,632,514,428,406,525,627,666,1370,1686,1469,1032,757,587,473,45 $0,442,534,539,769,1484,1400,1351$

$\mathrm{n} 27,1098,736,532,429,381,357,369,673,1408,1525,1454,1699,1366,887,621,489,4$ $10,368,400,681,1135,1464,1852,1837$

$\mathrm{n} 28,1098,942,642,539,470,438,417,540,1246,1810,1582,1524,1207,843,602,517,5$ $25,533,665,743,898,1303,1650,1757$

$\mathrm{n} 29,1098,754,604,548,519,518,554,726,880,1079,1643,1497,1360,839,684,548,47$ $7,539,579,811,1477,1233,1628,1114$

$\mathrm{n} 30,1098,710,571,458,411,391,430,518,860,1577,1321,1938,1317,911,744,573,45$ $5,405,468,566,766,2328,2132,2056$

$\mathrm{n} 31,1098,1394,887,638,533,486,504,649,1014,1423,1264,1480,1239,836,625,480$, $439,413,439,801,733,1384,1954,1893$

$\mathrm{n} 32,1098,890,691,524,439,400,424,532,946,948,1234,1348,836,583,451,382,350$, $337,397,699,1199,1710,1191,1584$

$\mathrm{n} 33,1098,653,493,419,360,361,361,545,888,1239,1488,1851,1242,744,541,466,40$ $3,406,400,713,894,901,904,1225$

$\mathrm{n} 34,1098,699,556,450,391,396,514,642,1331,1596,1488,1619,1174,765,587,493,4$ $27,424,431,586,756,1464,1618,1677$

$\mathrm{n} 35,1098,964,720,576,480,453,556,707,972,1392,2998,1634,1391,1013,752,663,5$ $56,498,579,770,842,1314,1423,1433$

\section{\$offdelim}

Table Ev(n,i) evaporacao

\section{Sondelim}

$n$, i1, i2, i3, i4, i5, i6, i7, i8, i9, i10, i11, i12, i13, i14, i15, i16, i17, i18, i19, i20, i2 $1, i 22, i 23, i 24$

$\mathrm{n} 1,0.026,0.021,0.025,0.002,0.004,0.025,0.032,0.045,0.056,0.023,0.022,0.041$, $0.026,0.021,0.025,0.002,0.004,0.025,0.032,0.045,0.056,0.023,0.022,0.041$ $\mathrm{n} 2,0.026,0.021,0.025,0.002,0.004,0.025,0.032,0.045,0.056,0.023,0.022,0.041$, $0.026,0.021,0.025,0.002,0.004,0.025,0.032,0.045,0.056,0.023,0.022,0.041$ $\mathrm{n} 3,0.026,0.021,0.025,0.002,0.004,0.025,0.032,0.045,0.056,0.023,0.022,0.041$, $0.026,0.021,0.025,0.002,0.004,0.025,0.032,0.045,0.056,0.023,0.022,0.041$ $\mathrm{n} 4,0.026,0.021,0.025,0.002,0.004,0.025,0.032,0.045,0.056,0.023,0.022,0.041$, $0.026,0.021,0.025,0.002,0.004,0.025,0.032,0.045,0.056,0.023,0.022,0.041$ $\mathrm{n} 5,0.026,0.021,0.025,0.002,0.004,0.025,0.032,0.045,0.056,0.023,0.022,0.041$, $0.026,0.021,0.025,0.002,0.004,0.025,0.032,0.045,0.056,0.023,0.022,0.041$ $\mathrm{n} 6,0.026,0.021,0.025,0.002,0.004,0.025,0.032,0.045,0.056,0.023,0.022,0.041$, $0.026,0.021,0.025,0.002,0.004,0.025,0.032,0.045,0.056,0.023,0.022,0.041$ $\mathrm{n} 7,0.026,0.021,0.025,0.002,0.004,0.025,0.032,0.045,0.056,0.023,0.022,0.041$, $0.026,0.021,0.025,0.002,0.004,0.025,0.032,0.045,0.056,0.023,0.022,0.041$ $\mathrm{n} 8,0.026,0.021,0.025,0.002,0.004,0.025,0.032,0.045,0.056,0.023,0.022,0.041$, $0.026,0.021,0.025,0.002,0.004,0.025,0.032,0.045,0.056,0.023,0.022,0.041$ $\mathrm{n} 9,0.026,0.021,0.025,0.002,0.004,0.025,0.032,0.045,0.056,0.023,0.022,0.041$, $0.026,0.021,0.025,0.002,0.004,0.025,0.032,0.045,0.056,0.023,0.022,0.041$ $\mathrm{n} 10,0.026,0.021,0.025,0.002,0.004,0.025,0.032,0.045,0.056,0.023,0.022,0.041$ $, 0.026,0.021,0.025,0.002,0.004,0.025,0.032,0.045,0.056,0.023,0.022,0.041$ 
$\mathrm{n} 11,0.026,0.021,0.025,0.002,0.004,0.025,0.032,0.045,0.056,0.023,0.022,0.041$ $, 0.026,0.021,0.025,0.002,0.004,0.025,0.032,0.045,0.056,0.023,0.022,0.041$ $\mathrm{n} 12,0.026,0.021,0.025,0.002,0.004,0.025,0.032,0.045,0.056,0.023,0.022,0.041$ $, 0.026,0.021,0.025,0.002,0.004,0.025,0.032,0.045,0.056,0.023,0.022,0.041$ $\mathrm{n} 13,0.026,0.021,0.025,0.002,0.004,0.025,0.032,0.045,0.056,0.023,0.022,0.041$ , $0.026,0.021,0.025,0.002,0.004,0.025,0.032,0.045,0.056,0.023,0.022,0.041$ $\mathrm{n} 14,0.026,0.021,0.025,0.002,0.004,0.025,0.032,0.045,0.056,0.023,0.022,0.041$ $, 0.026,0.021,0.025,0.002,0.004,0.025,0.032,0.045,0.056,0.023,0.022,0.041$ $\mathrm{n} 15,0.026,0.021,0.025,0.002,0.004,0.025,0.032,0.045,0.056,0.023,0.022,0.041$ $, 0.026,0.021,0.025,0.002,0.004,0.025,0.032,0.045,0.056,0.023,0.022,0.041$ $\mathrm{n} 16,0.026,0.021,0.025,0.002,0.004,0.025,0.032,0.045,0.056,0.023,0.022,0.041$ $, 0.026,0.021,0.025,0.002,0.004,0.025,0.032,0.045,0.056,0.023,0.022,0.041$ $\mathrm{n} 17,0.026,0.021,0.025,0.002,0.004,0.025,0.032,0.045,0.056,0.023,0.022,0.041$ $, 0.026,0.021,0.025,0.002,0.004,0.025,0.032,0.045,0.056,0.023,0.022,0.041$ $\mathrm{n} 18,0.026,0.021,0.025,0.002,0.004,0.025,0.032,0.045,0.056,0.023,0.022,0.041$ $, 0.026,0.021,0.025,0.002,0.004,0.025,0.032,0.045,0.056,0.023,0.022,0.041$ $\mathrm{n} 19,0.026,0.021,0.025,0.002,0.004,0.025,0.032,0.045,0.056,0.023,0.022,0.041$ $, 0.026,0.021,0.025,0.002,0.004,0.025,0.032,0.045,0.056,0.023,0.022,0.041$ $\mathrm{n} 20,0.026,0.021,0.025,0.002,0.004,0.025,0.032,0.045,0.056,0.023,0.022,0.041$ $, 0.026,0.021,0.025,0.002,0.004,0.025,0.032,0.045,0.056,0.023,0.022,0.041$ $\mathrm{n} 21,0.026,0.021,0.025,0.002,0.004,0.025,0.032,0.045,0.056,0.023,0.022,0.041$ $, 0.026,0.021,0.025,0.002,0.004,0.025,0.032,0.045,0.056,0.023,0.022,0.041$ $\mathrm{n} 22,0.026,0.021,0.025,0.002,0.004,0.025,0.032,0.045,0.056,0.023,0.022,0.041$ $, 0.026,0.021,0.025,0.002,0.004,0.025,0.032,0.045,0.056,0.023,0.022,0.041$ $\mathrm{n} 23,0.026,0.021,0.025,0.002,0.004,0.025,0.032,0.045,0.056,0.023,0.022,0.041$ $, 0.026,0.021,0.025,0.002,0.004,0.025,0.032,0.045,0.056,0.023,0.022,0.041$ $\mathrm{n} 24,0.026,0.021,0.025,0.002,0.004,0.025,0.032,0.045,0.056,0.023,0.022,0.041$ $, 0.026,0.021,0.025,0.002,0.004,0.025,0.032,0.045,0.056,0.023,0.022,0.041$ $\mathrm{n} 25,0.026,0.021,0.025,0.002,0.004,0.025,0.032,0.045,0.056,0.023,0.022,0.041$ , $0.026,0.021,0.025,0.002,0.004,0.025,0.032,0.045,0.056,0.023,0.022,0.041$ $\mathrm{n} 26,0.026,0.021,0.025,0.002,0.004,0.025,0.032,0.045,0.056,0.023,0.022,0.041$ $, 0.026,0.021,0.025,0.002,0.004,0.025,0.032,0.045,0.056,0.023,0.022,0.041$ $\mathrm{n} 27,0.026,0.021,0.025,0.002,0.004,0.025,0.032,0.045,0.056,0.023,0.022,0.041$ $, 0.026,0.021,0.025,0.002,0.004,0.025,0.032,0.045,0.056,0.023,0.022,0.041$ $\mathrm{n} 28,0.026,0.021,0.025,0.002,0.004,0.025,0.032,0.045,0.056,0.023,0.022,0.041$ $, 0.026,0.021,0.025,0.002,0.004,0.025,0.032,0.045,0.056,0.023,0.022,0.041$ $\mathrm{n} 29,0.026,0.021,0.025,0.002,0.004,0.025,0.032,0.045,0.056,0.023,0.022,0.041$ , $0.026,0.021,0.025,0.002,0.004,0.025,0.032,0.045,0.056,0.023,0.022,0.041$ $\mathrm{n} 30,0.026,0.021,0.025,0.002,0.004,0.025,0.032,0.045,0.056,0.023,0.022,0.041$ $, 0.026,0.021,0.025,0.002,0.004,0.025,0.032,0.045,0.056,0.023,0.022,0.041$ $\mathrm{n} 31,0.026,0.021,0.025,0.002,0.004,0.025,0.032,0.045,0.056,0.023,0.022,0.041$ $, 0.026,0.021,0.025,0.002,0.004,0.025,0.032,0.045,0.056,0.023,0.022,0.041$ $\mathrm{n} 32,0.026,0.021,0.025,0.002,0.004,0.025,0.032,0.045,0.056,0.023,0.022,0.041$ $, 0.026,0.021,0.025,0.002,0.004,0.025,0.032,0.045,0.056,0.023,0.022,0.041$ $\mathrm{n} 33,0.026,0.021,0.025,0.002,0.004,0.025,0.032,0.045,0.056,0.023,0.022,0.041$ $, 0.026,0.021,0.025,0.002,0.004,0.025,0.032,0.045,0.056,0.023,0.022,0.041$ $\mathrm{n} 34,0.026,0.021,0.025,0.002,0.004,0.025,0.032,0.045,0.056,0.023,0.022,0.041$ $, 0.026,0.021,0.025,0.002,0.004,0.025,0.032,0.045,0.056,0.023,0.022,0.041$ $\mathrm{n} 35,0.026,0.021,0.025,0.002,0.004,0.025,0.032,0.045,0.056,0.023,0.022,0.041$ $, 0.026,0.021,0.025,0.002,0.004,0.025,0.032,0.045,0.056,0.023,0.022,0.041$

\section{\$offdelim}

Table UC (n, i) uso consuntivo

\section{Sondelim}

$n$, i1, i2, i3, i4, i5, i6, i7, i8, i9, i10, i11, i12, i13, i14, i15, i16, i17, i18, i19, i20, i2 $1, i 22, i 23, i 24$

$\mathrm{n} 1,12.96,15.84,18.72,15.84,15.84,7.2,2.88,2.88,2.88,2.88,2.88,10.08,12.96,1$ $5.84,18.72,15.84,15.84,7.2,2.88,2.88,2.88,2.88,2.88,10.08$ 
$\mathrm{n} 2,12.96,15.84,18.72,15.84,15.84,7.2,2.88,2.88,2.88,2.88,2.88,10.08,12.96,1$ $5.84,18.72,15.84,15.84,7.2,2.88,2.88,2.88,2.88,2.88,10.08$ $\mathrm{n} 3,12.96,15.84,18.72,15.84,15.84,7.2,2.88,2.88,2.88,2.88,2.88,10.08,12.96,1$ $5.84,18.72,15.84,15.84,7.2,2.88,2.88,2.88,2.88,2.88,10.08$ $\mathrm{n} 4,12.96,15.84,18.72,15.84,15.84,7.2,2.88,2.88,2.88,2.88,2.88,10.08,12.96,1$ $5.84,18.72,15.84,15.84,7.2,2.88,2.88,2.88,2.88,2.88,10.08$ $\mathrm{n} 5,12.96,15.84,18.72,15.84,15.84,7.2,2.88,2.88,2.88,2.88,2.88,10.08,12.96,1$ $5.84,18.72,15.84,15.84,7.2,2.88,2.88,2.88,2.88,2.88,10.08$ $\mathrm{n} 6,12.96,15.84,18.72,15.84,15.84,7.2,2.88,2.88,2.88,2.88,2.88,10.08,12.96,1$ $5.84,18.72,15.84,15.84,7.2,2.88,2.88,2.88,2.88,2.88,10.08$ $\mathrm{n} 7,12.96,15.84,18.72,15.84,15.84,7.2,2.88,2.88,2.88,2.88,2.88,10.08,12.96,1$ $5.84,18.72,15.84,15.84,7.2,2.88,2.88,2.88,2.88,2.88,10.08$ $\mathrm{n} 8,12.96,15.84,18.72,15.84,15.84,7.2,2.88,2.88,2.88,2.88,2.88,10.08,12.96,1$ $5.84,18.72,15.84,15.84,7.2,2.88,2.88,2.88,2.88,2.88,10.08$ $\mathrm{n} 9,12.96,15.84,18.72,15.84,15.84,7.2,2.88,2.88,2.88,2.88,2.88,10.08,12.96,1$ $5.84,18.72,15.84,15.84,7.2,2.88,2.88,2.88,2.88,2.88,10.08$ $\mathrm{n} 10,12.96,15.84,18.72,15.84,15.84,7.2,2.88,2.88,2.88,2.88,2.88,10.08,12.96$, $15.84,18.72,15.84,15.84,7.2,2.88,2.88,2.88,2.88,2.88,10.08$ $\mathrm{n} 11,12.96,15.84,18.72,15.84,15.84,7.2,2.88,2.88,2.88,2.88,2.88,10.08,12.96$, $15.84,18.72,15.84,15.84,7.2,2.88,2.88,2.88,2.88,2.88,10.08$ $\mathrm{n} 12,12.96,15.84,18.72,15.84,15.84,7.2,2.88,2.88,2.88,2.88,2.88,10.08,12.96$, $15.84,18.72,15.84,15.84,7.2,2.88,2.88,2.88,2.88,2.88,10.08$

$\mathrm{n} 13,12.96,15.84,18.72,15.84,15.84,7.2,2.88,2.88,2.88,2.88,2.88,10.08,12.96$, $15.84,18.72,15.84,15.84,7.2,2.88,2.88,2.88,2.88,2.88,10.08$ $\mathrm{n} 14,12.96,15.84,18.72,15.84,15.84,7.2,2.88,2.88,2.88,2.88,2.88,10.08,12.96$, $15.84,18.72,15.84,15.84,7.2,2.88,2.88,2.88,2.88,2.88,10.08$ $\mathrm{n} 15,12.96,15.84,18.72,15.84,15.84,7.2,2.88,2.88,2.88,2.88,2.88,10.08,12.96$, $15.84,18.72,15.84,15.84,7.2,2.88,2.88,2.88,2.88,2.88,10.08$ $\mathrm{n} 16,12.96,15.84,18.72,15.84,15.84,7.2,2.88,2.88,2.88,2.88,2.88,10.08,12.96$, $15.84,18.72,15.84,15.84,7.2,2.88,2.88,2.88,2.88,2.88,10.08$ $\mathrm{n} 17,12.96,15.84,18.72,15.84,15.84,7.2,2.88,2.88,2.88,2.88,2.88,10.08,12.96$, $15.84,18.72,15.84,15.84,7.2,2.88,2.88,2.88,2.88,2.88,10.08$ $\mathrm{n} 18,12.96,15.84,18.72,15.84,15.84,7.2,2.88,2.88,2.88,2.88,2.88,10.08,12.96$, $15.84,18.72,15.84,15.84,7.2,2.88,2.88,2.88,2.88,2.88,10.08$ $\mathrm{n} 19,12.96,15.84,18.72,15.84,15.84,7.2,2.88,2.88,2.88,2.88,2.88,10.08,12.96$, $15.84,18.72,15.84,15.84,7.2,2.88,2.88,2.88,2.88,2.88,10.08$ $\mathrm{n} 20,12.96,15.84,18.72,15.84,15.84,7.2,2.88,2.88,2.88,2.88,2.88,10.08,12.96$, $15.84,18.72,15.84,15.84,7.2,2.88,2.88,2.88,2.88,2.88,10.08$ $\mathrm{n} 21,12.96,15.84,18.72,15.84,15.84,7.2,2.88,2.88,2.88,2.88,2.88,10.08,12.96$, $15.84,18.72,15.84,15.84,7.2,2.88,2.88,2.88,2.88,2.88,10.08$

$\mathrm{n} 22,12.96,15.84,18.72,15.84,15.84,7.2,2.88,2.88,2.88,2.88,2.88,10.08,12.96$, $15.84,18.72,15.84,15.84,7.2,2.88,2.88,2.88,2.88,2.88,10.08$ $\mathrm{n} 23,12.96,15.84,18.72,15.84,15.84,7.2,2.88,2.88,2.88,2.88,2.88,10.08,12.96$, $15.84,18.72,15.84,15.84,7.2,2.88,2.88,2.88,2.88,2.88,10.08$ $\mathrm{n} 24,12.96,15.84,18.72,15.84,15.84,7.2,2.88,2.88,2.88,2.88,2.88,10.08,12.96$, $15.84,18.72,15.84,15.84,7.2,2.88,2.88,2.88,2.88,2.88,10.08$ $\mathrm{n} 25,12.96,15.84,18.72,15.84,15.84,7.2,2.88,2.88,2.88,2.88,2.88,10.08,12.96$, $15.84,18.72,15.84,15.84,7.2,2.88,2.88,2.88,2.88,2.88,10.08$ $\mathrm{n} 26,12.96,15.84,18.72,15.84,15.84,7.2,2.88,2.88,2.88,2.88,2.88,10.08,12.96$, $15.84,18.72,15.84,15.84,7.2,2.88,2.88,2.88,2.88,2.88,10.08$ $\mathrm{n} 27,12.96,15.84,18.72,15.84,15.84,7.2,2.88,2.88,2.88,2.88,2.88,10.08,12.96$, $15.84,18.72,15.84,15.84,7.2,2.88,2.88,2.88,2.88,2.88,10.08$ $\mathrm{n} 28,12.96,15.84,18.72,15.84,15.84,7.2,2.88,2.88,2.88,2.88,2.88,10.08,12.96$, $15.84,18.72,15.84,15.84,7.2,2.88,2.88,2.88,2.88,2.88,10.08$ $\mathrm{n} 29,12.96,15.84,18.72,15.84,15.84,7.2,2.88,2.88,2.88,2.88,2.88,10.08,12.96$, $15.84,18.72,15.84,15.84,7.2,2.88,2.88,2.88,2.88,2.88,10.08$ $\mathrm{n} 30,12.96,15.84,18.72,15.84,15.84,7.2,2.88,2.88,2.88,2.88,2.88,10.08,12.96$, $15.84,18.72,15.84,15.84,7.2,2.88,2.88,2.88,2.88,2.88,10.08$

$\mathrm{n} 31,12.96,15.84,18.72,15.84,15.84,7.2,2.88,2.88,2.88,2.88,2.88,10.08,12.96$, $15.84,18.72,15.84,15.84,7.2,2.88,2.88,2.88,2.88,2.88,10.08$ 
$\mathrm{n} 32,12.96,15.84,18.72,15.84,15.84,7.2,2.88,2.88,2.88,2.88,2.88,10.08,12.96$, $15.84,18.72,15.84,15.84,7.2,2.88,2.88,2.88,2.88,2.88,10.08$

$\mathrm{n} 33,12.96,15.84,18.72,15.84,15.84,7.2,2.88,2.88,2.88,2.88,2.88,10.08,12.96$, $15.84,18.72,15.84,15.84,7.2,2.88,2.88,2.88,2.88,2.88,10.08$

$\mathrm{n} 34,12.96,15.84,18.72,15.84,15.84,7.2,2.88,2.88,2.88,2.88,2.88,10.08,12.96$, $15.84,18.72,15.84,15.84,7.2,2.88,2.88,2.88,2.88,2.88,10.08$

$\mathrm{n} 35,12.96,15.84,18.72,15.84,15.84,7.2,2.88,2.88,2.88,2.88,2.88,10.08,12.96$, $15.84,18.72,15.84,15.84,7.2,2.88,2.88,2.88,2.88,2.88,10.08$

\$offdelim

Table Rtini(n,i) vazao turbinada inicial

\$ondelim

$n$, i1, i2, i3, i4, i5, i6, i7, i8, i9, i10, i11, i12,i13, i14,i15, i16, i17, i18, i19, i20, i2 $1, i 22, i 23, i 24$

$\mathrm{n} 1,885.9593786,1068.76299,706.0000061,571.9999952,463.0000014,392.9999976,5$ $49.0000005,708.339793,1008.604142,1395.854852,1788.6,903.0000062,834.000002$ $, 914.0478176,558.999965,453.0000229,366.9999926,341.0000049,311.9999978,386$ $.479032,561.0980371,859.586045,1099.182637,1437.968878$

$\mathrm{n} 2,858.8024624,946.0478082,625.9999825,507.0000122,410,402.7362303,589.1029$ $638,902.5601587,1788.6,1663.777552,1186.999962,1010.000011,840.0000229,957$. $0477411,594.0000125,481.0000286,388.9999803,545.2570558,868.5271708,711.482$ $3062,924.9439086,1039.513424,1200.476238,1216.516106$

n3, 858.8024652,909.0477972,611.0000084,536.9999953,435,451.7378691,653.9057 $518,1040.569369,1527.350366,1788.6,1662.924472,1645.994128,1526.99991,1230$. $047914,814.9999662,664.9999476,539.000017,470.0000195,566.0926822,825.86476$ $, 1036.761215,1434.806807,1788.6,1788.6$

$\mathrm{n} 4,858.8024748,1025.047789,649.0000053,528.9999972,532,603.1093531,892.0047$ $179,716.1918135,946.4084059,1255.310627,1392.217927,1503.409158,1549.456558$ $, 1130.047759,739.0000051,599.0000442,484.999978,497.7835762,720.9159505,896$ $.1522621,1120.299141,1431.525714,1477.316475,1590.617537$

n5,858.8024705,1025.047789,649.0000053,528.9999972,532,603.1093531,892.0047 $179,716.1918135,946.4084059,1255.310627,1392.217927,1503.409158,1549.456558$ $, 1130.047759,739.0000051,599.0000442,484.999978,497.7835762,720.9159505,896$ $.1522621,1120.299141,1431.525714,1477.316475,1590.617537$

$\mathrm{n} 6,927.5339629,1117.5235,777.9999852,630.0000279,509.9999986,458.0000007,68$ $4.8868597,1028.861355,1253.489417,1604.549577,1788.6,1560.886142,985.995693$ $6,1180.460533,744.9999459,633.9999706,513.0000132,427.0000265,652.9367955,1$ $003.131597,1496.622114,1788.6,1788.6,1788.6$

n $7,858.8024553,1117.047807,723.999972,586.0000322,474.9999985,410,579.99999$ $96,848.7655231,1123.418144,1214.58598,1363.921308,1193.999948,874.0000035,9$ $48.0479233,586.9999008,518.0000051,419.9999811,502.8350635,739.4215955,1242$ $.416146,1788.6,1777.737126,1735.169391,1644.795488$

$\mathrm{n} 8,858.8024785,1075.047788,730.9999987,592.0000022,479.9999988,499.4478498$, $800.9705668,1115.052456,1788.6,1788.6,1431.000049,1597.670254,964.9999263,1$ $009.047745,636.0001156,514.9999299,417.0000362,337.9999861,679.0719555,1089$ $.740517,1773.411746,1617.059735,1788.6,1788.6$

$\mathrm{n} 9,914.0822865,1101.543208,760.999989,617.0000218,502.9999887,452.0000006,4$ $45.2792781,661.9135608,862.074899,1070.928888,1185.999989,1119.000007,982.9$ $999755,949.0478616,587.9999324,476.0000097,384.9999934,325.0000334,409.4545$ $515,612.3724423,970.3139349,1235.214747,1613.78528,1779.899125$

n10,858.802472,946.0477977,584.9999922,474.0000039,384,432,594.9999996, 712. $1307787,1045.893425,1475.078619,1788.6,1734.069337,908.9999605,992.0478172$, $638.9999591,518.0000465,418.9999867,412.7618319,595.1301407,908.7189515,120$ $3.120996,1600.789853,1633.199439,1788.6$

$\mathrm{n} 11,858.8024808,1028.047796,663.9999585,538.0000402,435.999993,352.9999962$, $453.2773247,666.6501723,1132.230061,1095.140745,1266.563829,940.1527201,110$ $1.316033,1057.047802,738.0000603,598.9999257,497.9999984,623.7507045,934.22$ $6351,1605.969476,1501.346605,1629.009178,1643.106824,1575.516023$ 
$\mathrm{n} 12,858.8024886,1042.047781,688.9999868,559.0000095,605.9776539,950.8950474$ ,535.9999968,706.9999821,1485.000022,791.3068996,1113.313885,1265.825747,11 $23.000137,1043.047744,666.9998996,564.0000405,542.2138565,857.0113526,448.9$ $999984,915.9999435,1681.572359,1788.6,1788.6,1788.6$

$\mathrm{n} 13,858.8024691,1082.047798,708.9999894,588.9999827,482.0000345,527.7279926$ $, 789.0511466,1630.485334,1750.316256,1788.6,1649.446257,1187.999969,1038.00$ $003,1038.047829,658.9999188,534.0000763,432.9999718,381.7595751,564.6132381$ $, 842.0290296,1354.57464,1577.071659,1605.525736,1733.051456$ n14,858.8024551,1046.047784,669.0000562,541.9999652,486.0000067,403,611.478 $7836,968.7846642,1674.05539,1732.251598,1579.181825,875.9999621,1056.999992$ $, 967.0478043,611.0000003,495.0000277,412.999994,494.0000002,625.2250818,950$ $.1368737,1788.6,1350.470855,1525.869413,1427.516036$

n15,858.8024541,970.0478206,603.9999982,491.0000061,396.9999707,341.000016, $447.674467,687.8493763,933.3898524,1272.959716,809.2188928,977.713028,686.0$ $000052,841.0477475,500.0000695,408.9999747,331.0000084,448.6736278,712.3705$ $911,1040.096964,1182.839188,1410.533507,1621.043872,1688.10009$

n16,858.8024828,1044.047786,665.9999914,539.0000059,474.281253,680.1944522, $1072.948777,1181.518505,1329.509841,1658.114648,1693.985453,1172.000012,922$ $.0000168,1022.047768,647.0000538,523.9999739,424.0000037,506.3715934,773.59$ $03248,444.6267626,622.6701323,804.0040465,974.5387947,1170.907926$

$\mathrm{n} 17,858.8024573,910.0477951,565.0000353,457.9999758,370.9999853,315.0000186$ ,516.0000021,716.4036714,971.7773219,859.3768568,1040.116037,718.0000303,63 $5.9999566,740.0477987,418.0000095,338.9999777,335.0000232,342.9999994,477.8$ $270659,689.648895,1029.140517,1180.201226,894.4018372,1085.890195$

$\mathrm{n} 18,858.8024872,875.0477823,531.999997,431,349,391.1690116,577.0493824,980$. $5849398,1511.050941,1508.930196,1178.000047,910.9999302,844.0000697,958.047$ $8106,594.9999438,481.9999992,390.000012,348.6735424,531.1188111,438.3784501$ $, 614.6480266,853.7946793,1039.110152,948.5160756$

$\mathrm{n} 19,858.8024813,823.0477817,489.0000035,428.0000007,357.9999975,398.9999969$ , 487.0000201,501.6614575,686.5866454,919.9924589,1165.73133,768.9999895,689 $.999974,819.047749,491.0000509,429.9999454,354.0000401,376.8945763,555.0038$ $909,880.6061372,1075.949091,1077.000057,1109.999988,1236.51604$ $\mathrm{n} 20,858.8024691,872.0477906,547.0000019,451.000008,371.9999964,456.7776834$, $683.3013186,1255.687819,1788.6,1788.6,1154.141261,1289.584117,996.9999086,1$ $075.04784,688.9999993,557.9999607,459.0000028,430.9999986,474.2875438,687.5$ $655934,1035.475689,1044.759711,1207.203608,1234.516073$

$\mathrm{n} 21,858.8024721,937.047816,578.9999707,502.9999943,408.000012,333,390,523.5$ $72976,713.9373227,961.3939413,1196.212153,1328.348795,1168.999993,1001.0478$ $21,578.9998913,444.0000694,371.0000165,362.9999986,526.5518648,771.5549164$, $1107.056572,1321.127584,1419.927107,1330.515993$

$\mathrm{n} 22,911.9413501,1100.615401,736.0000096,488.9999849,388.9999948,393.9429236$ , 577.1581464,848.5259271,1273.410234,1684.220102,1788.6,1788.6,1262.000028, $1283.047663,791.0000841,631.0000544,546.9999714,482.0000265,633.9954469,906$ $.0836283,1352.63039,1722.878349,1588.974371,1538.516048$

$\mathrm{n} 23,858.8024617,974.0478093,444.9999946,436,405,499,503.7896249,720.6844293$ $, 1007.75386,1579.516752,1788.6,1646.415703,1364.000055,1142.047802,748.9999$ $424,600.9999938,511.000046,510.0000027,508.9999694,726.5454036,1066.855491$, $1368.281539,1460.822978,1549.142575$

$\mathrm{n} 24,978.8611346,1182.844637,719.0000002,578.9999947,488.0000082,451.3800471$ $, 662.3116124,1005.514236,1364.079201,1716.846922,1619.409159,1529.999995,15$ $63.227638,1249.047841,769.9999473,619.0000688,522.9999476,514.0000028,585.9$ $999904,778.699913,1079.666997,1381.382852,1479.151028,1541.143239$

n25,858.802462,968.0478188,609.9999881,478.9999965,412,385,524,648.9364184, $869.4734841,1036.512609,1045.875396,1186.630453,1093.999961,1028.047853,556$ $.9999875,456.9999679,407.000001,417.0000076,520.7285617,758.0510802,1139.98$ $7684,1459.145071,1512.437707,1573.795076$

$\mathrm{n} 26,911.3133618,1098.22321,632.0000036,513.9999988,428.0000014,405.9999997$, $524.9999959,627.2597324,872.270494,1247.718303,1403.870582,1424.721153,1031$ $.999964,981.0477594,587.0000342,472.999988,449.9999974,441.999999,533.99999$ $19,613.857853,887.9089037,1225.058346,1347.067703,1473.85994$ 
$\mathrm{n} 27,858.8024504,960.047819,532.0000013,428.9999947,381,357,513.2157581,792$. $0274973,1204.091059,1393.832361,1486.070786,1520.596954,1366.000001,1111.04$ $7777,621.0000425,489.000009,409.9999688,367.9999846,505.4862197,761.9692647$ $, 1138.938597,1516.848958,1735.62464,1708.945661$

n28,919.1840342,1107.605268,642.0000312,538.9999987,470.0000003,437.9999961 ,499.8961977,742.8636764,1201.238482,1485.404443,1473.702336,1491.406126,12 $06.999984,1067.047825,601.9999624,516.9999807,525.0000001,532.9999985,664.9$ $999992,750.6892761,1012.900691,1345.013747,1597.202875,1647.802313$ n29,858.8024899,978.0477863,603.9999861,548.0000039,519,518,553.9999987,685 $.5408032,918.206262,1178.353498,1383.467366,1417.415948,1360.000011,1063.04$ $7822,683.9999934,548.0000144,476.9999739,538.9999991,634.5159743,902.666375$ $8,1192.686333,1327.604034,1430.303175,1345.516046$ $\mathrm{n} 30,858.8024863,934.0477877,570.999992,458.0000004,411,391,435.1469024,648$. $5531758,962.9786003,1325.647612,1496.995923,1566.126217,1317.000009,1135.04$ $776,743.9999787,573.0000558,455.000001,404.9999805,493.8509968,711.3405155$, $1124.121143,1788.6,1788.6,1772.534691$

$\mathrm{n} 31,1129.67422,1355.874712,886.9999493,638.0000164,533.0000117,486,504.0000$ $011,707.1821622,977.2379177,1203.621567,1326.718285,1397.088951,1238.99997$, $1060.047834,624.9999706,479.9999952,438.9999724,413.000014,492.8194323,726$. $4217716,990.64252,1467.319598,1788.6,1727.27349$

$\mathrm{n} 32,858.8024769,1114.047798,690.999988,524.0000021,439.0000005,400,424,555$. $5832345,772.9268336,970.3563193,1131.243414,1348.000021,835.9999788,807.047$ $7326,451.0000606,382.000009,349.9999909,336.9999962,514.9989855,773.1442308$ $, 1142.295076,1352.894965,1433.349058,1578.582279$

$\mathrm{n} 33,858.8024694,877.047821,492.9999943,418.9999799,360.0000012,361,406.7278$ $97,606.5678471,900.4574878,1228.169284,1478.037442,1529.329557,1241.999966$, $968.0478098,541.000012,465.9999845,402.999985,406.0000107,400,593.9278137,7$ $85.2005436,907.6503572,1078.077119,1292.624217$

n34,858.8024748,923.047768,556.0000515,449.9999736,391,396,566.6252917,818. $2300688,1205.314517,1406.752339,1470.942071,1502.651688,1173.999997,989.047$ $7914,587.0000548,492.9999417,427.0000561,423.9999595,439.7836588,650.113229$ $8,932.3350116,1347.497677,1546.283211,1618.581496$

$\mathrm{n} 35,929.0277604,1120.077681,720.0000026,576.0000017,480.0000052,452.9999962$ ,556,794.3576625,1111.245234,1692.8477,1788.6,1564.398705,1390.999988,1237. $047801,751.9999469,663.0000241,556.0000031,498.0000404,578.999979,722.74330$ $69,954.5751953,1225.394364,1380.829232,1500.330064$

\section{\$offdelim}

Table Rvini (n,i) vazao vertida inicial

\section{\$ondelim}

$n$, i1, i2, i3, i4, i5, i6, i7, i8, i9, i10, i11, i12, i13, i14, i15, i16, i17, i18, i19, i20, i2 $1, i 22, i 23, i 24$

$\mathrm{n} 1,0.000,0.000,0.000,0.000,0.000,0.000,0.000,0.000,0.000,0.000,105.320,0.00$ $0,0.000,0.000,0.000,0.000,0.000,0.000,0.000,0.000,0.000,0.000,0.000,0.000$ $\mathrm{n} 2,0.000,0.000,0.000,0.000,0.000,0.000,0.000,0.000,0.000,823.929,0.000,0.00$ $0,0.000,0.000,0.000,0.000,0.000,0.000,0.000,0.000,0.000,0.000,0.000,0.000$ $\mathrm{n} 3,0.000,0.000,0.000,0.000,0.000,0.000,0.000,0.000,0.000,0.000,400.422,1175$ $.006,0.000,0.000,0.000,0.000,0.000,0.000,0.000,0.000,0.000,0.000,0.000,416$. 481

$\mathrm{n} 4,0.000,0.000,0.000,0.000,0.000,0.000,0.000,0.000,0.000,0.000,0.000,0.000$, $0.000,0.000,0.000,0.000,0.000,0.000,0.000,0.000,0.000,0.000,0.000,0.000$ $\mathrm{n} 5,0.000,0.000,0.000,0.000,0.000,0.000,0.000,0.000,0.000,0.000,0.000,0.000$, $0.000,0.000,0.000,0.000,0.000,0.000,0.000,0.000,0.000,0.000,0.000,511.743$ $\mathrm{n} 6,0.000,0.000,0.000,0.000,0.000,0.000,0.000,0.000,0.000,0.000,36.320,17.11$ $4,0.000,0.000,0.000,0.000,0.000,0.000,0.000,0.000,0.000,170.240,287.350,200$ .531

$\mathrm{n} 7,0.000,0.000,0.000,0.000,0.000,0.000,0.000,0.000,0.000,0.000,0.000,0.000$, $0.000,0.000,0.000,0.000,0.000,0.000,0.000,0.000,1927.707,735.920,0.000,0.00$ 0 
$\mathrm{n} 8,0.000,0.000,0.000,0.000,0.000,0.000,0.000,0.000,0.000,317.107,0.000,510$. $330,0.000,0.000,0.000,0.000,0.000,0.000,0.000,0.000,0.000,170.540,138.703,1$ 743.849

$\mathrm{n} 9,0.000,0.000,0.000,0.000,0.000,0.000,0.000,0.000,0.000,0.000,0.000,0.000$, $0.000,0.000,0.000,0.000,0.000,0.000,0.000,0.000,0.000,0.000,0.000,0.000$ $\mathrm{n} 10,0.000,0.000,0.000,0.000,0.000,0.000,0.000,0.000,0.000,0.000,0.000,184.3$ $69,0.000,0.000,0.000,0.000,0.000,0.000,0.000,0.000,0.000,0.000,0.000,170.40$ 4

$\mathrm{n} 11,0.000,0.000,0.000,0.000,0.000,0.000,0.000,0.000,0.000,0.000,0.000,0.000$ $, 0.000,0.000,0.000,0.000,0.000,0.000,0.000,0.000,0.000,0.000,0.000,0.000$ $\mathrm{n} 12,0.000,0.000,0.000,0.000,0.000,0.000,0.000,0.000,0.000,0.000,0.000,0.000$ $, 0.000,0.000,0.000,0.000,0.000,0.000,0.000,0.000,133.428,917.707,248.409,37$ 9.517

$\mathrm{n} 13,0.000,0.000,0.000,0.000,0.000,0.000,0.000,0.000,0.000,0.000,0.000,0.000$ $, 0.000,0.000,0.000,0.000,0.000,0.000,0.000,0.000,0.000,0.000,19.158,61.270$ $\mathrm{n} 14,0.000,0.000,0.000,0.000,0.000,0.000,0.000,0.000,0.000,0.000,263.818,0.0$ $00,0.000,0.000,0.000,0.000,0.000,0.000,0.000,0.000,292.707,0.000,0.000,0.00$ 0

$\mathrm{n} 15,0.000,0.000,0.000,0.000,0.000,0.000,0.000,0.000,0.000,0.000,0.000,0.000$ $, 0.000,0.000,0.000,0.000,0.000,0.000,0.000,0.000,0.000,0.000,0.000,0.000$ $\mathrm{n} 16,0.000,0.000,0.000,0.000,0.000,0.000,0.000,0.000,0.000,0.000,0.000,0.000$ , $0.000,0.000,0.000,0.000,0.000,0.000,0.000,0.000,0.000,0.000,0.000,0.000$ $\mathrm{n} 17,0.000,0.000,0.000,0.000,0.000,0.000,0.000,0.000,0.000,0.000,0.000,0.000$ $, 0.000,0.000,0.000,0.000,0.000,0.000,0.000,0.000,0.000,0.000,0.000,0.000$ $\mathrm{n} 18,0.000,0.000,0.000,0.000,0.000,0.000,0.000,0.000,0.000,0.000,0.000,0.000$ $, 0.000,0.000,0.000,0.000,0.000,0.000,0.000,0.000,0.000,0.000,0.000,0.000$ $\mathrm{n} 19,0.000,0.000,0.000,0.000,0.000,0.000,0.000,0.000,0.000,0.000,0.000,0.000$ $, 0.000,0.000,0.000,0.000,0.000,0.000,0.000,0.000,0.000,0.000,0.000,0.000$ $\mathrm{n} 20,0.000,0.000,0.000,0.000,0.000,0.000,0.000,0.000,0.000,111.180,0.000,0.0$ $00,0.000,0.000,0.000,0.000,0.000,0.000,0.000,0.000,0.000,0.000,0.000,0.000$ $\mathrm{n} 21,0.000,0.000,0.000,0.000,0.000,0.000,0.000,0.000,0.000,0.000,0.000,0.000$ $, 0.000,0.000,0.000,0.000,0.000,0.000,0.000,0.000,0.000,0.000,0.000,0.000$ $\mathrm{n} 22,0.000,0.000,0.000,0.000,0.000,0.000,0.000,0.000,0.000,0.000,0.000,137.7$ $34,0.000,0.000,0.000,0.000,0.000,0.000,0.000,0.000,0.000,0.000,0.000,0.000$ $\mathrm{n} 23,0.000,0.000,0.000,0.000,0.000,0.000,0.000,0.000,0.000,0.000,0.000,598.7$ $30,0.000,0.000,0.000,0.000,0.000,0.000,0.000,0.000,0.000,0.000,0.000,0.000$ $\mathrm{n} 24,0.000,0.000,0.000,0.000,0.000,0.000,0.000,0.000,0.000,0.000,0.000,0.000$ $, 48.772,0.000,0.000,0.000,0.000,0.000,0.000,0.000,0.000,0.000,0.000,22.373$ $\mathrm{n} 25,0.000,0.000,0.000,0.000,0.000,0.000,0.000,0.000,0.000,0.000,0.000,0.000$ $, 0.000,0.000,0.000,0.000,0.000,0.000,0.000,0.000,0.000,0.000,0.000,0.000$ $\mathrm{n} 26,0.000,0.000,0.000,0.000,0.000,0.000,0.000,0.000,0.000,0.000,0.000,0.000$ $, 0.000,0.000,0.000,0.000,0.000,0.000,0.000,0.000,0.000,0.000,0.000,0.000$ $\mathrm{n} 27,0.000,0.000,0.000,0.000,0.000,0.000,0.000,0.000,0.000,0.000,0.000,0.000$ $, 0.000,0.000,0.000,0.000,0.000,0.000,0.000,0.000,0.000,0.000,0.000,0.000$ $\mathrm{n} 28,0.000,0.000,0.000,0.000,0.000,0.000,0.000,0.000,0.000,0.000,0.000,0.000$ $, 0.000,0.000,0.000,0.000,0.000,0.000,0.000,0.000,0.000,0.000,0.000,0.000$ $\mathrm{n} 29,0.000,0.000,0.000,0.000,0.000,0.000,0.000,0.000,0.000,0.000,0.000,0.000$ $, 0.000,0.000,0.000,0.000,0.000,0.000,0.000,0.000,0.000,0.000,0.000,0.000$ $\mathrm{n} 30,0.000,0.000,0.000,0.000,0.000,0.000,0.000,0.000,0.000,0.000,0.000,0.000$ $, 0.000,0.000,0.000,0.000,0.000,0.000,0.000,0.000,0.000,0.000,514.761,150.90$ 3

$\mathrm{n} 31,0.000,0.000,0.000,0.000,0.000,0.000,0.000,0.000,0.000,0.000,0.000,0.000$ $, 0.000,0.000,0.000,0.000,0.000,0.000,0.000,0.000,0.000,0.000,0.000,0.000$ $\mathrm{n} 32,0.000,0.000,0.000,0.000,0.000,0.000,0.000,0.000,0.000,0.000,0.000,0.000$ $, 0.000,0.000,0.000,0.000,0.000,0.000,0.000,0.000,0.000,0.000,0.000,18.023$ $\mathrm{n} 33,0.000,0.000,0.000,0.000,0.000,0.000,0.000,0.000,0.000,0.000,0.000,0.000$ $, 0.000,0.000,0.000,0.000,0.000,0.000,0.000,0.000,0.000,0.000,0.000,0.000$ $\mathrm{n} 34,0.000,0.000,0.000,0.000,0.000,0.000,0.000,0.000,0.000,0.000,0.000,0.000$ $, 0.000,0.000,0.000,0.000,0.000,0.000,0.000,0.000,0.000,0.000,0.000,0.000$ $\mathrm{n} 35,0.000,0.000,0.000,0.000,0.000,0.000,0.000,0.000,0.000,0.000,409.320,69$. $601,0.000,0.000,0.000,0.000,0.000,0.000,0.000,0.000,0.000,0.000,0.000,0.000$ 
\$offdelim

Table Sini $(n, j)$ armazenamento inicial

\$ondelim

$n$, i0, i1, i2, i3, i4, i5, i6, i7, i8, i9, i10, i11, i12, i13, i14, i15, i16, i17, i18, i19, i20 , i21, i22, i23, i24

$\mathrm{n} 1,2480,3029.609291,2500.000003,2499.999987,2500,2499.999996,2500.000002,25$ $00.000001,2164.751258,2538.053364,1095.000072,3100.000042,3100.000025,3100$. $00002,2499.999965,2500.000055,2499.999994,2500.000014,2500.000001,2500.0000$ $07,2459.878356,2095.407813,2779.406385,1845.230585,2479.999929$

$\mathrm{n} 2,2480,3100.000018,2499.999987,2500.000033,2500,2500,2451.435691,2156.5799$ $54,1095.000023,2705.549223,3099.999909,3100.000004,3099.999975,3099.999916$, $2500.000065,2500.000033,2499.999956,2500.000009,1952.42172,2499.999957,2623$ $.165819,3100.000032,2774.587084,3100.000064,2479.999932$

$\mathrm{n} 3,2480,3100.00001,2500.000009,2499.999987,2500,2500,2412.551443,1879.88184$ ,1943.206035,1387.921756,2446.802956,3100.000034,3099.999967,3100.0002,2499 $.999886,2499.999973,2500.000113,2500.000068,2500.000017,2274.799814,2915.37$ $4356,2128.681823,1649.837193,1808.039793,2479.999918$

$\mathrm{n} 4,2480,3099.999985,2500.000006,2499.999992,2500,2500,2167.940557,2499.9999$ $22,2683.534742,2117.383031,2553.06517,2780.565045,2466.14332,3099.999921,25$ $00.000022,2500.000009,2499.999891,2499.999949,2443.53692,2500.000004,2992.0$ $85341,1847.778242,2853.298381,2564.671829,2480.000065$

$\mathrm{n} 5,2480,3099.999997,2499.999991,2500.000019,2500,2500,2026.427837,2500.0000$ $28,2338.686494,3100.000059,2692.148766,3100.000016,3100.000044,3099.999947$, $2500.000164,2500.000112,2499.999994,2500.000006,2461.488001,2208.449629,253$ $6.96912,1561.321338,1608.082764,2245.247364,2479.99201$

$\mathrm{n} 6,2480,2921.847968,2500.000036,2500.000074,2499.999999,2500.000003,2500.00$ $0001,2020.940991,2332.34036,2861.2737,1094.999933,3100.000039,3100.000034,2$ $905.611196,2499.999888,2500.000029,2500.000107,2500.000072,2500.000003,1948$ $.501265,2106.272166,1095.000145,3012.875513,1984.920945,2480.000186$

$\mathrm{n} 7,2480,3100.000036,2500.00001,2500.000082,2499.999996,2500,2500,2500.00000$ $1,2158.463765,3099.999976,2573.542721,3099.999923,3100.000062,3100.000053,2$ $499.999714,2499.999972,2499.999958,2500.000009,2414.891524,1819.246491,1094$ $.99984,3100.000105,1901.173171,2924.000415,2480.000098$

$\mathrm{n} 8,2480,3099.999976,2499.999999,2500.000003,2499.999997,2500,2224.087173,24$ $99.999995,1095.000029,1623.637229,3100.000153,3100.00003,3099.999847,3100.0$ $00038,2500.000177,2499.999877,2500.000065,2499.999968,2500.000004,1996.3433$ $07,1094.999887,2893.513231,2557.156295,1608.175236,2479.99983$

$\mathrm{n} 9,2480,2956.714713,2500.000001,2500.00003,2499.999971,2500.000002,2500,244$ $0.336093,2824.176144,2593.667564,3100.000002,3100.00003,3100.000011,3100.00$ $0075,2499.999901,2500.000077,2500.000051,2500.000068,2499.999982,2260.44069$ $3,1906.963322,2546.164605,2098.363513,1593.311921,2480.000064$

$\mathrm{n} 10,2480,3099.999993,2499.99999,2500.000011,2500,2500,2500,2500.000001,2110$ $.861023,2036.16243,1567.301887,1904.108287,3099.999936,3100.000038,2499.999$ $984,2500.00009,2499.999965,2500.000001,2472.105333,2021.852816,2730.197294$, $1377.483265,3100.000039,1382.027595,2479.997083$

$\mathrm{n} 11,2480,3099.99997,2499.999972,2500.000079,2499.999972,2499.99999,2500,224$ $2.169324,1499.172078,3099.999974,2620.261058,3100.000102,2976.403118,3099.9$ $99961,2499.999947,2499.999791,2499.99999,2499.999994,2231.078168,1095,2740$. $999119,2833.800912,2137.496333,3099.999926,2480.000017$

$\mathrm{n} 12,2480,3099.99995,2499.999991,2500.000026,2500,2162.631843,1094.99988,109$ $4.999889,1094.999935,1094.999877,3100,3016.515403,3100.000053,3099.999697,2$ $499.999838,2500.000098,2499.999989,2271.797282,1094.999856,1094.99986,1095$. $000007,1095.000209,3100.000011,1634.064462,2479.999844$

$\mathrm{n} 13,2480,3100,2499.999998,2500.000025,2500.000072,2499.999979,2166.337023,1$ $095.000052,2081.294066,1812.647133,2349.318333,3100.000012,3100.000095,3100$ $.000017,2499.999932,2500.000142,2499.999938,2500.000014,2420.271195,2166.89$ $6943,1702.853699,1722.738813,3002.63091,2030.957761,2480.000022$

$\mathrm{n} 14,2480,3100.000036,2500.000071,2499.999925,2500.000018,2500,2500,2032.745$ $818,1094.999968,1542.077635,3099.999855,3099.999958,3100.000059,3100.000079$ 
$, 2500.000059,2500.000059,2499.999985,2500.000001,2500,2202.139231,1095.0004$ $55,3100.000056,1882.927105,3099.999995,2480.000049$

$\mathrm{n} 15,2480,3100.000039,2499.999975,2499.99998,2499.999964,2500.000042,2500.00$ $0001,2246.461778,2656.388195,1825.16417,3100.000051,2946.585505,3100.000016$ , $3100.000003,2500.000135,2499.999955,2500.000023,2500,2042.061957,2011.6115$ $14,3100.000183,2613.034839,2268.822109,2118.737983,2479.999943$

$\mathrm{n} 16,2480,3099.999965,2499.999994,2500.000016,2500,2400.160804,1800.904784,2$ $499.99996,3099.999994,2271.13264,1719.157612,3100.000067,3100.000034,3099.9$ $99991,2500.000068,2499.999929,2499.999999,2499.999989,2180.220819,2499.9999$ $29,2799.047361,2893.660746,2968.63391,2843.961565,2480.000139$

$\mathrm{n} 17,2480,3100.000031,2500.000035,2499.999944,2500.000009,2500.000048,2500,2$ $499.999994,2320.105678,3100.00001,2807.088787,3099.999999,3099.999918,3100$. $00003,2500.000025,2500.000001,2500.000061,2499.999999,2500,2417.445117,1944$ $.019182,2816.670877,3099.999995,2905.507951,2480.000008$

$\mathrm{n} 18,2480,3099.999953,2499.999992,2500,2500,2500,2310.345922,1822.817676,146$ $1.013512,2328.549091,3100.000026,3099.999908,3100.000095,3099.999914,2499.9$ $99877,2500.000023,2500.000025,2499.999993,2436.046171,2499.999995,2711.5630$ $53,2433.993637,2739.835486,3100.000028,2479.999977$

n19,2480,3099.999968,2500.000009,2500,2499.999998,2500.000005,2500.000013,2 $499.999959,2762.669461,2603.096425,2252.29862,3099.999908,3099.999936,3100$. $000003,2500.000131,2500,2500.000146,2500.000038,2378.449296,1960.670877,268$ $7.451769,3100.000104,3099.99995,3099.999979,2480.000023$

n20,2480,3100,2500.000017,2500.000012,2499.99999,2500,2199.904245,1532.2753 $14,1574.556488,1492.609688,3100.000044,2876.612042,3099.999777,3100.000014$, $2499.999898,2499.9999,2500.000005,2499.999997,2500.000001,2392.109959,1877$. $427941,3100.000046,2773.92754,3100.000011,2479.999968$

$\mathrm{n} 21,2480,3099.999992,2499.999941,2500.000017,2500.000032,2500,2500,2500,272$ $4.018846,2488.522696,2463.365721,2608.182066,3099.999994,3100.000011,2499.9$ $99945,2500.000227,2500.000041,2499.999997,2500,2348.554106,2041.259763,2461$ $.554262,2536.196592,3099.99992,2480.000091$

$\mathrm{n} 22,2480,2962.264021,2499.999976,2499.999952,2499.999992,2500.000006,2484.5$ $95948,2286.000432,2020.253229,1590.674622,2329.213187,1558.367587,3100.0000$ $25,3099.999952,2500.000311,2500.000093,2499.999947,2500.000024,2499.999955$, $2443.774148,2049.573384,1541.743199,2342.79098,3099.999976,2480.000001$

$\mathrm{n} 23,2480,3100.000019,2499.999986,2500,2500,2500,2500,2487.173385,2410.23134$ $4,1800.306506,1314.204645,2696.013045,3100.000032,3099.999889,2499.999876,2$ $500.000025,2500.000041,2499.999918,2499.999911,2499.999993,2086.458307,2052$ $.031302,2549.385342,2748.171558,2479.989744$

$\mathrm{n} 24,2480,2788.807939,2500.000002,2500.000001,2500.000015,2499.999993,2416.0$ $70911,2005.502413,2219.305514,1667.425413,2171.299357,3100.000006,3100.0000$ $18,3100.00003,2499.999913,2500.00005,2499.999865,2500.000006,2499.999999,25$ $00.000024,2267.49785,2182.693633,2251.296355,3100.000019,2479.999976$

$\mathrm{n} 25,2480,3100.000019,2499.99996,2499.999991,2500,2500,2500,2500,2583.108803$ ,2978.184813,3100.000046,3080.264305,3099.999953,3100.000055,2499.999906,24 $99.999938,2500.000024,2500.000022,2500.000002,2353.436914,1990.424514,1923$. $507496,2469.430997,2790.099184,2479.999971$

$\mathrm{n} 26,2480,2963.891766,2500.000009,2500,2500.000003,2499.999999,2500,2500.000$ $011,2499.326785,1946.934402,2274.404785,2981.421108,3099.999861,3099.999953$ ,2500.000053,2499.999965,2499.999997,2500.000004,2500.000006,2500.000028,23 $05.968473,1987.530429,2680.976178,2809.019405,2480.000484$

$\mathrm{n} 27,2480,3100.000049,2499.999989,2499.999986,2500,2500,2500,2113.7902,1805$. $270927,2351.33907,2702.606009,2622.236618,3099.999974,3099.999973,2500.0000$ $25,2499.999915,2499.999891,2499.999974,2500.000014,2217.507918,2007.635584$, $1997.088022,1855.558513,2137.070509,2480.000028$

$\mathrm{n} 28,2480,2943.490983,2500.000075,2499.999994,2499.999997,2499.999996,2500.0$ $00007,2278.003989,1752.18134,1872.052685,2741.319586,3012.713531,3099.99992$ $5,3099.999965,2499.999891,2499.999989,2500.00004,2500.00004,2500.000044,250$ $0.000046,2480.069442,2172.365393,2059.852579,2187.568823,2480.00023$ n29,2480,3099.999946,2499.999974,2500.00001,2500,2500,2500,2500.000004,2604 $.870242,2502.553872,2236.485204,2886.873984,3100.000075,3100.000047,2499.99$ 
$9981,2499.999998,2499.999959,2500.000029,2500.000031,2351.328252,2113.72900$ $6,2875.121007,2621.771404,3100.000023,2480.000051$

$\mathrm{n} 30,2480,3099.999956,2499.99998,2500.000001,2500,2500,2500,2486.216595,2147$ $.822764,1872.046072,2545.167766,2104.121984,3099.999975,3099.999952,2500.00$ $005,2500.000105,2499.999955,2499.999953,2500.000004,2430.771034,2054.048418$ , $1094.999997,2539.513197,2124.991796,2479.99413$

$\mathrm{n} 31,2480,2397.900423,2499.999944,2500.000075,2500.000031,2500,2500,2499.999$ $997,2349.191833,2447.640689,3035.136132,2877.964109,3099.999899,3099.999977$ ,2499.999878,2499.999954,2499.999967,2500.000041,2500.000004,2355.871565,25 $49.178333,1859.211664,1636.081781,2036.184381,2479.999975$

n32,2480,3099.99998,2499.999976,2500.000007,2500.000001,2500,2500,2500,2438 $.872256,2902.362196,2842.491973,3099.999976,3099.99992,3099.999975,2500.000$ $147,2499.99999,2499.999966,2499.99999,2500,2183.998717,1991.816871,2143.672$ $658,3099.999942,2513.757571,2479.999899$

$\mathrm{n} 33,2480,3099.999999,2499.999935,2499.999949,2500.000003,2500,2500,2377.540$ $692,2217.956832,2184.59568,2213.600339,2238.566508,3099.999955,3100.000042$, $2500.000008,2499.999976,2500.000018,2500.000058,2500.00003,2500.00003,2808$. $635137,3100.000081,3082.190425,2661.097875,2480.000221$

$\mathrm{n} 34,2480,3099.999985,2500.000063,2499.999929,2500,2500,2500,2359.069469,190$ $2.28113,2238.866853,2745.67209,2788.419259,3100.000039,3100.000047,2500.000$ $061,2499.999919,2500.000075,2499.999925,2500.00003,2476.477392,2310.2959,18$ $38.070739,2150.063961,2323.546874,2479.991628$

$\mathrm{n} 35,2480,2917.976045,2500.000015,2500.000009,2500.000004,2499.99999,2500,25$ $00,2273.568939,1900.670202,1095.000061,3100.000026,3099.999977,3100.000008$, $2499.999996,2500.000134,2500.000069,2500.000061,2499.999956,2500.000012,262$ $2.489361,2321.012988,2558.29888,2660.309967,2480.000055$

\$offdelim

Table SSmax(n,i) limite máximo de armazenamento

\$ondelim

$n$, i1, i2, i3, i4, i5, i6, i7, i8, i9, i10, i11, i12, i13, i14, i15, i16, i17, i18, i19, i20, i2 $1, i 22, i 23, i 24$

$\mathrm{n} 1,3100,3100,2500,2500,2500,2500,2500,2500,3100,3100,3100,3100,3100,3100,25$ $00,2500,2500,2500,2500,2500,3100,3100,3100,2480$

$\mathrm{n} 2,3100,3100,2500,2500,2500,2500,2500,2500,3100,3100,3100,3100,3100,3100,25$ $00,2500,2500,2500,2500,2500,3100,3100,3100,2480$

$\mathrm{n} 3,3100,3100,2500,2500,2500,2500,2500,2500,3100,3100,3100,3100,3100,3100,25$ $00,2500,2500,2500,2500,2500,3100,3100,3100,2480$

$\mathrm{n} 4,3100,3100,2500,2500,2500,2500,2500,2500,3100,3100,3100,3100,3100,3100,25$ $00,2500,2500,2500,2500,2500,3100,3100,3100,2480$

$\mathrm{n} 5,3100,3100,2500,2500,2500,2500,2500,2500,3100,3100,3100,3100,3100,3100,25$ $00,2500,2500,2500,2500,2500,3100,3100,3100,2480$

$\mathrm{n} 6,3100,3100,2500,2500,2500,2500,2500,2500,3100,3100,3100,3100,3100,3100,25$ $00,2500,2500,2500,2500,2500,3100,3100,3100,2480$

$\mathrm{n} 7,3100,3100,2500,2500,2500,2500,2500,2500,3100,3100,3100,3100,3100,3100,25$ $00,2500,2500,2500,2500,2500,3100,3100,3100,2480$

$\mathrm{n} 8,3100,3100,2500,2500,2500,2500,2500,2500,3100,3100,3100,3100,3100,3100,25$ $00,2500,2500,2500,2500,2500,3100,3100,3100,2480$

$\mathrm{n} 9,3100,3100,2500,2500,2500,2500,2500,2500,3100,3100,3100,3100,3100,3100,25$ $00,2500,2500,2500,2500,2500,3100,3100,3100,2480$

$\mathrm{n} 10,3100,3100,2500,2500,2500,2500,2500,2500,3100,3100,3100,3100,3100,3100,2$ $500,2500,2500,2500,2500,2500,3100,3100,3100,2480$

$\mathrm{n} 11,3100,3100,2500,2500,2500,2500,2500,2500,3100,3100,3100,3100,3100,3100,2$ $500,2500,2500,2500,2500,2500,3100,3100,3100,2480$

$\mathrm{n} 12,3100,3100,2500,2500,2500,2500,2500,2500,3100,3100,3100,3100,3100,3100,2$ $500,2500,2500,2500,2500,2500,3100,3100,3100,2480$

$\mathrm{n} 13,3100,3100,2500,2500,2500,2500,2500,2500,3100,3100,3100,3100,3100,3100,2$ $500,2500,2500,2500,2500,2500,3100,3100,3100,2480$

$\mathrm{n} 14,3100,3100,2500,2500,2500,2500,2500,2500,3100,3100,3100,3100,3100,3100,2$ $500,2500,2500,2500,2500,2500,3100,3100,3100,2480$ 
$\mathrm{n} 15,3100,3100,2500,2500,2500,2500,2500,2500,3100,3100,3100,3100,3100,3100,2$ $500,2500,2500,2500,2500,2500,3100,3100,3100,2480$

$\mathrm{n} 16,3100,3100,2500,2500,2500,2500,2500,2500,3100,3100,3100,3100,3100,3100,2$ $500,2500,2500,2500,2500,2500,3100,3100,3100,2480$

$\mathrm{n} 17,3100,3100,2500,2500,2500,2500,2500,2500,3100,3100,3100,3100,3100,3100,2$ $500,2500,2500,2500,2500,2500,3100,3100,3100,2480$

$\mathrm{n} 18,3100,3100,2500,2500,2500,2500,2500,2500,3100,3100,3100,3100,3100,3100,2$ $500,2500,2500,2500,2500,2500,3100,3100,3100,2480$

$\mathrm{n} 19,3100,3100,2500,2500,2500,2500,2500,2500,3100,3100,3100,3100,3100,3100,2$ $500,2500,2500,2500,2500,2500,3100,3100,3100,2480$

$\mathrm{n} 20,3100,3100,2500,2500,2500,2500,2500,2500,3100,3100,3100,3100,3100,3100,2$ $500,2500,2500,2500,2500,2500,3100,3100,3100,2480$

$\mathrm{n} 21,3100,3100,2500,2500,2500,2500,2500,2500,3100,3100,3100,3100,3100,3100,2$ $500,2500,2500,2500,2500,2500,3100,3100,3100,2480$

$\mathrm{n} 22,3100,3100,2500,2500,2500,2500,2500,2500,3100,3100,3100,3100,3100,3100,2$ $500,2500,2500,2500,2500,2500,3100,3100,3100,2480$

$\mathrm{n} 23,3100,3100,2500,2500,2500,2500,2500,2500,3100,3100,3100,3100,3100,3100,2$ $500,2500,2500,2500,2500,2500,3100,3100,3100,2480$

$\mathrm{n} 24,3100,3100,2500,2500,2500,2500,2500,2500,3100,3100,3100,3100,3100,3100,2$ $500,2500,2500,2500,2500,2500,3100,3100,3100,2480$

$\mathrm{n} 25,3100,3100,2500,2500,2500,2500,2500,2500,3100,3100,3100,3100,3100,3100,2$ $500,2500,2500,2500,2500,2500,3100,3100,3100,2480$

$\mathrm{n} 26,3100,3100,2500,2500,2500,2500,2500,2500,3100,3100,3100,3100,3100,3100,2$ $500,2500,2500,2500,2500,2500,3100,3100,3100,2480$

$\mathrm{n} 27,3100,3100,2500,2500,2500,2500,2500,2500,3100,3100,3100,3100,3100,3100,2$ $500,2500,2500,2500,2500,2500,3100,3100,3100,2480$

$\mathrm{n} 28,3100,3100,2500,2500,2500,2500,2500,2500,3100,3100,3100,3100,3100,3100,2$

$500,2500,2500,2500,2500,2500,3100,3100,3100,2480$

$\mathrm{n} 29,3100,3100,2500,2500,2500,2500,2500,2500,3100,3100,3100,3100,3100,3100,2$ $500,2500,2500,2500,2500,2500,3100,3100,3100,2480$

$\mathrm{n} 30,3100,3100,2500,2500,2500,2500,2500,2500,3100,3100,3100,3100,3100,3100,2$ $500,2500,2500,2500,2500,2500,3100,3100,3100,2480$

$\mathrm{n} 31,3100,3100,2500,2500,2500,2500,2500,2500,3100,3100,3100,3100,3100,3100,2$ $500,2500,2500,2500,2500,2500,3100,3100,3100,2480$

$\mathrm{n} 32,3100,3100,2500,2500,2500,2500,2500,2500,3100,3100,3100,3100,3100,3100,2$ $500,2500,2500,2500,2500,2500,3100,3100,3100,2480$

$\mathrm{n} 33,3100,3100,2500,2500,2500,2500,2500,2500,3100,3100,3100,3100,3100,3100,2$ $500,2500,2500,2500,2500,2500,3100,3100,3100,2480$

$\mathrm{n} 34,3100,3100,2500,2500,2500,2500,2500,2500,3100,3100,3100,3100,3100,3100,2$ $500,2500,2500,2500,2500,2500,3100,3100,3100,2480$

$\mathrm{n} 35,3100,3100,2500,2500,2500,2500,2500,2500,3100,3100,3100,3100,3100,3100,2$ $500,2500,2500,2500,2500,2500,3100,3100,3100,2480$

\$offdelim

Table a $(\mathrm{n}, \mathrm{p})$ cota volume

\$ondelim

$\mathrm{n}, \mathrm{p} 0, \mathrm{p} 1, \mathrm{p} 2, \mathrm{p} 3, \mathrm{p} 4$

$\mathrm{n} 1,281.80755,1.2946698 \mathrm{E}-2,-3.3665774 \mathrm{E}-6,5.3235843 \mathrm{E}-10,-3.6591819 \mathrm{E}-14$ $\mathrm{n} 2,281.80755,1.2946698 \mathrm{E}-2,-3.3665774 \mathrm{E}-6,5.3235843 \mathrm{E}-10,-3.6591819 \mathrm{E}-14$ $\mathrm{n} 3,281.80755,1.2946698 \mathrm{E}-2,-3.3665774 \mathrm{E}-6,5.3235843 \mathrm{E}-10,-3.6591819 \mathrm{E}-14$ $\mathrm{n} 4,281.80755,1.2946698 \mathrm{E}-2,-3.3665774 \mathrm{E}-6,5.3235843 \mathrm{E}-10,-3.6591819 \mathrm{E}-14$ $\mathrm{n} 5,281.80755,1.2946698 \mathrm{E}-2,-3.3665774 \mathrm{E}-6,5.3235843 \mathrm{E}-10,-3.6591819 \mathrm{E}-14$ $\mathrm{n} 6,281.80755,1.2946698 \mathrm{E}-2,-3.3665774 \mathrm{E}-6,5.3235843 \mathrm{E}-10,-3.6591819 \mathrm{E}-14$ $\mathrm{n} 7,281.80755,1.2946698 \mathrm{E}-2,-3.3665774 \mathrm{E}-6,5.3235843 \mathrm{E}-10,-3.6591819 \mathrm{E}-14$ $\mathrm{n} 8,281.80755,1.2946698 \mathrm{E}-2,-3.3665774 \mathrm{E}-6,5.3235843 \mathrm{E}-10,-3.6591819 \mathrm{E}-14$ $\mathrm{n} 9,281.80755,1.2946698 \mathrm{E}-2,-3.3665774 \mathrm{E}-6,5.3235843 \mathrm{E}-10,-3.6591819 \mathrm{E}-14$ $\mathrm{n} 10,281.80755,1.2946698 \mathrm{E}-2,-3.3665774 \mathrm{E}-6,5.3235843 \mathrm{E}-10,-3.6591819 \mathrm{E}-14$ $\mathrm{n} 11,281.80755,1.2946698 \mathrm{E}-2,-3.3665774 \mathrm{E}-6,5.3235843 \mathrm{E}-10,-3.6591819 \mathrm{E}-14$ $\mathrm{n} 12,281.80755,1.2946698 \mathrm{E}-2,-3.3665774 \mathrm{E}-6,5.3235843 \mathrm{E}-10,-3.6591819 \mathrm{E}-14$ $\mathrm{n} 13,281.80755,1.2946698 \mathrm{E}-2,-3.3665774 \mathrm{E}-6,5.3235843 \mathrm{E}-10,-3.6591819 \mathrm{E}-14$ 
$\mathrm{n} 14,281.80755,1.2946698 \mathrm{E}-2,-3.3665774 \mathrm{E}-6,5.3235843 \mathrm{E}-10,-3.6591819 \mathrm{E}-14$ $\mathrm{n} 15,281.80755,1.2946698 \mathrm{E}-2,-3.3665774 \mathrm{E}-6,5.3235843 \mathrm{E}-10,-3.6591819 \mathrm{E}-14$ $\mathrm{n} 16,281.80755,1.2946698 \mathrm{E}-2,-3.3665774 \mathrm{E}-6,5.3235843 \mathrm{E}-10,-3.6591819 \mathrm{E}-14$ $\mathrm{n} 17,281.80755,1.2946698 \mathrm{E}-2,-3.3665774 \mathrm{E}-6,5.3235843 \mathrm{E}-10,-3.6591819 \mathrm{E}-14$ $\mathrm{n} 18,281.80755,1.2946698 \mathrm{E}-2,-3.3665774 \mathrm{E}-6,5.3235843 \mathrm{E}-10,-3.6591819 \mathrm{E}-14$ $\mathrm{n} 19,281.80755,1.2946698 \mathrm{E}-2,-3.3665774 \mathrm{E}-6,5.3235843 \mathrm{E}-10,-3.6591819 \mathrm{E}-14$ $\mathrm{n} 20,281.80755,1.2946698 \mathrm{E}-2,-3.3665774 \mathrm{E}-6,5.3235843 \mathrm{E}-10,-3.6591819 \mathrm{E}-14$ $\mathrm{n} 21,281.80755,1.2946698 \mathrm{E}-2,-3.3665774 \mathrm{E}-6,5.3235843 \mathrm{E}-10,-3.6591819 \mathrm{E}-14$ $\mathrm{n} 22,281.80755,1.2946698 \mathrm{E}-2,-3.3665774 \mathrm{E}-6,5.3235843 \mathrm{E}-10,-3.6591819 \mathrm{E}-14$ $\mathrm{n} 23,281.80755,1.2946698 \mathrm{E}-2,-3.3665774 \mathrm{E}-6,5.3235843 \mathrm{E}-10,-3.6591819 \mathrm{E}-14$ $\mathrm{n} 24,281.80755,1.2946698 \mathrm{E}-2,-3.3665774 \mathrm{E}-6,5.3235843 \mathrm{E}-10,-3.6591819 \mathrm{E}-14$ $\mathrm{n} 25,281.80755,1.2946698 \mathrm{E}-2,-3.3665774 \mathrm{E}-6,5.3235843 \mathrm{E}-10,-3.6591819 \mathrm{E}-14$ $\mathrm{n} 26,281.80755,1.2946698 \mathrm{E}-2,-3.3665774 \mathrm{E}-6,5.3235843 \mathrm{E}-10,-3.6591819 \mathrm{E}-14$ $\mathrm{n} 27,281.80755,1.2946698 \mathrm{E}-2,-3.3665774 \mathrm{E}-6,5.3235843 \mathrm{E}-10,-3.6591819 \mathrm{E}-14$ $\mathrm{n} 28,281.80755,1.2946698 \mathrm{E}-2,-3.3665774 \mathrm{E}-6,5.3235843 \mathrm{E}-10,-3.6591819 \mathrm{E}-14$ $\mathrm{n} 29,281.80755,1.2946698 \mathrm{E}-2,-3.3665774 \mathrm{E}-6,5.3235843 \mathrm{E}-10,-3.6591819 \mathrm{E}-14$ $\mathrm{n} 30,281.80755,1.2946698 \mathrm{E}-2,-3.3665774 \mathrm{E}-6,5.3235843 \mathrm{E}-10,-3.6591819 \mathrm{E}-14$ $\mathrm{n} 31,281.80755,1.2946698 \mathrm{E}-2,-3.3665774 \mathrm{E}-6,5.3235843 \mathrm{E}-10,-3.6591819 \mathrm{E}-14$ $\mathrm{n} 32,281.80755,1.2946698 \mathrm{E}-2,-3.3665774 \mathrm{E}-6,5.3235843 \mathrm{E}-10,-3.6591819 \mathrm{E}-14$ $\mathrm{n} 33,281.80755,1.2946698 \mathrm{E}-2,-3.3665774 \mathrm{E}-6,5.3235843 \mathrm{E}-10,-3.6591819 \mathrm{E}-14$ $\mathrm{n} 34,281.80755,1.2946698 \mathrm{E}-2,-3.3665774 \mathrm{E}-6,5.3235843 \mathrm{E}-10,-3.6591819 \mathrm{E}-14$ $\mathrm{n} 35,281.80755,1.2946698 \mathrm{E}-2,-3.3665774 \mathrm{E}-6,5.3235843 \mathrm{E}-10,-3.6591819 \mathrm{E}-14$ \$offdelim

Table b $(n, p)$ cota descarga

\$ondelim

$\mathrm{n}, \mathrm{p} 0, \mathrm{p} 1, \mathrm{p} 2, \mathrm{p} 3, \mathrm{p} 4$

$\mathrm{n} 1,271.96675,9.2084693 \mathrm{E}-4,2.3795484 \mathrm{E}-7,-7.1196339 \mathrm{E}-11,5.3060022 \mathrm{E}-15$ $\mathrm{n} 2,271.96675,9.2084693 \mathrm{E}-4,2.3795484 \mathrm{E}-7,-7.1196339 \mathrm{E}-11,5.3060022 \mathrm{E}-15$ $\mathrm{n} 3,271.96675,9.2084693 \mathrm{E}-4,2.3795484 \mathrm{E}-7,-7.1196339 \mathrm{E}-11,5.3060022 \mathrm{E}-15$ $\mathrm{n} 4,271.96675,9.2084693 \mathrm{E}-4,2.3795484 \mathrm{E}-7,-7.1196339 \mathrm{E}-11,5.3060022 \mathrm{E}-15$ $\mathrm{n} 5,271.96675,9.2084693 \mathrm{E}-4,2.3795484 \mathrm{E}-7,-7.1196339 \mathrm{E}-11,5.3060022 \mathrm{E}-15$ $\mathrm{n} 6,271.96675,9.2084693 \mathrm{E}-4,2.3795484 \mathrm{E}-7,-7.1196339 \mathrm{E}-11,5.3060022 \mathrm{E}-15$ $\mathrm{n} 7,271.96675,9.2084693 \mathrm{E}-4,2.3795484 \mathrm{E}-7,-7.1196339 \mathrm{E}-11,5.3060022 \mathrm{E}-15$ $\mathrm{n} 8,271.96675,9.2084693 \mathrm{E}-4,2.3795484 \mathrm{E}-7,-7.1196339 \mathrm{E}-11,5.3060022 \mathrm{E}-15$ $\mathrm{n} 9,271.96675,9.2084693 \mathrm{E}-4,2.3795484 \mathrm{E}-7,-7.1196339 \mathrm{E}-11,5.3060022 \mathrm{E}-15$ $\mathrm{n} 10,271.96675,9.2084693 \mathrm{E}-4,2.3795484 \mathrm{E}-7,-7.1196339 \mathrm{E}-11,5.3060022 \mathrm{E}-15$ $\mathrm{n} 11,271.96675,9.2084693 \mathrm{E}-4,2.3795484 \mathrm{E}-7,-7.1196339 \mathrm{E}-11,5.3060022 \mathrm{E}-15$ $\mathrm{n} 12,271.96675,9.2084693 \mathrm{E}-4,2.3795484 \mathrm{E}-7,-7.1196339 \mathrm{E}-11,5.3060022 \mathrm{E}-15$ $\mathrm{n} 13,271.96675,9.2084693 \mathrm{E}-4,2.3795484 \mathrm{E}-7,-7.1196339 \mathrm{E}-11,5.3060022 \mathrm{E}-15$ $\mathrm{n} 14,271.96675,9.2084693 \mathrm{E}-4,2.3795484 \mathrm{E}-7,-7.1196339 \mathrm{E}-11,5.3060022 \mathrm{E}-15$ $\mathrm{n} 15,271.96675,9.2084693 \mathrm{E}-4,2.3795484 \mathrm{E}-7,-7.1196339 \mathrm{E}-11,5.3060022 \mathrm{E}-15$ $\mathrm{n} 16,271.96675,9.2084693 \mathrm{E}-4,2.3795484 \mathrm{E}-7,-7.1196339 \mathrm{E}-11,5.3060022 \mathrm{E}-15$ $\mathrm{n} 17,271.96675,9.2084693 \mathrm{E}-4,2.3795484 \mathrm{E}-7,-7.1196339 \mathrm{E}-11,5.3060022 \mathrm{E}-15$ $\mathrm{n} 18,271.96675,9.2084693 \mathrm{E}-4,2.3795484 \mathrm{E}-7,-7.1196339 \mathrm{E}-11,5.3060022 \mathrm{E}-15$ $\mathrm{n} 19,271.96675,9.2084693 \mathrm{E}-4,2.3795484 \mathrm{E}-7,-7.1196339 \mathrm{E}-11,5.3060022 \mathrm{E}-15$ $\mathrm{n} 20,271.96675,9.2084693 \mathrm{E}-4,2.3795484 \mathrm{E}-7,-7.1196339 \mathrm{E}-11,5.3060022 \mathrm{E}-15$ $\mathrm{n} 21,271.96675,9.2084693 \mathrm{E}-4,2.3795484 \mathrm{E}-7,-7.1196339 \mathrm{E}-11,5.3060022 \mathrm{E}-15$ $\mathrm{n} 22,271.96675,9.2084693 \mathrm{E}-4,2.3795484 \mathrm{E}-7,-7.1196339 \mathrm{E}-11,5.3060022 \mathrm{E}-15$ $\mathrm{n} 23,271.96675,9.2084693 \mathrm{E}-4,2.3795484 \mathrm{E}-7,-7.1196339 \mathrm{E}-11,5.3060022 \mathrm{E}-15$ $\mathrm{n} 24,271.96675,9.2084693 \mathrm{E}-4,2.3795484 \mathrm{E}-7,-7.1196339 \mathrm{E}-11,5.3060022 \mathrm{E}-15$ $\mathrm{n} 25,271.96675,9.2084693 \mathrm{E}-4,2.3795484 \mathrm{E}-7,-7.1196339 \mathrm{E}-11,5.3060022 \mathrm{E}-15$ $\mathrm{n} 26,271.96675,9.2084693 \mathrm{E}-4,2.3795484 \mathrm{E}-7,-7.1196339 \mathrm{E}-11,5.3060022 \mathrm{E}-15$ $\mathrm{n} 27,271.96675,9.2084693 \mathrm{E}-4,2.3795484 \mathrm{E}-7,-7.1196339 \mathrm{E}-11,5.3060022 \mathrm{E}-15$ $\mathrm{n} 28,271.96675,9.2084693 \mathrm{E}-4,2.3795484 \mathrm{E}-7,-7.1196339 \mathrm{E}-11,5.3060022 \mathrm{E}-15$ $\mathrm{n} 29,271.96675,9.2084693 \mathrm{E}-4,2.3795484 \mathrm{E}-7,-7.1196339 \mathrm{E}-11,5.3060022 \mathrm{E}-15$ $\mathrm{n} 30,271.96675,9.2084693 \mathrm{E}-4,2.3795484 \mathrm{E}-7,-7.1196339 \mathrm{E}-11,5.3060022 \mathrm{E}-15$ $\mathrm{n} 31,271.96675,9.2084693 \mathrm{E}-4,2.3795484 \mathrm{E}-7,-7.1196339 \mathrm{E}-11,5.3060022 \mathrm{E}-15$ $\mathrm{n} 32,271.96675,9.2084693 \mathrm{E}-4,2.3795484 \mathrm{E}-7,-7.1196339 \mathrm{E}-11,5.3060022 \mathrm{E}-15$ $\mathrm{n} 33,271.96675,9.2084693 \mathrm{E}-4,2.3795484 \mathrm{E}-7,-7.1196339 \mathrm{E}-11,5.3060022 \mathrm{E}-15$ 
$\mathrm{n} 34,271.96675,9.2084693 \mathrm{E}-4,2.3795484 \mathrm{E}-7,-7.1196339 \mathrm{E}-11,5.3060022 \mathrm{E}-15$ $\mathrm{n} 35,271.96675,9.2084693 \mathrm{E}-4,2.3795484 \mathrm{E}-7,-7.1196339 \mathrm{E}-11,5.3060022 \mathrm{E}-15$ \$offdelim

Table $\mathrm{c}(\mathrm{n}, \mathrm{p})$ area volume

\$ondelim

$\mathrm{n}, \mathrm{p} 0, \mathrm{p} 1, \mathrm{p} 2, \mathrm{p} 3, \mathrm{p} 4$

$\mathrm{n} 1,-3.93655780 \mathrm{E}+08,5.2724387 \mathrm{E}+06,-2.6477074 \mathrm{E}+04,5.9084885 \mathrm{E}+01,-4.9435901 \mathrm{E}-$ 02

$\mathrm{n} 2,-3.93655780 \mathrm{E}+08,5.2724387 \mathrm{E}+06,-2.6477074 \mathrm{E}+04,5.9084885 \mathrm{E}+01,-4.9435901 \mathrm{E}-$ 02

$n 3,-3.93655780 E+08,5.2724387 E+06,-2.6477074 E+04,5.9084885 E+01,-4.9435901 E-$ 02

$\mathrm{n} 4,-3.93655780 \mathrm{E}+08,5.2724387 \mathrm{E}+06,-2.6477074 \mathrm{E}+04,5.9084885 \mathrm{E}+01,-4.9435901 \mathrm{E}-$ 02

$\mathrm{n} 5,-3.93655780 \mathrm{E}+08,5.2724387 \mathrm{E}+06,-2.6477074 \mathrm{E}+04,5.9084885 \mathrm{E}+01,-4.9435901 \mathrm{E}-$ 02

$\mathrm{n} 6,-3.93655780 \mathrm{E}+08,5.2724387 \mathrm{E}+06,-2.6477074 \mathrm{E}+04,5.9084885 \mathrm{E}+01,-4.9435901 \mathrm{E}-$ 02

$\mathrm{n} 7,-3.93655780 \mathrm{E}+08,5.2724387 \mathrm{E}+06,-2.6477074 \mathrm{E}+04,5.9084885 \mathrm{E}+01,-4.9435901 \mathrm{E}-$ 02

$\mathrm{n} 8,-3.93655780 \mathrm{E}+08,5.2724387 \mathrm{E}+06,-2.6477074 \mathrm{E}+04,5.9084885 \mathrm{E}+01,-4.9435901 \mathrm{E}-$ 02

$\mathrm{n} 9,-3.93655780 \mathrm{E}+08,5.2724387 \mathrm{E}+06,-2.6477074 \mathrm{E}+04,5.9084885 \mathrm{E}+01,-4.9435901 \mathrm{E}-$ 02

$\mathrm{n} 10,-3.93655780 \mathrm{E}+08,5.2724387 \mathrm{E}+06,-2.6477074 \mathrm{E}+04,5.9084885 \mathrm{E}+01,-4.9435901 \mathrm{E}-$ 02

$\mathrm{n} 11,-3.93655780 \mathrm{E}+08,5.2724387 \mathrm{E}+06,-2.6477074 \mathrm{E}+04,5.9084885 \mathrm{E}+01,-4.9435901 \mathrm{E}-$ 02

$\mathrm{n} 12,-3.93655780 \mathrm{E}+08,5.2724387 \mathrm{E}+06,-2.6477074 \mathrm{E}+04,5.9084885 \mathrm{E}+01,-4.9435901 \mathrm{E}-$ 02

$\mathrm{n} 13,-3.93655780 \mathrm{E}+08,5.2724387 \mathrm{E}+06,-2.6477074 \mathrm{E}+04,5.9084885 \mathrm{E}+01,-4.9435901 \mathrm{E}-$ 02

$\mathrm{n} 14,-3.93655780 \mathrm{E}+08,5.2724387 \mathrm{E}+06,-2.6477074 \mathrm{E}+04,5.9084885 \mathrm{E}+01,-4.9435901 \mathrm{E}-$ 02

$\mathrm{n} 15,-3.93655780 \mathrm{E}+08,5.2724387 \mathrm{E}+06,-2.6477074 \mathrm{E}+04,5.9084885 \mathrm{E}+01,-4.9435901 \mathrm{E}-$ 02

$\mathrm{n} 16,-3.93655780 \mathrm{E}+08,5.2724387 \mathrm{E}+06,-2.6477074 \mathrm{E}+04,5.9084885 \mathrm{E}+01,-4.9435901 \mathrm{E}-$ 02

$\mathrm{n} 17,-3.93655780 \mathrm{E}+08,5.2724387 \mathrm{E}+06,-2.6477074 \mathrm{E}+04,5.9084885 \mathrm{E}+01,-4.9435901 \mathrm{E}-$ 02

$\mathrm{n} 18,-3.93655780 \mathrm{E}+08,5.2724387 \mathrm{E}+06,-2.6477074 \mathrm{E}+04,5.9084885 \mathrm{E}+01,-4.9435901 \mathrm{E}-$ 02

$\mathrm{n} 19,-3.93655780 \mathrm{E}+08,5.2724387 \mathrm{E}+06,-2.6477074 \mathrm{E}+04,5.9084885 \mathrm{E}+01,-4.9435901 \mathrm{E}-$ 02

$\mathrm{n} 20,-3.93655780 \mathrm{E}+08,5.2724387 \mathrm{E}+06,-2.6477074 \mathrm{E}+04,5.9084885 \mathrm{E}+01,-4.9435901 \mathrm{E}-$ 02

$\mathrm{n} 21,-3.93655780 \mathrm{E}+08,5.2724387 \mathrm{E}+06,-2.6477074 \mathrm{E}+04,5.9084885 \mathrm{E}+01,-4.9435901 \mathrm{E}-$ 02

$\mathrm{n} 22,-3.93655780 \mathrm{E}+08,5.2724387 \mathrm{E}+06,-2.6477074 \mathrm{E}+04,5.9084885 \mathrm{E}+01,-4.9435901 \mathrm{E}-$ 02

$\mathrm{n} 23,-3.93655780 \mathrm{E}+08,5.2724387 \mathrm{E}+06,-2.6477074 \mathrm{E}+04,5.9084885 \mathrm{E}+01,-4.9435901 \mathrm{E}-$ 02

$\mathrm{n} 24,-3.93655780 \mathrm{E}+08,5.2724387 \mathrm{E}+06,-2.6477074 \mathrm{E}+04,5.9084885 \mathrm{E}+01,-4.9435901 \mathrm{E}-$ 02

$\mathrm{n} 25,-3.93655780 \mathrm{E}+08,5.2724387 \mathrm{E}+06,-2.6477074 \mathrm{E}+04,5.9084885 \mathrm{E}+01,-4.9435901 \mathrm{E}-$ 02

$\mathrm{n} 26,-3.93655780 \mathrm{E}+08,5.2724387 \mathrm{E}+06,-2.6477074 \mathrm{E}+04,5.9084885 \mathrm{E}+01,-4.9435901 \mathrm{E}-$ 02 
$\mathrm{n} 27,-3.93655780 \mathrm{E}+08,5.2724387 \mathrm{E}+06,-2.6477074 \mathrm{E}+04,5.9084885 \mathrm{E}+01,-4.9435901 \mathrm{E}-$ 02

$\mathrm{n} 28,-3.93655780 \mathrm{E}+08,5.2724387 \mathrm{E}+06,-2.6477074 \mathrm{E}+04,5.9084885 \mathrm{E}+01,-4.9435901 \mathrm{E}-$ 02

$\mathrm{n} 29,-3.93655780 \mathrm{E}+08,5.2724387 \mathrm{E}+06,-2.6477074 \mathrm{E}+04,5.9084885 \mathrm{E}+01,-4.9435901 \mathrm{E}-$ 02

$\mathrm{n} 30,-3.93655780 \mathrm{E}+08,5.2724387 \mathrm{E}+06,-2.6477074 \mathrm{E}+04,5.9084885 \mathrm{E}+01,-4.9435901 \mathrm{E}-$ 02

$\mathrm{n} 31,-3.93655780 \mathrm{E}+08,5.2724387 \mathrm{E}+06,-2.6477074 \mathrm{E}+04,5.9084885 \mathrm{E}+01,-4.9435901 \mathrm{E}-$ 02

$\mathrm{n} 32,-3.93655780 \mathrm{E}+08,5.2724387 \mathrm{E}+06,-2.6477074 \mathrm{E}+04,5.9084885 \mathrm{E}+01,-4.9435901 \mathrm{E}-$ 02

$\mathrm{n} 33,-3.93655780 \mathrm{E}+08,5.2724387 \mathrm{E}+06,-2.6477074 \mathrm{E}+04,5.9084885 \mathrm{E}+01,-4.9435901 \mathrm{E}-$ 02

$\mathrm{n} 34,-3.93655780 \mathrm{E}+08,5.2724387 \mathrm{E}+06,-2.6477074 \mathrm{E}+04,5.9084885 \mathrm{E}+01,-4.9435901 \mathrm{E}-$ 02

$\mathrm{n} 35,-3.93655780 \mathrm{E}+08,5.2724387 \mathrm{E}+06,-2.6477074 \mathrm{E}+04,5.9084885 \mathrm{E}+01,-4.9435901 \mathrm{E}-$ 02

\$offdelim

Table Qvmin(n,i) Limite de defluência

\$ondelim

$n$, i1, i2, i3, i4, i5, i6, i7, i8, i9, i10, i11, i12, i13, i14, i15, i16, i17, i18, i19, i20, i2 $1, i 22, i 23, i 24$

$\mathrm{n} 1,0,0,0,0,0,0,0,0,0,0,0,0,0,0,0,0,0,0,0,0,0,0,0,0$ $\mathrm{n} 2,0,0,0,0,0,0,0,0,0,0,0,0,0,0,0,0,0,0,0,0,0,0,0,0$ $\mathrm{n} 3,0,0,0,0,0,0,0,0,0,0,0,0,0,0,0,0,0,0,0,0,0,0,0,0$ $\mathrm{n} 4,0,0,0,0,0,0,0,0,0,0,0,0,0,0,0,0,0,0,0,0,0,0,0,0$ $\mathrm{n} 5,0,0,0,0,0,0,0,0,0,0,0,0,0,0,0,0,0,0,0,0,0,0,0,0$ $\mathrm{n} 6,0,0,0,0,0,0,0,0,0,0,0,0,0,0,0,0,0,0,0,0,0,0,0,0$ $\mathrm{n} 7,0,0,0,0,0,0,0,0,0,0,0,0,0,0,0,0,0,0,0,0,0,0,0,0$ $\mathrm{n} 8,0,0,0,0,0,0,0,0,0,0,0,0,0,0,0,0,0,0,0,0,0,0,0,0$ $\mathrm{n} 9,0,0,0,0,0,0,0,0,0,0,0,0,0,0,0,0,0,0,0,0,0,0,0,0$ $\mathrm{n} 10,0,0,0,0,0,0,0,0,0,0,0,0,0,0,0,0,0,0,0,0,0,0,0,0$ $\mathrm{n} 11,0,0,0,0,0,0,0,0,0,0,0,0,0,0,0,0,0,0,0,0,0,0,0,0$ $\mathrm{n} 12,0,0,0,0,0,0,0,0,0,0,0,0,0,0,0,0,0,0,0,0,0,0,0,0$ $\mathrm{n} 13,0,0,0,0,0,0,0,0,0,0,0,0,0,0,0,0,0,0,0,0,0,0,0,0$ $\mathrm{n} 14,0,0,0,0,0,0,0,0,0,0,0,0,0,0,0,0,0,0,0,0,0,0,0,0$ $\mathrm{n} 15,0,0,0,0,0,0,0,0,0,0,0,0,0,0,0,0,0,0,0,0,0,0,0,0$ $\mathrm{n} 16,0,0,0,0,0,0,0,0,0,0,0,0,0,0,0,0,0,0,0,0,0,0,0,0$ $\mathrm{n} 17,0,0,0,0,0,0,0,0,0,0,0,0,0,0,0,0,0,0,0,0,0,0,0,0$ $\mathrm{n} 18,0,0,0,0,0,0,0,0,0,0,0,0,0,0,0,0,0,0,0,0,0,0,0,0$ $\mathrm{n} 19,0,0,0,0,0,0,0,0,0,0,0,0,0,0,0,0,0,0,0,0,0,0,0,0$ $\mathrm{n} 20,0,0,0,0,0,0,0,0,0,0,0,0,0,0,0,0,0,0,0,0,0,0,0,0$ $\mathrm{n} 21,0,0,0,0,0,0,0,0,0,0,0,0,0,0,0,0,0,0,0,0,0,0,0,0$ $\mathrm{n} 22,0,0,0,0,0,0,0,0,0,0,0,0,0,0,0,0,0,0,0,0,0,0,0,0$ $\mathrm{n} 23,0,0,0,0,0,0,0,0,0,0,0,0,0,0,0,0,0,0,0,0,0,0,0,0$ $\mathrm{n} 24,0,0,0,0,0,0,0,0,0,0,0,0,0,0,0,0,0,0,0,0,0,0,0,0$ $\mathrm{n} 25,0,0,0,0,0,0,0,0,0,0,0,0,0,0,0,0,0,0,0,0,0,0,0,0$ $\mathrm{n} 26,0,0,0,0,0,0,0,0,0,0,0,0,0,0,0,0,0,0,0,0,0,0,0,0$ $\mathrm{n} 27,0,0,0,0,0,0,0,0,0,0,0,0,0,0,0,0,0,0,0,0,0,0,0,0$ $\mathrm{n} 28,0,0,0,0,0,0,0,0,0,0,0,0,0,0,0,0,0,0,0,0,0,0,0,0$ $\mathrm{n} 29,0,0,0,0,0,0,0,0,0,0,0,0,0,0,0,0,0,0,0,0,0,0,0,0$ $\mathrm{n} 30,0,0,0,0,0,0,0,0,0,0,0,0,0,0,0,0,0,0,0,0,0,0,0,0$ $\mathrm{n} 31,0,0,0,0,0,0,0,0,0,0,0,0,0,0,0,0,0,0,0,0,0,0,0,0$ $\mathrm{n} 32,0,0,0,0,0,0,0,0,0,0,0,0,0,0,0,0,0,0,0,0,0,0,0,0$ $\mathrm{n} 33,0,0,0,0,0,0,0,0,0,0,0,0,0,0,0,0,0,0,0,0,0,0,0,0$ $\mathrm{n} 34,0,0,0,0,0,0,0,0,0,0,0,0,0,0,0,0,0,0,0,0,0,0,0,0$ $\mathrm{n} 35,0,0,0,0,0,0,0,0,0,0,0,0,0,0,0,0,0,0,0,0,0,0,0,0$ Soffdelim 
Parameter SSmin(n) limite de armazenamento

/ n1 1015

n2 1015

n3 1015

n4 1015

n5 1015

n6 1015

n7 1015

n8 1015

n9 1015

n10 1015

n11 1015

n12 1015

n13 1015

n14 1015

n15 1015

n16 1015

n17 1015

n18 1015

n19 1015

n20 1015

n21 1015

n22 1015

n23 1015

n24 1015

n25 1015

n26 1015

n27 1015

n28 1015

n29 1015

n30 1015

n31 1015

n32 1015

n33 1015

n34 1015

n35 $1015 /$

Parameter NAMIN(n) nivel minimo do reservatorio

/ n1 292

n2 292

n3 292

n4 292

n5 292

n6 292

n7 292

n8 292

n9 292

n10 292

n11 292

n12 292

n13 292

n14 292

n15 292

n16 292

n17 292

n18 292

n19 292

n20 292

n21 292 


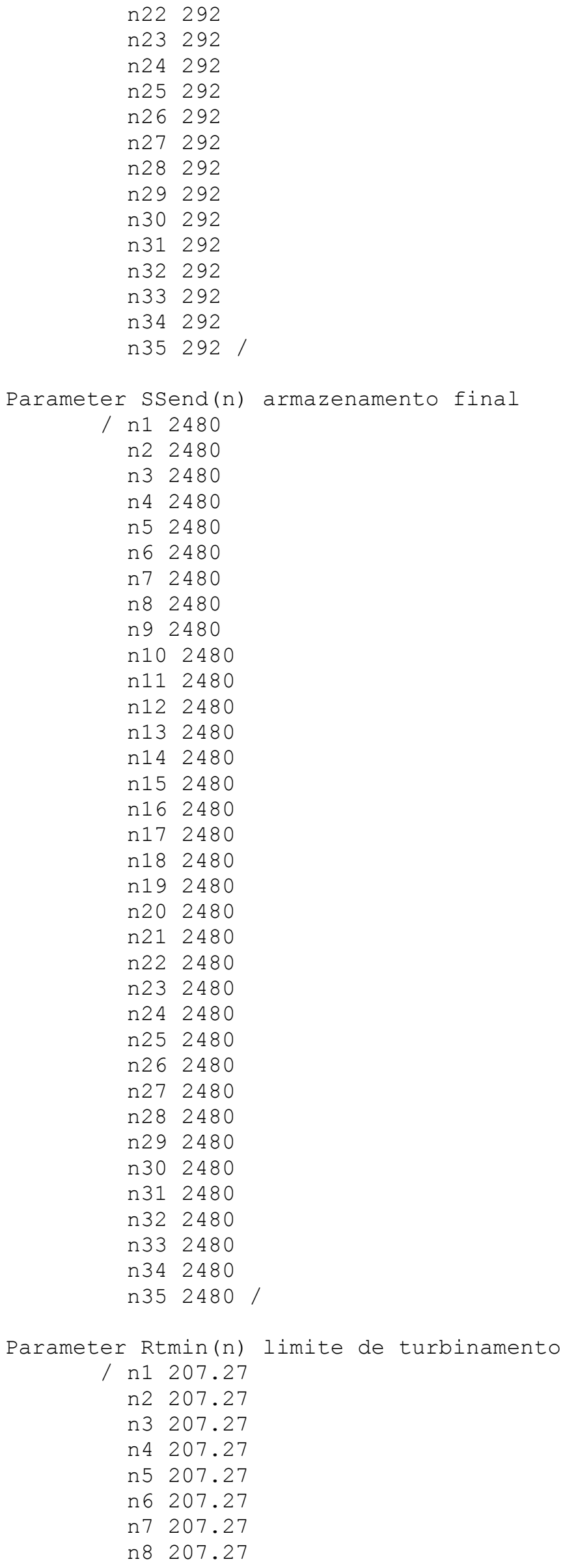

Parameter Rtmin(n) limite de turbinamento / n1 207.27

n2 207.27

n3 207.27

n4 207.27

n5 207.27

n6 207.27

n7 207.27

n8 207.27 


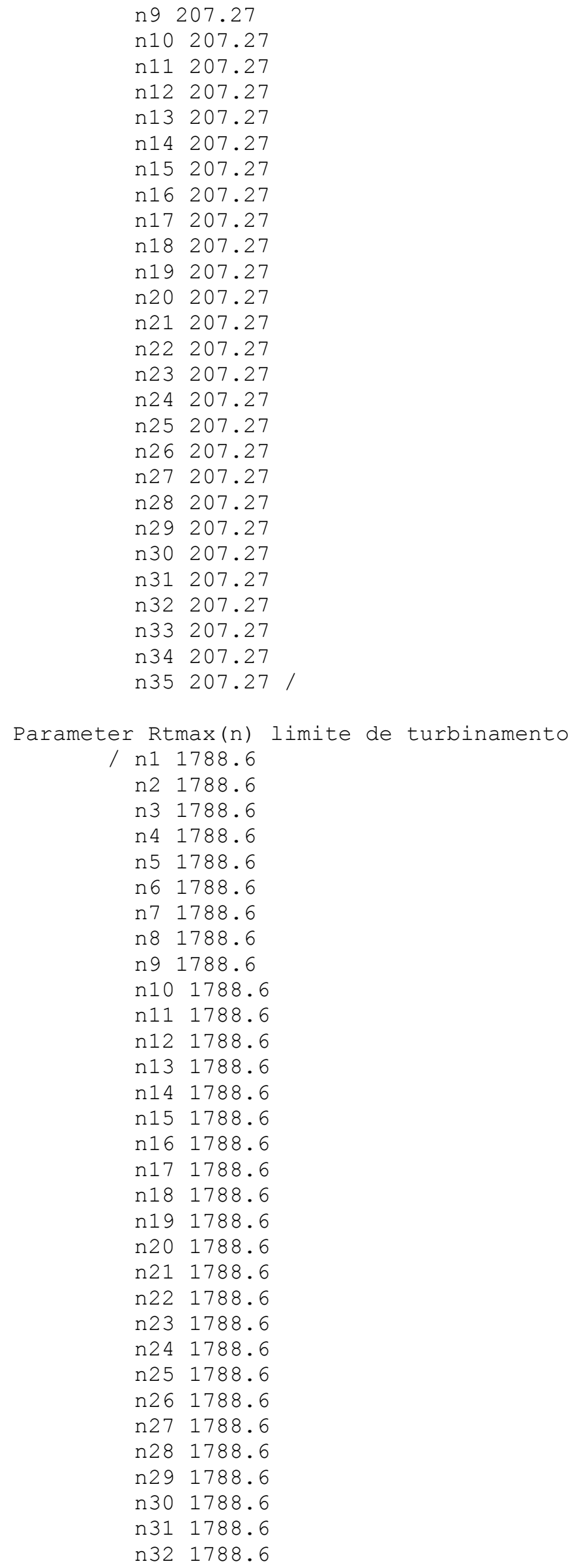


$\begin{array}{ll}\text { n33 } & 1788.6 \\ \text { n34 } & 1788.6 \\ \text { n35 } & 1788.6\end{array}$

Parameter Pmax(n) limite de potencia

/ n1 400

n2 400

n3 400

n4 400

n5 400

n 6400

n7 400

n8 400

n9 400

n10 400

n11 400

n12 400

n13 400

n14 400

n15 400

n16 400

n17 400

n18 400

n19 400

n20 400

n21 400

n22 400

n23 400

n24 400

n25 400

n26 400

n27 400

n28 400

n29 400

n30 400

n31 400

n32 400

n33 400

n34 400

n35 400 /

Parameter ID(n) indice de disponibilidade

/ n1 0.89376

n2 0.89376

n3 0.89376

n4 0.89376

n5 0.89376

n $6 \quad 0.89376$

n7 0.89376

n8 0.89376

n9 0.89376

n10 0.89376

n11 0.89376

$\mathrm{n} 12 \quad 0.89376$

n13 0.89376

n14 0.89376

n15 0.89376

n16 0.89376

n17 0.89376

n18 0.89376

n19 0.89376 


$\begin{array}{ll}\mathrm{n} 20 & 0.89376 \\ \mathrm{n} 21 & 0.89376 \\ \mathrm{n} 22 & 0.89376 \\ \mathrm{n} 23 & 0.89376 \\ \mathrm{n} 24 & 0.89376 \\ \mathrm{n} 25 & 0.89376 \\ \mathrm{n} 26 & 0.89376 \\ \mathrm{n} 27 & 0.89376 \\ \mathrm{n} 28 & 0.89376 \\ \mathrm{n} 29 & 0.89376 \\ \mathrm{n} 30 & 0.89376 \\ \mathrm{n} 31 & 0.89376 \\ \mathrm{n} 32 & 0.89376 \\ \mathrm{n} 33 & 0.89376 \\ \mathrm{n} 34 & 0.89376 \\ \mathrm{n} 35 & 0.89376\end{array}$

Parameter nn(n) produtividade especifica / n1 0.00925

n2 0.00925

n3 0.00925

n4 0.00925

n5 0.00925

n $6 \quad 0.00925$

n7 0.00925

n8 0.00925

n9 0.00925

n10 0.00925

n11 0.00925

n12 0.00925

n13 0.00925

n14 0.00925

n15 0.00925

n16 0.00925

n17 0.00925

n18 0.00925

n19 0.00925

n20 0.00925

n21 0.00925

n22 0.00925

n23 0.00925

n24 0.00925

n25 0.00925

n26 0.00925

n27 0.00925

n28 0.00925

n29 0.00925

n30 0.00925

n31 0.00925

n32 0.00925

n33 0.00925

n34 0.00925

n35 $0.00925 /$ 
$\operatorname{Rt} .1(n, i)=\operatorname{Rtini}(n, i)$;

$\operatorname{Rv} \cdot 1(n, i)=\operatorname{Rvini}(n, i)$;

$\operatorname{R.l}(\mathrm{n}, \mathrm{i})=\operatorname{Rtini}(\mathrm{n}, \mathrm{i})+\operatorname{Rvini}(\mathrm{n}, \mathrm{i})$;

Ht.l $(n, i)=$

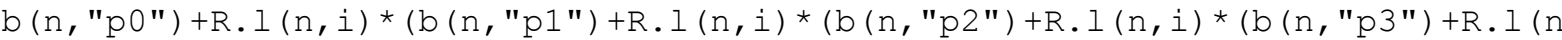
, i) *b (n, "p4"))) );

Ht.l $(n, i)$;

$\operatorname{Hg} .1(n, i)=(\operatorname{Hr} .1(n, i-1)+\operatorname{Hr} .1(n, " i 0 ") \$ i i(i)+\operatorname{Hr} .1(n, i)) * 0.5-$

Pot.l $(n, i)=n n(n) * H g \cdot l(n, i) * R t . l(n, i) ;$

Equation

$\operatorname{QTN}(n, i)$

restrição para vazão turbinada inicial ser

igual nos cenarios

$\mathrm{CON}(\mathrm{n}, \mathrm{i})$

equação da continuidade para o cenário

tempo i

QQ $(n, i)$

$\mathrm{CV}(n, j)$

$\mathrm{CT}(\mathrm{n}, \mathrm{i})$

$\operatorname{CQr}(n, i)$

$\mathrm{AA}(\mathrm{n}, \mathrm{i})$

$\operatorname{GERA}(n, i)$

$\operatorname{COMP}(n, i)$

e a potência gerada

SOMACOMP ( $n$ )

OBJ1

OBJ2

OBJM1

OBJM2

vazao

cota no reservatorio

cota no canal de fuga

queda

area

potencia

complementação entre a potência instalada

somatória da complementação

objetivo 1

desvio padrão

objetivo final modelo 1

objetivo final modelo 2

$\operatorname{QTN}(n, i) \ldots \operatorname{Rt}(n, " i 1 ")=e=\operatorname{Rt}(" n 1 ", " i 1 ")$

$\operatorname{CON}(n, i) \ldots S(n, i)=e=S(n, i-1)+S(n, " i 0 ") \$ i i(i)+d t(i) *($

$+Q I(n, i)-R(n, i)-U C(n, i))$

$-\operatorname{Ev}(n, i) *(\operatorname{Ar}(n, i-1)+\operatorname{Ar}(n, " i 0 ")$ \$i(i));

$Q Q(n, i) \ldots R(n, i)=e=\operatorname{Rt}(n, i)+\operatorname{Rv}(n, i)$;

$C V(n, j) \ldots \operatorname{Hr}(n, j)=e=$

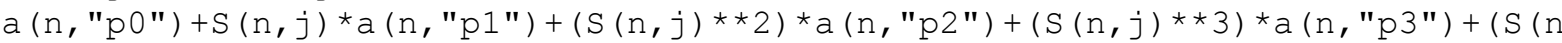
$, j) * \star 4) * a(n, " p 4 ")$;

$\operatorname{CT}(n, i) \ldots H t(n, i)=e=$

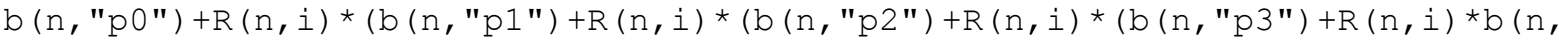
"p4")))) ;

$\operatorname{CQr}(n, i) \ldots \operatorname{Hg}(n, i)=e=(\operatorname{Hr}(n, i-1)+\operatorname{Hr}(n, " i 0 ")$ \$ii $(i)+\operatorname{Hr}(n, i)) * 0.5-H t(n, i) ;$

$A A(n, i) \ldots A r(n, i)=e=$

$c(n, " p 0 ")+\operatorname{Hr}(n, i) * c(n, " p 1 ")+(\operatorname{Hr}(n, i) * \star 2) * c(n, " p 2 ")+(\operatorname{Hr}(n, i) \star \star 3) * c(n, " p 3 ")+($

$\operatorname{Hr}(\mathrm{n}, \mathrm{i}) * * 4) * \mathrm{C}(\mathrm{n}, \mathrm{p} 4 ")$;

$\operatorname{GERA}(n, i) \ldots \operatorname{Pot}(n, i)=e=n n(n) * \operatorname{Hg}(n, i) * \operatorname{Rt}(n, i) ;$

$\operatorname{COMP}(n, i) \ldots F 1(n, i)=e=d t(i) * \operatorname{sqr}(400-\operatorname{Pot}(n, i))$;

$\operatorname{SOMACOMP}(n) \ldots F 2(n)=e=(\operatorname{sum}(i, F 1(n, i))) ;$ 
OBJ1 . F 3 $=e=\operatorname{sum}(n, F 2(n)) / 35$;

OBJ2 .. DP $=e=\operatorname{sqrt}(\operatorname{sum}(n,(\operatorname{sqr}(F 2(n)-F 3))) / 34) ;$

\$ontext

Para alteração dos coeficientes de ponderação, mudar os valores apresentados

precedentes à $F 3$ e DP na função OBJM1 abaixo.

Sofftext

$\mathrm{OBJM1} \ldots \mathrm{Z} 1=\mathrm{e}=1 * \mathrm{~F} 3+1 * \mathrm{DP} ;$

$\mathrm{OBJM} 2 \ldots \mathrm{Z} 2=\mathrm{e}=\mathrm{F} 3 ;$

Model ROBUSTA / QTN, CON, QQ, CV , CT, CQr, AA, GERA, COMP , SOMACOMP , OBJ1, OBJ2, OBJM1 / ;

Model ROBUSTA2 / QTN, CON, QQ , CV , CT, CQr, AA, GERA, COMP, SOMACOMP, OBJ1, OBJ2 , OBJM2 / ;

Option NLP = MINOS;

ROBUSTA. nodlim $=7000$;

ROBUSTA. workspace $=350$;

ROBUSTA.optfile $=1$;

Option reslim $=36000$;

Option iterlim $=200000$;

\$ontext

Primeira Etapa

\$offtext

Solve ROBUSTA using NLP minimizing Z1;

Rt.fx(n,"il") = Rt.l(n,"il")

sontext

Segunda Etapa

sofftext

Solve ROBUSTA2 using NLP minimizing Z2;

Display Pot.1;

Display S.l;

Display Rt.l;

Display Rv.1; 
Display F1.1;

Display F2.1;

Display F3.1;

Display DP.1;

Display Z1.1;

Display Z2.1;

file temph /temph.dat/;

put temph;

loop (n, loop (i, put (Rt.l(n,i)) /))

loop $(\mathrm{n}, \operatorname{loop}(i, \operatorname{put}(\operatorname{Rv} . l(\mathrm{n}, \mathrm{i})) /$ ))

putclose temph; 